\title{
A double-edged sword: studies on the benefits and risks of brand leveraging strategies
}

Citation for published version (APA):

Lei, J. (2006). A double-edged sword: studies on the benefits and risks of brand leveraging strategies.

[Doctoral Thesis, Maastricht University]. Maastricht University. https://doi.org/10.26481/dis.20060608jl

Document status and date:

Published: 01/01/2006

DOI:

10.26481/dis.20060608jl

Document Version:

Publisher's PDF, also known as Version of record

\section{Please check the document version of this publication:}

- A submitted manuscript is the version of the article upon submission and before peer-review. There can be important differences between the submitted version and the official published version of record.

People interested in the research are advised to contact the author for the final version of the publication, or visit the DOI to the publisher's website.

- The final author version and the galley proof are versions of the publication after peer review.

- The final published version features the final layout of the paper including the volume, issue and page numbers.

Link to publication

\footnotetext{
General rights rights.

- You may freely distribute the URL identifying the publication in the public portal. please follow below link for the End User Agreement:

www.umlib.nl/taverne-license

Take down policy

If you believe that this document breaches copyright please contact us at:

repository@maastrichtuniversity.nl

providing details and we will investigate your claim.
}

Copyright and moral rights for the publications made accessible in the public portal are retained by the authors and/or other copyright owners and it is a condition of accessing publications that users recognise and abide by the legal requirements associated with these

- Users may download and print one copy of any publication from the public portal for the purpose of private study or research.

- You may not further distribute the material or use it for any profit-making activity or commercial gain

If the publication is distributed under the terms of Article $25 \mathrm{fa}$ of the Dutch Copyright Act, indicated by the "Taverne" license above, 


\section{A Double-Edged Sword:}

Studies on the Benefits and Risks

of Brand Leveraging Strategies 


\section{(c) 2006, Jing Lel}

All rlights reserved. No part of this publication may be reprinted or utilized in any form or by any electronic, mechanical or other means, no known, or hereafter invented, including photocopying and recording, or in any information storage or retrieval system, without written permission from the copyright owner

ISBN-10:90-5278-532-5

ISBN-13: $978-905278-532-5$

Printed by: Datawyse / Universitaire Pers Maastricht 


\section{A Double-Edged Sword:}

Studies on the Benefits and Risks

of Brand Leveraging Strategies

\section{PROEFSCHRIFT}

ter verkrijging van de graad van doctor aan de Universiteit Maastricht, op gezag van de Rector Magnificus, Prof. Mr. G.P.M.F. Mols volgens het besluit van het College van Decanen, in het openbaar te verdedigen op donderdag 8 juni 2006 om 12.00 uur

door

Jing Lei

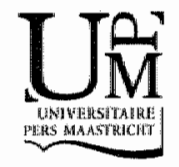




\section{Promotor}

Prof. dr. J. G. A. M. Lemmink

\section{Copromotor}

Dr. J. Ouwersloot

\section{Beoordelingscommissie}

Prof. dr. Ir. B. G. C. Dellaert (Voorzitter)

Prof. N. Dawar, PhD. (University of Western Ontario, Canada)

Prof. dr. W. H. Gijselaers 
For my parents and my husband 


\section{Acknowledgements}

The process of writing a dissertation is an exceptional journey - one that needs strength and persistence to overcome the hardship and bitterness along the way. I would like to take this chance to thank several people who guided me through my journey. Without their help and encouragement, I fear that I would not have begun this journey, or I would have returned back long ago.

First of all, I would like to express my greatest gratitude to my promoter Jos Lemmink for his guidance, support and encouragement at every stage of my doctoral program. Despite his extremely busy schedule as the head of the marketing department, he always made time for me to discuss the research ideas and problems that I encountered during the study. I am especially grateful that he gave me the opportunity to conduct collaborative research with scholars in other institutions and spend some time abroad with my family. I also want to thank my co-promoter Hans Ouwersloot who introduced me to the thesis topic of Brand Management. I appreciate his understanding of my specific personal situation and his supervision in various projects included in the dissertation.

In addition, I would like to express my gratitude to my dissertation committee, Benedict Dellaert, Niraj Dawar, and Wim Gijselaers. To begin with, I would like to thank the chair of the committee Benedict Dellaert for his critical and constructive comments on my work. His kindness and broad knowledge on various research topics made him a great resource for Ph.D. students. I am deeply indebted to Niraj Dawar for his invaluable advices on my dissertation projects and research methodology in general. He taught me how to position a research paper from different perspectives and how to conduct experimental studies in a very rigorous way. Our cooperation on papers has been enjoyable and productive, and we had great times visiting each other in Maastricht and London. I would also like to thank Wim Gijselaers for his valuable feedbacks that allow me to make further improvements on my dissertation.

Also, I would like to thank Ko de Ruyter and Martin Wetzels for their involvement in the research projects of my dissertation. Ko has been a great resource for creative ideas and Martin provided valuable advices on the analysis 
pait. Also thanks to Paul Janssen, Marjolein Böggemann and Leon Poeligoal for their help with the data collection process.

Furthermore, I would like to thank my colleagues as well as riends at work. I would like to thank Mark Arts for helping me program questionnaires online. Thanks to Sandra Streukens for her help in statistical matters. I would also like to thank Plet Pauwels and Roger Pruppers for their valuable feedbacks on the early drafts of my research papers. My special thanks go to my friends and roommates, Lisa, Vera and Caroline. They have made my life in Netherlands much easier and more enjoyable.. They helped me settle down when I moved to Maastricht; they provided valuable feedbacks on my papers and conference proposals; they accommodated me when I came back to visit Maastricht; and they assisted me in arranging various administrative matters while I am in Canada. Thank you for your friendship and support!

I would like to thank my Chinese friends in Maastricht for entertaining me from time to time with wonderful Chinese food and saving me from "culture shocks". I especially would like to thank my parents and my little brother. My brother kept me updated on new happenings at home in China. My parents have always encouraged and supported me through the years. They taught me how to value things in life and how to balance the professional life with personal life. Their love and confidence in me have made me come this far in my academic career.

Most importantly, my husband Liwu deserves my deepest gratitude. He has been an ideal soul mate, a dear friend, and a wonderful partner in life in all these years. He was always supportive, patient, and inspiring when I encountered frustration, doubts, and difficulties in my study. I could not have finished this journey successful without his support and love. Thank you "Liwu. 


\section{Table of Content}

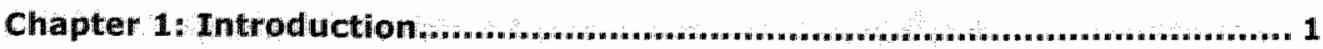

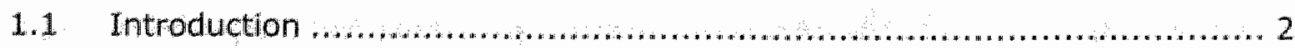

1.2 Academic Development of Brand Leveraging Strategies ..................... 4

1.3 Brand Extensions and Line Extensions .......................................... 5

1.4 Brand Architecture .................................................................... 10

1.5 Objectives of Different Studies ................................................ 12

1.6 Outline of the Dissertation ...................................................... 14

Chapter 2: Service Intensiveness and Brand Extension EValuations.......... 17

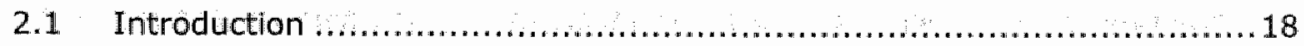

2.2 Brand Extension and Brand Extension Evaluations ...........................20

2.3 Conceptual Development and Research Hypotheses..........................21

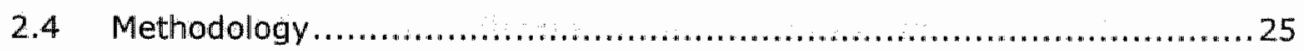

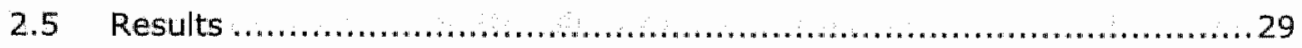

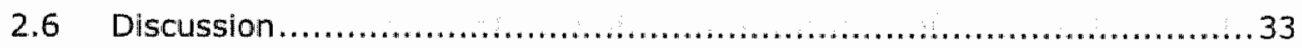

2.7 Limitations and Future Research .............................................. 34

Chapter 3: Consumer EVAluations of Vertical Service Line Extensions ...... 37

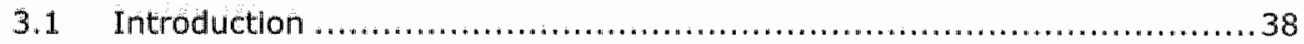

3.2 Development of a Conceptual Framework................................... 40

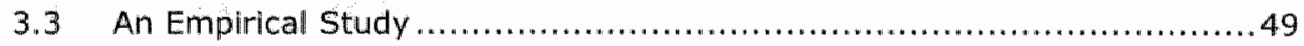

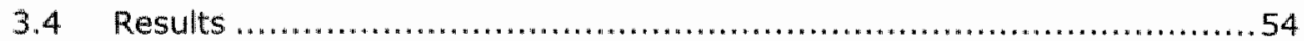

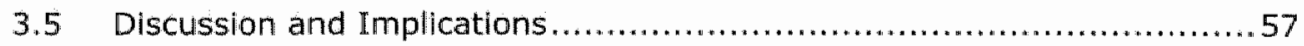

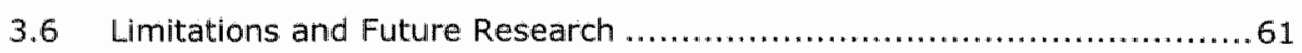

Chapter 4: Mapping Cognitive Brand ARchitecture by Examining the Spillover Effects of Product-harm Crises ................................................63

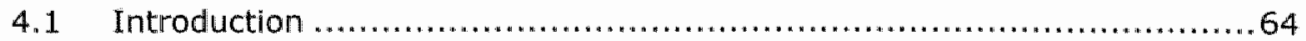

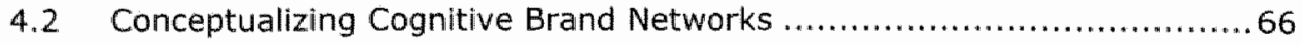


4.3 Spllover Effects and the 'Retrieval-Updating" Process .........................67

4.4 Product-Harm Crises as a Prime ...................................................70

4.5 Hypothesis Development.........................................................70

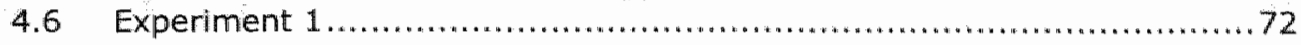

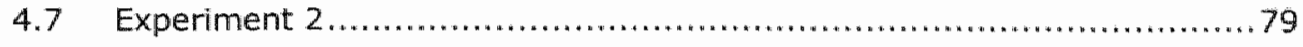

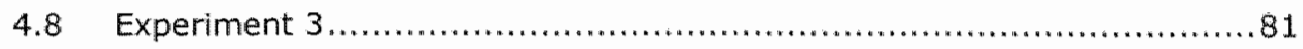

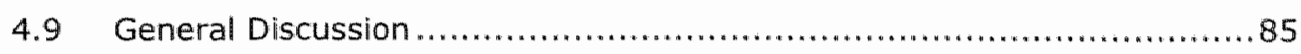

4.10 Limitations and Future Research ........................................... 88

Chapter 5: Information And Processing Characteristics as Moderators of

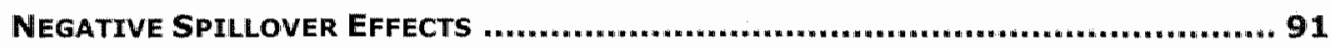

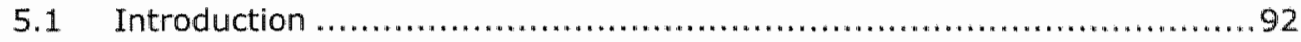

5.2 Negative Spillovers in Brand Portfolios ......................................... 93

5.3 Impact of Crisis Severity on Spillover Effects .................................94

5.4 Impact of Crisis Attribution on Spillover Effects .............................96

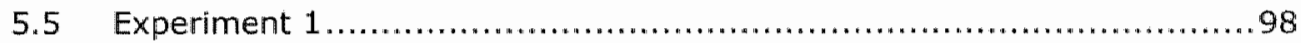

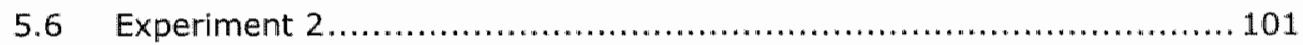

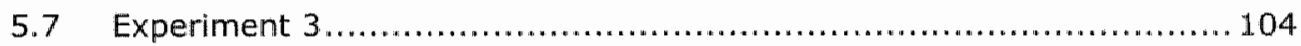

5.8 General Discussion......................................................... 106

5.9 Limitations and Future Research ...................................... 108

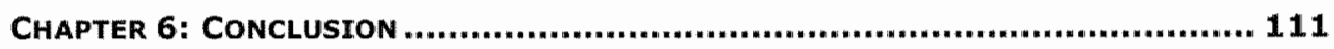

6.1 Synopsis .....................................................................112

6.2 The Influence of Service Intensiveness on Brand Extension Evaluations 113

6.3 The Role of Risk Perceptions in Verticall Line Extension Evaluations.......114

6.4 Negative Spillowers in Brand Architecture ...................................116

6.5 A Perspective on Future Research ....................................... 118

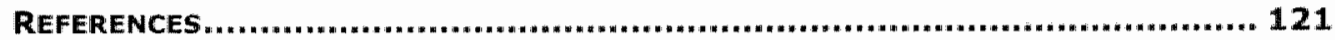

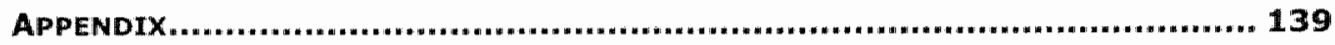




\section{Chapter 1: Introduction}


"The branding game is shifting from brand building to brand leverage" (Court, Leiter, and Loch 1999, p110)

"Yet brand leveraging is not a panacea". (Lane 1998, p75)

\subsection{Introduction}

In the marketing literature, there is a growing attention on the management of brand equity (e.g., Aaker 1991, 1996; Keller 2003). Brand equity, the added value of a brand name to the product, is one of the most valuable assets in a company (Aaker 1996). It differentiates the product in the "world of product parity" with look-alike advertising and over-copying of me-too brands (Park and Srinivasan 1994). It also shields the company from frequent price battles and enhances consumers loyalty to the brand despite their changes of product preferences. However, such an asset is not born with the introduction of a brand name. It often requires vast amounts of financial investments and various marketing programs to establish favourable brand-related belliefs among consumers. Therefore, aside from building brand equity, one important management issue in the current marketplace is to leverage this asset for marketing efficiency and profit increase (Court, Leiter, and Loch 1999). A brand leveraging strategy capitalizes on the power of an existing brand for newly introduced entities (e.g., products or sub-brands) in a company. However, any sharp sword has double edges, so do brand leveraging strategies. Hence, the success of a leveraging strategy depends on not only the benefits but also the strategic management of possible negative consequences of such strategies (Aaker and Keller 1990; Romeo 1991).

Two commonly used and the most researched leveraging strategies are brand and line extensions (e.g., Aaker and Keller 1990; Desai and Hoyer 1993). Brand extensions use an existing brand name to enter a different product category (e.g. Ivory Shampoo) and line extensions extend the brand name to new variants in the same product category (e.g., Cola-light). Since two seminal papers on extensions (Aaker and Keller 1990; Boush et al. 1987), numerous studies have examined the benefits and risks of brand and line extensions (e.g., Balachander and Ghose 2003; Broniarczyk and Alba 1994; Desal and Hoyer 1993; 
Gurhan-Canli and Maheswaran 1998; Keller and Aaker 1992, Kim and Sullivan 1998, Reddy, Holak, and Bhat 1994). However, an analysis of this rapidy accumulating body of kmowledge reveals several conceptual and empirical lacunae. To begin with, the focus has been virtually exclusively on extensions of tangible goods. This is surprising, as service aspects have become increasingly important for all products, and the service industry represents a large $(66 \%-80 \%)$ and steadily increasing share of the global economy (Shugan 1994). Also, services consist primarily of intangible properties compared to goods. Hence, the introduction of new services may encounter greater risks, more entry barriers; and higher failure rates (Zeitham॥ and Bitner 1996). These all underline the importance of understanding how services can both benefit from a brand leveragilng strategy and avoid its negative consequences.

Next, despite the proliferation of extension studies, limited formats of extension strategies have been investigated. For instance, most previous research examines extensions in a parallel format (i.e. extending firom goods to goods, from services to services), whereas many firms in the marketplace employ the so called "cross-extension" strategy (i.e. extending from services to goods or vice versa). Also, most of the line extension studies (e.g., Lee, Lee, and Kamakura 1996) investiglate horizontal line extensions (e.g., Diet Pepsi), and not much is known about vertical line extensions ( $e_{n} g_{*}$, Courtyard by Marriot) that have been widely used in industries such as automobiles, hotels, and financial services. Different extension formats consist of different extension variables (e.g., extension direction in vertical line extensions) that constitute the antecedents of consumer extension evaluations. Therefore, it is imperative for us to examine these various formats of brand and line extensions, seeking muitiple possibilities of obtaining managerial benefits from extension strategles.

Furthermore, brand and line extensions are conventional strategles to leverage single brand equity. In the current marketplace, many companies have multiple brands, including sub-brands, endorsed brands, and even acquired brands from mergers and acquisitions, forming a brand portfollo. A brand architecture strategy can leverage multiple brands through the cognitive relatedness among them. For instance, promotion of Kellogg's Cornflakes also increases awareness and sales of other Kellogg's brands, such as Specialk and vector, as a result of consumers' exposure to the common corporate logo similar packages, or related advertisement of these brands. Contrary to the wide 
application of brand architecture in the marketplace, knowledge about its effects is very limited: Especially, there is little theoreticall research on how consumers organize and represent a portfollo of brands in memory, and what consequences of such representation might be for consumer behaviour. Thus, extending the knowledge from leveraging single brand equity (brand/line extension) to leveraging the equity of multiple brands in a portfolio (brand architecture) will give us a broader perspective on brand leveraging strategiles.

This dissertation intends to address the aforementioned gaps in the brand leveraging literature. We investigate brand and line extensions in different contexts (i.e. goods and service context) and formats (i.e. cross-extension and vertical line extension). We also extend the current knowledge of brand leveraging strategies into the brand portfolio scenario through examining the cognitive representation of brand portfolio information in consumers' memory. Thus, the overall aim of this dissertation is to gain knowledge about the benefits and risks of brand leveraging strategies in different contexts, formats, and market scenarios.

\subsection{Academic Development of Brand Leveraging Strategies}

Although in practice multiple brand leveraging strategies are often employed simultaneously, the academic development of these strategies follows a historical trend from brand extension, line extension, to brand architecture. Brand extension has become a focus of brand leveraging research since 1990 . Numerous studies cumulating in various marketing and consumer journals (e.g., Journal of Marketing, Joumal of Marketing Research, Journal of Consumer Research, and Journal of Consumer Psychology) examined a wide range of antecedents of consumer responses to extensions and the feedback effects of these extensions on the parent brand. Amidst the focus on brand extensions, researchers start to realize that line extensions are much more prevallent than brand extensions in the marketplace. According to Aaker (1991, p. 208), "One survey of leading consumer product companies found that $89 \%$ of new product introductions were line extensions, $6 \%$ were brand extensions, and only $5 \%$ were new brands". Since line extensions are assumingly similar to brand extensions, relatively small amount of research has been particularly conducted on line extensions. However, Lee et al. (1996, p. 289) argued that, although line and brand extensions are conceptually related, the distinction between them is "a 
matter of type, not a matter of degree". Based on the characteristics of ine extensions, Lee et al. identified a few differences of evaluation mechanisms between line extensions and brand extensions. Nevertheless, many of the influential factors on consumer evaluations of brand extensions, such as parent brand characteristics, are also antecedents of consumer evaluations of line extensions. Furthermore, Nijssen (1999) and Reddy et al. (1994) developed a comprehensive framework for the success factors of line extensions in consumer products especially fast-moving consumer goods.

Despite the enthusiasm for brand and line extensions; brand managers now face a much more complex situation than just these extensions. A complex brand portfolio with multiple brands is often developed to fulfill market segmentation, brand strategy, and marketing efficiency objectives (Aaker and Joachimsthaler 2000). Aaker and Joachimsthaler introduced the concept of brand architecture that describes the number and nature of brands employed and the relationship between each brand in the marketing of a range of products and services. Although brand architecture is recognized as an organizer through which the brand portfolio functions as a unit to "create synergy, clarity, and leverage" (Aaker and Joachimsthaler 2000, p133), there is hardly any empirical research on the effect and cognitive process of this leveraging strategy. Following this historical line from brand/line extensions to brand architecture, we will explain the main issues of these brand leveraging strategies in the following sections.

\subsection{Brand Extensions and Line Extensions}

\subsubsection{Benefits of Brand and Line Extensions}

For many firms launching products in a new brand name is a risky endeavour because of high introduction costs and low success rates (Aaker and Keller 1990). This seems particularly true when products are extended to categories in which the company has no proven expertise. Furthermore, it may cost over 50million dollars to introduce a new brand given the expenses in marketing communications, promotions, and acquisitions of distribution channels (Pitta and Katsanis 1995). Still, 30-35\% of new products fall to win consumers" acceptance and withdraw from the market shortly after their introduction (Reddy et al. 1994). An extension can benefit from the parent brand awareness and 
positive brand associations (Keller and Aaker 1992). Thus, brand and line extensions become common practices for managers to facilitate product acceptance and minimize risks when introducing new products in the same or a different product category (Boush and Loken 1991; Delvecchio and Smith 2005; Smith and Park 1992). Moreover, as an established brand name reduces consumers perceived risks associated with the purchase of new products, brand and line extensions of a strong brand can even command price premiums relative to comparable products associated with lower equity brands (Delvecchio and Simith 2005).

Next, extensions can increase efficiency of marketing communication and promotion expenditures, as exposure of extensions produces economies of information and "halo effect" on the parent brand. For instance, Balachander and Ghose (2003) found that exposure to advertising of an extension has a positive effect on the choice probability of the parent brand. Smith and Park (1992) concluded that extensions capture greater market share and advertising efficiency then individual brands. Similarly, Erdem and Sun (2002) investigated the positive spillover effects of advertising and sales promotion for extension products in fast-moving consumer product categories.

Furthermore, a brand or line extension may even improve the parent brand image and clarify the brand meaning. One example of such benefits is the impact of brand extensions on consumer memory of parent brand information. Morrin (1999) demonstrated that exposure of extensions facilitates parent brand categorization, recall, and recognition through the strengthened cognitive linkage between extensions and the parent brand. Finally, extensions especially line extensions can enhance consumers' loyalty to the brand by offering them a portfollo of brand variants within a product category. Consumers often changes products because of their variety-seeking behaviour. A cohesive product line offers consumers' different but complementary products within the same brand name, which not only prevents brand switching but also encourages consumers to use the brand to a greater extent than otherwise might have been the case (Keller 2003; Nijssen 1999).

\subsubsection{Risks of Brand and Line Extensions}

Contrary to these benefits, brand and line extensions could have some negative consequences. Based on categorization theory, previous studies show 
that the inconsistent attributes of brand and line extensions with parent brand bellefs weaken the corresponding brand beliefs (Gurhan-Canli and Maheswaran 1998; Loken and Deborah Roedder 1993; Milberg, Park, and McCathy 1997). Similar to the information of inconsistent attributes, negative information or failure of extensions can harm the parent brand image even more (Ahluwalia and Gurhan-Canli 2000, Romeo 1991). However, not only inconsistent and negative information dillutes the parent brand, positive information or the success of brand and line extensions may also have an adverse impact on the parent brand. For instance, Kumar (2005) argued that a successful brand extension from product category $A$ to category $B$ increases the perceived similarity between the two categories. This can indirectly dilute the parent brand in category $A$ as the increased perceived similarity would lead to more favourable evaluations of extensions that other brands in category B may launch into category A. Also, as line extensions are in the same product category as the parent brand, the increased sales of line extensions may have been resulted from consumers switching to extensions from existing product offerings of the parent brand, cannibalizing the parent brand by decreasing its sales (Keller 2003).

\subsubsection{Influential Factors of Brand and Line Extensions}

The benefits and risks of extensions are traditionally reflected by how consumers evaluate extensions and the parent brand after the introduction of extensions. Previous research has mainly identified four categories of influentlal factors on extension evaluations and the feedback effects of extensions on the parent brand. First, as extensions are developed under the parent brand name, consumers evaluate both brand and line extensions on the basis of their parent brand-related attitudes. These attitudes are composed of cognitive and affective dimensions, including perceived quality (Aaker and Keller 1990), affect (Yeung and Wyer JR 2005), strength and breadth (Meyvis and Janiszewski 2004; Reddy et al. 1994), and specific associations of the parent brand (Bronlarczyk and Alba 1994). For instance, perceived quality and spontaneously elicited affect of the parent brand help consumers to form favourable extension evaluations. However, the prototypicality or specific associations of the parent brand in a product class may become restrictions of the extendibility of the brand. For instance, Jun, Mazumdar, and Raj (1999) found that a specific association of the parent brand, the technological level, can be an impediment to develop extensions with a more 
advanced technology level compared to the parent product. Broniarczyk and Alba (1994) also argued that these brand-specific associations may dominate the effects of brand affect, particularly when consumers' knowledge of the brand is high.

Next, previous research demonistrates that the transfer of parent brand attitudes to extenslons will be enhanced when there is a perceived fit between brand/line extensions and the parent brand (Aaker and Keller 1990; Nijssen 1999). The perceived fit can be based on either product feature similarity or brand concept consistency (Park, Milberg, and Lawson 1991). Moreover, percelved fit also has a direct positive effect on extension evaluations, as a poor fit may make consumers question the firm's ability to produce the extension or consider the extension as "ridiculous" (Aaker and Keller 1990). Thus, when there is lack of perceived fit, information of extensions leads to negative extension evaluations and dilution of parent brand beliefs (Boush and Loken 1991; Loken and Deborah Roedder 1993; Nijssen 1999). However, because line extensions are in the same product category with the parent brand, Lee et al. (1996) argued that there is at least some level of perceived fit between line extensions and the parent brand. Hence, the role of perceived fit in line extension evaluations is much less influential than that in brand extension evaluations. Instead, favourable line extension evaluations should be more dependent on whether new features of a line extension are perceived as important and appealing (Lee et al. 1996).

Furthermore, company-rellated strategy variables, such as the sequence of extension introduction (Keller and Aaker 1992; Nijssen 1999), number of previous extensions (Dacin and Smith 1994), and extension-related adverting expenditure (Nijssen 1999) also influence consumer reactions to extensions. For instance, the successful introduction of previous extensions can increase consumers' confidence and favorability in their quality evaluations of subsequent extensions. Finally "the effects of the above listed factors are often moderated by consumer-related variables, including knowledge (Muthukrishnan and Weitz 1991), involvement (Maoz and Tybout 2002), mood (Barone, Miniard, and Romeo 2000), motivation (Gurhan-Canli and Maheswaran 1998), self-monitoring (Czellar 2003), and age (Czellar 2003). For instance, more knowledgeable consumers in the parent and extension product categories judge the perceived fit between the parent brand and extensions on the basis of deep cues (e.g., 
technology smillarity) whereas less knowledgeable consumers on the basis of surface levell cues (e.g., package, shape). Also, positive mood can enhance extension evaluations through its effect on perceived fit as well as percelved competence of the marketer in producing the extension.

\subsubsection{Research Gaps in Brand and Line Extension Literature}

Research on the antecedents of consumer evaluations of extensions in the past 15 years has been extensive. Ample empirical evidence attests the main effects and interactions between parent brand attitudes, perceived fit, marketercontrolled, and consumer-level factors (Czellar 2003). A common ground of these studies is that consumers evaluate extensions based on the perceived variation of extensions compared to the parent brand. Previous studies examined such variation in terms of the changes of product categories (brand extension) and product features (line extension). However, it is important to note that the perceived variation between extensions and the parent brand may consist of multiple dimensions, such as the changes of product types or product classes. Nevertheless, little research has been published about the impacts of these dimensions of perceived variation and their interactions on extensions evaluations. Furthermore, several studies have shown the importance of service extensions in the development of service industries (Martínez and Pina 2005; de Ruyter and Wetzels 2000; van Riel, Lemmink, Ouwersloot 2001). Given the important distinctions between services and goods, consumers may employ a different mechanism to evaluate service extensions compared to goods extensions. However, systematic research on how consumers evaluate service extensions still remains underdeveloped.

Another issue that is worthy of attention is the measurement of consumer reactions to extensions. Most of previous research measures extension evaluations (e.g., Keller and Aaker 1992; Kumar 2005; Milberg et al. 1997), but such a measurement may not fully reflect the impact of varlous antecedents on consumer responses to extensions (Woadruff 1997). Instead, perceived value is considered a more comprehensive measurement as it is based on the trade-off between the benefits and sacrifices that consumers foresee in an extension product (Zeithaml 1988). Also, prior studies often assess consumers' attitudes toward extensions with the standard bipolar measure of attitude valence. However, Ahluwalia, Burnkrant, and Unnava (2000) argued that the impact of 
negative information on brands can be better judged through the attitudinal ambivalence measurement rather than the bipolar valence measurement. This is because consumers often have both positive and negative components in their attitudes toward a brand and such attitudes can be described as "ambivalent". The ambivalence of brand attitudes can provide important information related to the ability of this attitude to predict consumers' future purchase behaviour. These different measurements can reflect different aspects of consumer reactions to extensions. Therefore, it is important to employ multiple measurements for consumer reactions to extensions and investigate the relative importance of various antecedents (e.g., extension variables) in terms of their impacts on these measurements.

\subsection{Brand Architecture}

\subsubsection{Definition and Types of Brand Architecture}

Aaker and Joachimsthaler (2000) introduced the concept of brand architecture and defined it as "an organizing structure of the brand portfolio that specifies brand roles and the nature of relationships between brands". They specifled four types of brand architecture based on the extent to which brands are linked in a brand portfolio. These four types of brand architecture are: house of brands, endorsed brands, sub-brands, and branded houses. The house of brands type involves an independent set of stand-alone brands (e.g., Pantene and Tide from Proctor \& Gamble). Such an arrangement can prevent channel conflicts and avoid linking incompatible associations of one brand to another brand in the portfolio. Similar to house of brands, endorsed brands are independent from each other, but they are usually endarsed by an organizational brand, such as Courtyard by Marriot and Lexus by Toyota. The impact of such endorsement on the endorsed brand depends on how it is presented with the endorser brand and the strength and credibility of the endorser brand. The subbrand type is employed when the parent brand introduces new products with madified associations, such as Microsoft Office and Sony Walkman. Sub-brands are supposed to have much closer relationships with their parent brand than the endorsed brands. This closeness leads to greater leveraging benefits for the subbrands but also considerable risk for the parent brand. Finally, a branded house offers multiple products under one brand name, such as various products of 
Adidas. A branded house is often developed through multiple brand and/or line extensions, and it enhances the brand clarity, synergy and leverage. Logically, this type of brand architecture, on the other hand, limits the firm's ability to target specific groups. These four types of brand architecture are not independent from each other. Rather, they represent four general categories of branding strategies through which marketers intend to control the level of relatedness between brands in a portfolio along a continuous brand relationship spectrum ranging from weak to strong.

\subsubsection{Research Issues on Brand Architecture}

Under different market situations, brand managers adopt one or a mix of different types of brand architecture in order to leverage parent brand associations, achieve communication efficiencies, and avoid incompatible associations and conflicts between brands in a portfolio. An important rationale here is that different brand architecture strategies influence how consumers encode, process, and react to brand information, which subsequently determines consumer behaviour in brand-related issues. However, hardly any research has examined the impact of brand architecture from a consumers' perspective. For a number of reasons, consumers may not respond to a particular brand architecture strategy as brand managers have expected. Depending on the level of familliarity and knowledge with the product category, in some instances, consumers may not perceive the connection between brands. In other cases, consumers may still associate brands together while brand managers try to protect the distinctiveness of each brand through using the house of brands strategy. Therefore, it is important to understand how consumers organize brand information in a portfolio. In other words, a cognitive counterpart to this marketplace construct of brand architecture needs to be conceptualized, as it allows us to examine the antecedents and consequences related to different brand architecture strategies. For instance, a brand may receive positive spillover effect from promotion and advertising of other brands in the same brand portfolio. On the other hand, exposure to negative information such as product failure, negative word-of-mouth, product-harm crises at one brand in a portfolio may also hurt other brands which are not directly involved. In order to understand and study these benefits and risks of brand architecture, researchers need to investigate how consumers represent brand architecture information in their 
memory and how this representation influences their processing of external information.

\subsection{Objectives of Different Studies}

The main purpose of this dissertation is to investigate the impact of brand leveraging strategies in different contexts, formats, and market scenarios. Four studies are conducted in this dissertation: Study one examines consumer evaluations and the consequences of cross-extensions in both goods and service contexts. Study two investigates consumer reactions to vertical line extensions in a service context. Study three and four focus on consumers cognitive representation of brand portfolio information, the effects of such representation on consumer behaviour, and the boundary conditions of these effects. The next section briefly describes all four studies and their respective objectives.

\subsubsection{Objectives of Study 1}

Previous studies on brand extensions identified two critical factors on consumer evaluations of extensions: parent brand attitudes and perceived fit between extensions and the parent brand. Most of prior research investigates extensions with an equal amount of service components to the parent brand. However, many extension products in the marketplace contain distinctly different levels of service components than the parent brand. Also, Shostack's (1977) conceptualization of the service-goods spectrum indicates that products are often a combination of goods and service components. Given services' special characteristics, it is possible that the amount of service components of a parent brand influences the attributes and associations that consumers perceive in the parent brand. Therefore, the main objective of this study is to investigate the impact of parent brand's relative service intensiveness and its interaction with perceived fit on consumer evaluations of extensions as well as consumer evaluations of the parent brand after the introduction of extensions.

\subsubsection{Objectives of Study 2}

The existing research on line extensions mainly investigated horizontal line extensions in the goods area. There is hardly any research on how consumers evaluate vertical service line extensions. Also, although consumers' risk perceptions are considered to be central to evaluations (Dowling 1999), most of 
prior studies on extensions have ignored the role of perceived risk 1 h extension evaluations. Furthermore, as consumers often assess both benefits and sacrifices associated with an extension, perceived value is a more comprehensive measurement than extension evaluations that are commonly measured to reflect consume reactions to extensions in previous studies. Hence, the purpose of this study is to investigate the impact of various antecedents (e. 9 ., extension factor, marketer-controlled factor, and consumer-level factor) on consumer reactions to vertical service line extensions with respect to percelved risk, extension evaluations, and perceived value of extensions.

\subsubsection{Objectives of Study3}

As a result of market fragmentation and sub-brand proliferation; a complex brand portfolio, with multiple brands and sub-brands, is often developed in companies. Due to exposures to company logos, related advertisements, and other market-based information, consumers establish associations and linkages between brands in a portfolio to help them navigate the "brandscape" in which they consume. Once these linkages are established in consumers' memory, a brand cannot be insulated from exposure to information about related brands. This constitutes the basic rationale for both positive and negative spillover effects in which external information (e.g., advertising, or a negative news) about a brand can change evaluations of brands that are not directly implicated (Roehm and Tybout 2005). In order to investigate such spillover effects, it is imperative to understand how brand portfolio information is represented in consumers' memory. Therefore, the main objective of this study is to explore and map the cognitive representation of brand architecture through predicting and measuring patterns of spillover effects elicited by product-harm crises in a brand portfolio.

\subsubsection{Objectives of Study 4}

Study 3 in this dissertation examines the impact of negative information in a brand portfolio and concludes that the magnitude of negative spillover effects is a function of the strength of association between brands in a portfolio. A spillover effect occurs as a result of consumers' processing of external information and the spread of consumers' reactions to such information through the cognitive structure of brand architecture. Therefore, it is very likely that not only the structure of brand architecture, but also the characteristics of the information 
spreading through the structure as well as the nature of processing that negative information undergoes influence the pattern of spillover effects. Hence, this study intends to investigate the impact of information characteristics, processing characteristics, and their interaction with the structure of brand architecture on the spillover effect of product-harm crises in a brand portfolio.

\subsection{Outline of the Dissertation}

This dissertation addresses four inter-related issues about brand leveraging strategles. The outline of four studies in this dissertation is presented in figure 1.1. Chapter two and three (study one and two) focus on the benefits of brand and line extensions. In particular, chapter two (study one) examines the impact of the relative service intensiveness of an extension (compared to its parent brand) on consumer evaluations of the extension. It complements current extension evaluation models by examining extensions in a different format and context. To close the gap between line extension proliferation in practice and a lack of theoretical development, chapter three (study two) investigates the influential factors on consumer reactions to vertical service line extensions. Chapter four and five (study three and four) extend brand leveraging strategies from leveraging single brand equilty to leveraging the equity of multiple branids in a portfolio. Study three investigates an associative network conceptualization of brand architecture through measuring patterns of spillover effects in a brand portfolio. Study four examines the boundary conditions of such spillover effects. Finally, chapter six presents a summary of main results, discusses theoretical and managerial implications, and provides future research directions based on the limitations of the dissertation. 
Figure 1.1: Outline of the Dissertation

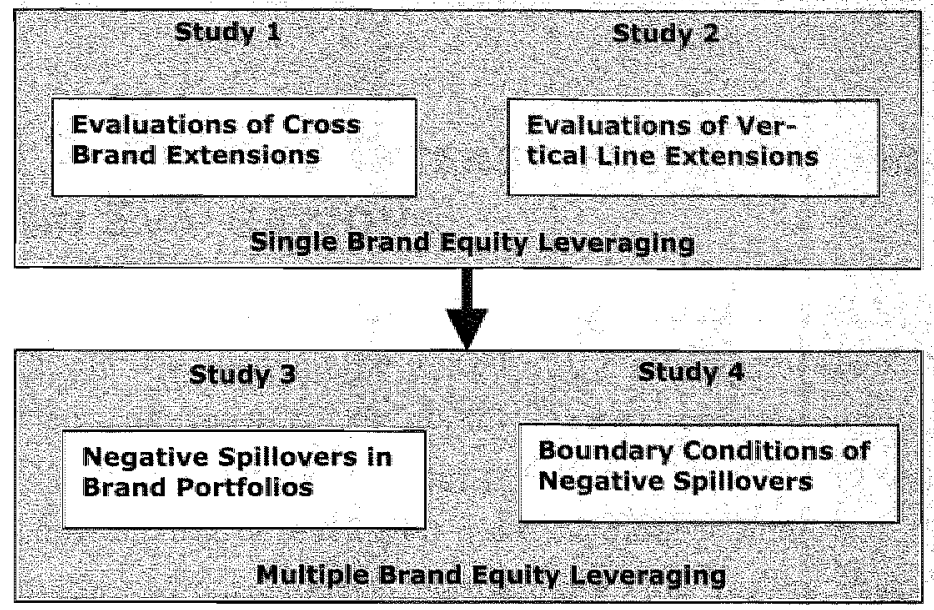




\section{ChAPTER 2: SERVICE INTENSIVENESS AND BRAND EXTENSION EVALUATIONS ${ }^{1}$}

In this study, we examine the impact of the relative service intensiveness of an extension compared to its parent product on consumers' extension evaluations. The empirical evidence from this study indicates that the quality of an extension product will be evaluated more favourably when it is less service intensive than the parent product. Furthermore, the results reveal that the impact of service intensiveness on extension evaluations is positively moderated by the perceived similarity between an extension and its parent product. Finally, it is also found that the relative service intensiveness of an extension compared to the parent product influences consumers' post-evaluations of the parent product after the extension introduction. Meanwhile, the perceived similarity reinforces this effect on consumers' post-evaluations.

\footnotetext{
'This clhapter is largely based on Lei, Jing, Roger Pruppers, Hans Ouwersloot, and Jos Lemmink (2004), "Service Intensiveness and Brand Extension Evaluations', Journal of Service Research, Vol.6 $(3), 243-55$.
} 
"No longer do marketing managers ask whether or not to extend a brand --the primary question is how far we can reasonably stretch the brand."

(Farquhar et al. 1992, p3:2)

\subsection{Introduction}

The introduction of brand extensions has emerged as an increasingly important strategy used by firms in launching new products in the marketplace (Loken and Deborah Roedder 1993). It provides the benefits of facilitating the acceptance of new products (e.g., Hankinson and Cowking 1993; Keller 1993) and minimizing risks (e.g., Kapferer 1997; Smith and Park 1992). Given the important distinctions between services and goods, many studies draw a clear dichotomy between them with respect to research conclusions as well as marketing implications. However, examining business reality, it is commonly acknowledged that there are only a few pure consumer goads or services (e.g., De Chernatony and Dall'Olmo Rilley 1999; Zeithaml and Bitner 1996), and most products are combinations of goods and services.

Therefore, the goods-service spectrum conceptualized by Shostack (1977) is often used to understand the nature of a product, based on the level of its intangibility. This conceptualization bridges the chasm between goods and services, illustrating the possibility of a continuous extension process from goods to services or vice versa. Meanwhile, as the service component in many products has been dramatically increased (Shugan 1994), the service aspects have become more and more important in evaluating the quality of a product. However, an in-depth investigation into the impacts of a parent product's service intensiveness relative to its extensions on consumers' extension evaluations is largely lacking.

Moreover, many present studies investigated the influential factors of consumer evaluations of parallel extensions (e.g., from goods-intensive products. extending to goods-intensive products or from service-intensive products extending to service-intensive products) (e.g., Aaker and Keller 1990; Bottomley and Doyle 1996; Broniarczyk and Alba 1994; van Riel, Lemmink, and Ouwersloot 2001). However, there are abundant real-life cases where service-intensive extensions are developed from goods-intensive parent products, or vice versa. For example, Sears, a traditional department store chain in which products are highly goods intensive, extended its brand into automotive services and 
insurance business lines. In contrast, Carluccio, a famous Italian restaurant, extended its service-intensive brand to goods-intensive extensions such as Carluccio pasta and Carluccio chocolate biscuit.

Therefore, our main research purpose is to investigate whether consumers develop different attitudes in evaluating a more service-intensive extension (an extension with more service intensiveness than the parent product, e.g., extending from copy machines to document reproduction consultancy) compared to a less service-intensive extension (an extension with less service intensiveness than the parent product, e.g., extending from copy machines to toner cartridges). We refer to this as the service intensiveness effect in our research. Second, it has been well documented that the similarity between the parent product and extensions has a great impact on the consumers' extension evaluations directly or indirectly (e.g., Aaker and Keller 1990). In this article, we investigate the extent to which perceived similarity moderates the service intensiveness effect. Third, besides the research on extension evaluations, the reciprocal effect on the parent product has also received a lot of attention in previous studies (e.g., Loken and Deborah Roedder 1993; Park, Jun and Shocker 1996). It explains consumers" post-evaluations of the parent product after being exposed to extensions. Previous studies found that the inconsistent information conveyed by extensions can lead to a positive or negative feedback effect on the parent product and perceived similarity may moderate this effect. In the current research context, when extensions involve different degrees of service intensiveness relative to their parent product, we examine consumers' subsequent evaluations of the parent product ${ }^{2}$ due to this inconsistent information brought by extensions.

We begin this article by giving the theoretical background of brand extensions and brand extension evaluations. In the sections that follow, we develop our hypotheses about the service intensiveness effect, the effect of similarity, and the reciprocal effect. Subsequently, we develop our experimental design adapted from Jun, Mazumdar, and Raj's (1999) technology hierarchy study, which investigates the impacts of a parent product's relative technology level on consumer evaluations. Finally, we conclude the study by discussing our findings as well as their theoretical and managerial implications.

\footnotetext{
${ }^{2}$ In this study, the terms parent product and parent brand are interchangeable because we assume the parent brand is linked to a single product category.
} 


\subsection{Brand Extension and Brand Extension Evaluations}

Research on brand extensions has been a subject of substantial interest (e.g., Aaker and Keller 1990; Bottomley and Holden 2001; Boush and Loken 1991; Broniarczyk and Alba 1994; Dacin and Smith 1994; Keller and Aaker 1992; Loken and Deborah Roedder 1993; Reddy, Holak, and Bhat 1994; Sunde and Brodie 1993). Existing studies on brand extensions have been mainly conducted in either the goods domain (e.g., Aaker andKeller 1990; Boush and Loken 1991; Dacin and Smith 1994) or the service domain (de Ruyter and Wetzels 2000; van Riel, Lemmink, and Ouwersloot 2001), where relatively less attention has been dedicated to the latter.

Previous brand extension studies have primarily focused on consumers" responses to brand extensions. It appears that extension evaluations mainly depend on consumers' initial attitudes toward the parent brand and the perceived similarity (e.g., Barone, Miniard, and Romeo 2000; Broniarczyk and Alba 1994; Jun, Mazumdar, and Raj 1999) or "fit" (e.g., Aaker and Keller 1990; Bottomley and Doyle 1996; Park, Milberg, and Lawson 1991) between an extension and the parent product. Based on these two main influential factors, consumers' overall attitude toward an extension is developed.

Consumers' overall attitude toward an extension product may contain affect that can hardly be measured by those specific attributes such as "serviceability and durability," even when a large set of attributes are included (Aaker and Keller 1990). As a result; based on the existing studies (e.g., Aaker and Keller 1990), quality perception is often used as a general measurement instrument for consumers' overall brand attitude.

Zeithaml (1988) defined quality as a global assessment of consumers' judgments on the superiority or excellence of a product. Hence, quality is considered as a higher level of abstraction than a specific attribute of a product. Specifically, the concept of quality reflects a measure of "goodness" that spreads over all elements of a brand (Aaker 1996). This implies that even when a brand's identity is strongly based on certain specific attributes, the perceptions of these attributes are closely related to perceived quality (Aaker 1996; de Ruyter and Wetzels 2000; Jun, Mazumdar, and Raj 1999). Therefore, the previous endorsement of this concept (e.g., Aaker and Keller 1990; Jun, Mazumdar, and Raj 1999; Keller and Aaker 1992; van Riel, Lemmink, and Ouwersloot 2001) 
justifies the use of perceived quality as the measurement of consumers" overall attitude toward extensions in this research.

\subsection{Conceptual Development and Research Hypotheses}

\subsubsection{Service Intensiveness Effect}

Services are featured by four distinct characteristics (simultaneity, heterogeneity, intangibility, and perishability) (Iacobucci 1998). As we discussed before, there is no clear dichotomy between service and goods products in reality. For instance, a restaurant is basically classified as a service provider, but it also contains physical goods elements, such as the foods it serves.

Therefore, the differences between goods and services are more of emphasis than of nature or kind (Zeithaml and Bitner 1996). In other words, products should be described in terms of their service intensiveness or goods intensiveness. Shostack's (1977) goods-service continuum is mainly based on the degree of intangibility or tangibility to illustrate the service intensiveness of a product This approach is also supported by Iacobucci's $(1992 ; 1998)$ study that the fundamental features of service are determined by its degree of intangibility. Supported by the arguments reviewed above, the degree of service intensiveness will be based on the degree of intangibility in this article.

The service intensiveness effect in this study explains the impact of the service intensiveness of an extension relative to its parent product on consumers' brand extension evaluations. As indicated above, we employ perceived quality as a proxy construct to measure consumers' extension evaluations. Service quallty is conceptualized as technical quality and process quality (Zeithaml and Bitner 1996). The process quality describes how and by whom the service is delivered. Research on service quality reveals that process quality is more decisive in determining the overall quality of services than technical quality (Kasper, van Helsdingen, and de Vries 1999). The inherently large quality variation in services during the delivery process (Lovelock 1984) may be perceived as noise and errors by consumers, leading to inconsistencies and unpredictable performance of service quality (Iacobucci 1998). Meanwhile, the complexity and intangibility of services (Iacobucci 1992; 1998) lead to consumers' perception that the likelihood of higlh quality may be inherently low (Iacobucci 1998), and services are riskier purchases than goods (Iacobucci and Ostrom 1996). 
As a consequence of these properties, consumers attach a greater risk perception in case of a more service-intensive extension relative to its parent product. Theory suggests that risk perceptions are considered to be central to consumers' evaluations, choices, and behaviors (Campbell and Goodstein 2001; Dowling 1999). Perceived risk increases with higher level of uncertainty (Campbell and Goodstein 2001), which in turn leads to less favorable evaluations and less intention of buying a product (Dowling and Staelin 1994). In contrast, in case of a less service-intensive extension relative to its parent product, less risk concern is involved in the quality evaluation.

Furthermore, the difficulty in evaluating services due to the existence of credence quality (quality that may be impossible to evaluate even after purchase and consumption; Zeithaml 1984) prompts consumers to rely more on tangible and quality-consistent elements when evaluating the quality of a product (Berry 1984; De Chernatony and Dall'Olmo Riley 1999; Zeithaml 1984; Zeithaml and Bitner 1996).

Therefore, a less service-intensive extension, comprising less intangible and more tangible elements compared to the parent product, will attract more favorable evaluations than a more service-intensive extension. The essential rationale is that the former reduces consumers' perceived risk on quality evaluation while strengthening the beneficial impression of quality consistency. Hence, we hypothesize the following:

H1: Consumers will have more favorable extension evaluations when an extension is less service intensive relative to its parent product than when an extension is more service intensive relative to its parent product. (This effect is referred to as the service intensiveness effect.)

\subsubsection{Main Effect of Perceived Similarity on Extension Evaluations}

Perceived similarity is conceptualized as the attribute or association overlap between an extension and the parent product (e.g., Aaker and Keller 1990; Bridges, Keller, and Sood 2000). The shared associations can be product related associations (functional attributes) (Aaker and Keller 1990; Boush and Loken 1991), image-based associations (brand concept attributes) (Park, Milberg, and Lawson 1991), or unique brand-specific associations (Broniarczyk and Alba 1994). In general, studies of perceived similarity have shown its positive effect on consumer evaluations of an extension product. However, the re-examination 
of existing studies reveals that the distinction between the main and the moderating effects of perceived similarity lacks attention.

The main effect of perceived similarity emphasizes a direct link between high similarity and more favourable evaluations. The rationale is based on the expectation that low similarity makes consumers question a firm's general competences and abilities to produce the extension product (Barone, Miniard, and Romeo 2000; Broniarczyk and Alba 1994). In the worst case, the lack of fit may even lead consumers to perceive an extension scenario as "humorous" or "ridiculous" (Aaker and Keller 1990). Kapferer (1997) considered the relevance of fit as an indicator that the product stays within the boundaries of the know-how of the company as it is imagined. Therefore, in line with the earlier research, we hypothesize the following:

H2: Consumers will have more favourable extension evaluations when the perceived similarity between an extension and the parent product is high than when it is low.

\subsubsection{The Moderating Effect of Perceived Similarity}

The moderating effect of perceived similarity serves as a catalyst facilitating the transfer of associations of a parent product to the extension product (Aaker and Keller 1990; Barone, Minilard, and Romeo 2000; Boush and Loken 1991; Cohen and Basu 1987). Specifically, the greater the percelved similarity, consumers are more likely to rely on the existing associations of the parent product to infer the attributes or benefits of the extension (e.g., Cohen and Basu 1987; Keller and Aaker 1992), such as the product quality of the extension.

According to Hypothesis 1, consumers evaluate various extensions differentlly, depending on the parent product's service intensiveness relative to extensions. Therefore, the relative service intensiveness of the parent product can be considered as a specific association that affects consumers' extension evaluations. In line with the reasoning above, we expect a more sallent impact conveyed by this assaciation in the high-similarity condition than in the lowsimilarity condition. Specifically, the effect size of the service intensiveness effect as discussed in Hypothesis 1 is reinforced by the degree of similarity. Therefore, we hypothesize the following: 
H3: The service intensiveness effect will be more pronounced when the perceived similarity between an extension and the parent product is high than when it is low.

\subsubsection{Reciprocal Effect}

Apart from the attention given to extension evaluations, the reciprocal effects that extensions might have on the parent product also demand more investigation. Bellefs conveyed by an extension from another product category than the parent product category are the primary sources in formulating the feedback on the parent product (Sheinin 2000). The "bookkeeping model" (e.g., Weber and Crocker 1983) demonstrates that brand beliefs change incrementally by incorporating the available inconsistent information (Loken and Deborah Roedder 1993). Changes as such can lead to positive (Deborah Roedder, Loken, and Joiner 1998) as well as negative feedback on the parent product (Jun, Mazumdar, and Raj 1999; Park, Jun, and Shocker 1996).

Due to the diversity of customer demands and customer involvement in the service delivery process (Batt 1999; Larsson and Bowen 1989; Lovelock 1991), companies producing more service-intensive products are presupposed to be of higher competence (Sjoholt 1999). The variabillity and complexity of service production (De Bandt 1999) also require employees to be more flexible and adaptable in performing service activities, solving problems interactively (Ottewill, Fennings, and Magirr 2000), and mobilizing the acquired knowledge in an organization (De Brandt 1999). Therefore, the introduction of a more serviceintensive extension, containing a higher proportion of service components, is perceived as an accomplishment of the firm. This new information ("accomplishment" feeling) will be included into the brand memory structure, influencing the parent brand's beliefs and, consecutively, consumers' attitudes in a positive way (Loken and Deborah Roedder 1993). However, a less serviceintensive extension runs the risk that it will be interpreted as a dilution of the firm's competence to produce high-quality and complex products. Consequently, this perception may have a negative influence on the subsequent evaluations of the parent brand. Thus, we hypothesize the following:

H4: Consumers will have more favourable evaluations of the parent brand after the exposure to a more service-intensive extension compared to a less serviceintensive extension (reciprocal effect). 


\subsubsection{Moderating Effect of Perceived Similarity on the Reciprocal Effect}

An extension less similar to its parent product has less feedback infuence on the parent product. For example, Morrin (1999) shows that "low fit extensions are expected to result in less facilitation of parent retrieval than are high fit

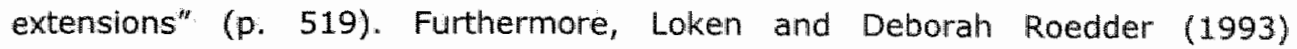
demonstrate the inherent logic of incorporating the moderating effect of similarity in the feedback process by saying that "the generalization of beliefs about a brand extensiom to the family brand should be greater for extensions in product categories that are the same as those currently occupled by the family brand" (p. 74). Therefore, we hypothesize the following:

H5: The impacts of an extension on the parent brand will be more pronounced when the perceived similarity between the extension and the parent product is bigh than when it is low.

\subsection{Methodology}

\subsubsection{Experiment Design}

The design involved a $2 \times 2$ between-subjects factorial design, adapted from Jun, Mazumdar, and Raj's (1999) study about the technology hierarchy effect. The first factor, the service intensiveness (more service-intensive extension vs. less service-intensive extension), was employed to control extensions' service intensiveness relative to their parent product. The second factor was perceived similarity, with extensions being described as having high similarity or low similarity with the parent product.

The purpose of this study primarily concerns the service intensiveness effect. Hence, it is crucial to ensure the relative service intensiveness being the central diagnostic information for consumer evaluations. As a result of this consideration, we used a hypothetical brand name to eliminate the possible confounding effects conveyed by the associations of existing brand names (Kapferer 1997). Furthermore, on the basis of the comparative approach (Jun, Mazumdar, and Raj 1999) in this study, we chose one common parent product as the reference point, eliminating possible quality variations among different parent products and thus keeping the initial attitudes to the parent product constant for each extension scenario. 


\subsubsection{Stimulus Development}

The stimulus development (praduct category, extensions, and brand name) was conducted in a focus group consisting of five undergraduate studients from a European university. We asked students to propose a list of parent products satisfying the requirements of (a) respondents familiarity with this product and (b) its extendability. Panel members decided to choose the printing system category including laser printer and copy machine from the proposed list based on its extensive and realistic extension possibilities.

Four extensions were generated, each reflecting one treatment condition depicted in the experiment design (Figure 2.1). The selected extensions were: (a) toner cartridge (Extension 1, less service intensiveness and high similarity), (b) recordable compact discs (Extension 2, less service intensiveness and low similarity), (c) document reproduction consultancy (Extension 3, more service Intensiveness and high similarity), and (d) graphic layout and design consultancy (Extension 4, more service intensiveness and low similarity).

Figure 2.1: Service Intensiveness Framework

(Adapted From the Technology Hierarchy Framework)

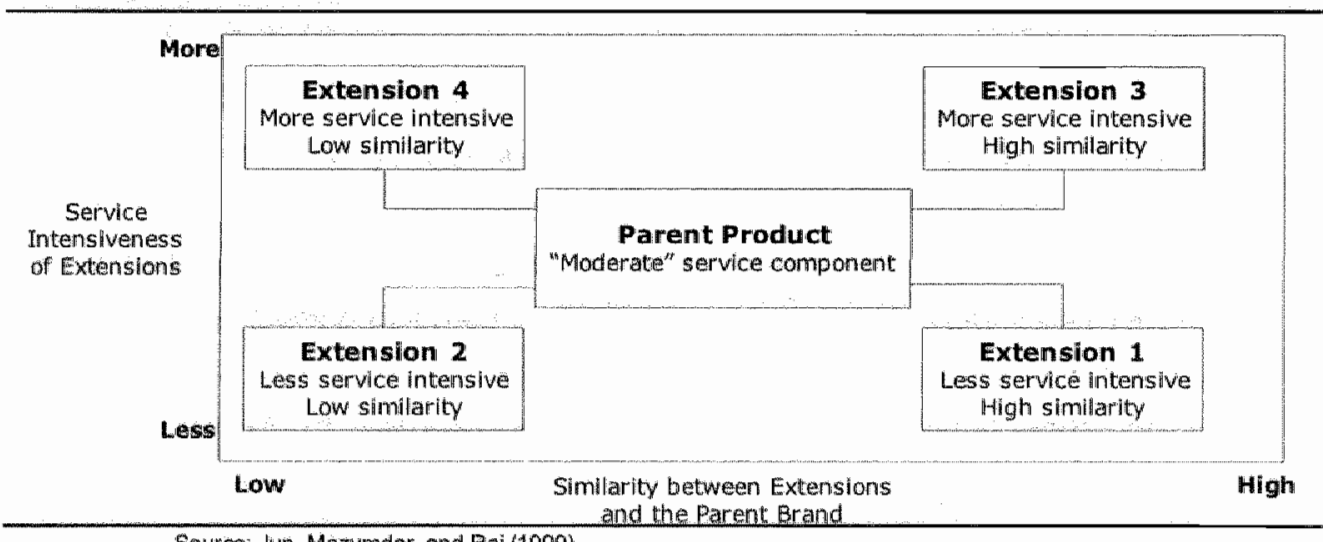

Source: Jun, Mazumdar and Raj (1999)

\subsubsection{Pretests}

We conducted four pretests to confirm the appropriateness of the selected stimuli. To avoid potential confounding effects due to the presenting order of extension scenarios in each questionnaire, four versions of questionnaires were developed for the pretests. Every two questionnaires covered two same 
extension scenarios, but these two scenarios were presented in a different onder in the two questionnaires.

All scale items were measured with a 7 point Lkert scale, ranging from 1 (strongly disagree) to 7 (strongly agree). Twenty-four business undergraduate students participated in the pretest, where 6 students filled in the same version of questionnaires.

The pretests revealed that the stimuli were overall successfully introduced in creating the desired experiment scenarios (Table 2.1). The results showed that there is a significant difference between more service-intensive and less serviceintensive extensions $(F(1,46)=93.6, p<0.001)$, and between simillar and dissimilar extensions $(F(1,46)=36.4, p<0.001)$. Thus, for four extensions, the differences as intended by the design exist. For the detailed results of four

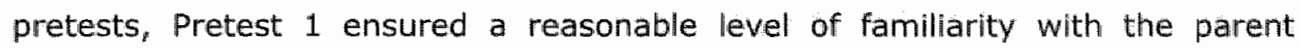
product and extensions. Pretest 2 showed that Extension 1 and 3 were more similar extensions ( $M=5.23$ and 5.19 , respectively), and Extension 2 and 4 were less similar extensions ( $M=2.79$ and 4.13 , respectively). Pretest 3 showed that Extension 1 and 2 were less service-intensive extensions $(M=2.79$ and 2.17 , respectively), and Extension 3 and 4 were more service-intensive extensions ( $M$ $=6.08$ and 5.50, respectively). Finally, the appropriateness of brand names adopted in this research was checked in Pretest 4. Respondents were asked to evaluate whether the brand name was suitable for the parent brand category and extension categories. From a list of preliminarily selected brand names (Lexon, Accura, Copytech, Logicom), Accura was the most suitable brand name for the parent product as well as the extensions ( $M_{\text {Accura }}=4.63$ for the parent brand, $M_{\text {Actura }}=5.13$ for the extension brand). 
Tablle 2, 1: Pretests for Familiarity, Service Intensiveness, and Similarity

\begin{tabular}{|c|c|c|c|c|c|c|}
\hline \multirow[b]{2}{*}{ Treatment Conditions } & \multicolumn{3}{|c|}{ High Similarity Extensions } & \multicolumn{3}{|c|}{ Low Similarity Extensions } \\
\hline & Extension 1 & Mean & SD & Extension 2 & Mean: & So \\
\hline \multirow{3}{*}{$\begin{array}{l}\text { Less service } \\
\text { intensive extensions }\end{array}$} & Famillarity & 5.67 & 1.21 & Familiarty & 6.08 & 1.05 \\
\hline & Serveo Intensiveness & 2.79 & 1.39 & Service Intensweriess & 2.17 & 1.27 \\
\hline & Simnlarity & 5.23 & 0.99 & Similanty & 2.79 & 0.53 \\
\hline & Extension 3 & Mean & SD & Extension 4 & Mean & SD \\
\hline \multirow{3}{*}{$\begin{array}{l}\text { More service } \\
\text { Intemsive extensions }\end{array}$} & Familiarity & 4.75 & 1.11 & Famillarity & $4 \ldots 92$ & 1.30 \\
\hline & Service Intensiveness & 6.08 & $\$ .12$ & Service Intensiveness & 5,50 & 0.83 \\
\hline & Simillarity & 5.19 & 0.74 & Simillarity & 4.13 & 1.20 \\
\hline Parent product & Familiarity & 5.79 & 1.15 & & & \\
\hline
\end{tabular}

\subsubsection{Sample and Experiment Procedure}

Our objective was to have an equal number of participants in the four experimental conditions. To achieve this, 247 business undergraduate students from the same university participated in the experiment, and seven responses were excluded due to incomplete information. This resulted in an effective sample of 240 participants who were randomly assigned across the experimental cells in such a way that each cell had 60 participants (Table 2.2).

Table 2.2: Extensilon Scenarios and Cell size

\begin{tabular}{|c|c|c|}
\hline & $\begin{array}{l}\text { High Similarity } \\
\text { Extensilons }\end{array}$ & $\begin{array}{l}\text { Low Similarilty } \\
\text { Extensions }\end{array}$ \\
\hline Treatment Condit ons & Extenslion 1 & Extension 2 \\
\hline \multirow[t]{2}{*}{$\begin{array}{l}\text { Less service } \\
\text { intensive extensilons }\end{array}$} & $\begin{array}{l}\text { Toner cartridges } \\
(n=60)\end{array}$ & $\begin{array}{l}\text { Recordable compact discs } \\
(n=60)\end{array}$ \\
\hline & Extension 3 & Extension 4 \\
\hline $\begin{array}{l}\text { More service } \\
\text { intensive extensilons }\end{array}$ & $\begin{array}{l}\text { Document reproduction } \\
\text { consultancy } \\
(n=60)\end{array}$ & $\begin{array}{l}\text { Graphic layout and } \\
\text { design consultancy } \\
(n=60)\end{array}$ \\
\hline
\end{tabular}

\subsubsection{Measurement}

The quality evaluation of extension products was operationalized by two items: the overall quality perception (Jun, Mazumdar, and Raj 1999) and the superiority of the goods/services (Jun, Mazumdar, and Raj 1999; Zeithaml 1988). Given the Cronbach's alpha of 0.89 , we averaged them to obtain one single measurement in the analysis.

Two items of feedback on the parent product were adapted from a scalle developed by Jun, Mazumdar, and Raj (1999). Item 1 examined the change in consumers' attitudes toward the parent product due to the introduction of 
extension products. Item 2 tested how extensions would affect consumers' purchase intention of the parent product (Aaker and Keller 1990; van Riel, Lemmink, and Ouwersloot 2001). We averaged both items into one single measure, based on an acceptable value of Cronbach's alpha (0.66).

The measurement for similarity consists of three items. Item 1 dealt with the general similarity between the parent product and extensions (Keller and Aaker 1992). Item 2 investigated whether respondents perceived extensions as "lagical" or "consistent" derivatives of the parent product (Keller and Aaker 1992; Tauber 1988). The third item investigated whether respondents associated extensions with the parent product (Park, Jun, and Schocker 1996). With a fair Cronbach's alpha (0.89), we averaged these three items to obtain a single measurement for similarity in the analysis.

Service intensiveness was measured by two items. Item 1 was asking respondents whether they perceived extensions as more service intensive than the parent product, and the other item asked about the perceived importance of the service component in the extension compared with that in the parent product. We averaged these two items into a single measurement (Cronbach's alpha $=$ 0.91).

A single measurement was used to ask respondents' familiarity with the extensions and the parent product respectively. Measurement items and reliability are presented in Appendix A.

\subsection{Results}

\subsubsection{Measurement}

Before testing the hypothesized effects, we verified that respondents perceived the manipulated service intensiveness and simillarity as intended (Broniarczyk and Alba 1994). We performed manipulation checks with respect to stimuli's familiarity, service intensiveness, and similarity.

Familiarity with the product categories. The mean ratings of participants' familiarity with the product categories used in this experiment are presented in Table 2.3. The results revealed that participants were familiar with the parent product category $(M=5.04, p<0.01)$ and extension products ( $M$ Extension $1=4.93$, $p<0.01 ; M_{\text {Extension } 2}=5.23, p<0.01 ; M_{\text {Extension } 3}=4.30, p=0.053 ; M_{\text {Extension } 4}=$ 
$438, p<0,05$ ) (all the tests were against the mean value of 4 ). Therefore, a possible confounding effect due to the lack of understanding was avolded.

Service intensiveness and similarity. The cell means for service intensiveness and similarity are shown in Table 2.3. Consistent with findings in the pretests, there is a significant difference between more service-intensive and less service-intensive extensions $(F(1,238)=267.9, p<0,01)$ and between high-similarity and low-similarity extensions $(F(1,238)=157.0, p<0.01)$. Meanwhile, a post hoc test (Bonferroni) shows that Extension 1 and 3 (similar extensions) were both significantly $(p<0.001)$ different from Extension 2 and 4 (dissimilar extensions) in terms of similarity, and no significant differences were found between Extension 1 and 3 and between Extension 2 and 4 . As for service intensiveness, the test results show that Extension 1 and 2 (less serviceintensive extensions) were both significantly ( $p<0.001)$ different from Extension 3 and 4 (more service-intensive extensions), and no significant differences were found between Extension 1 and 2 and between Extension 3 and 4 . Therefore, the manipulation for similarity and service intensiveness was successful. In addition, we ran a correlation test between the two variables, service intensiveness and similarity, to check whether consumers' perception of one variable influences the other. We found that the coefficient is very low $(r<0.03)$. Hence, respondents' perception of similarity has not been affected by the differences in service intensiveness between the parent product and extensions.

Tablle 2.3: Manipulation Check for Familiarity, Service Intensiveness, and Similarity

\begin{tabular}{|c|c|c|c|c|c|c|}
\hline \multirow[b]{2}{*}{ Treatment Conditions } & \multicolumn{3}{|c|}{ High Simílarity Extensions } & \multicolumn{3}{|c|}{ Low Similarity Extensions } \\
\hline & Extension 1 & Mean & SD & Extension 2 & Mean & SD \\
\hline \multirow{4}{*}{$\begin{array}{l}\text { Less siervice } \\
\text { Intensive extensilons }\end{array}$} & Familiarity & 4.93 & 1.56 & Familiarity & 5.23 & 1. 13 \\
\hline & Service Intensiveness & 3.00 & 1.12 & Service Intensiveness & 2.72 & 1.10 \\
\hline & Similarity & 4.94 & 0.75 & Similarity & 3.13 & 1.20 \\
\hline & Extension 3 & Mean & SD & Extension 4 & Mean & SD \\
\hline \multirow{3}{*}{$\begin{array}{l}\text { More servic } \\
\text { intensilve extensions }\end{array}$} & Famillarity & 4.30 & 1.42 & Familliarity & 4.38 & 1.46 \\
\hline & Service Intensiveness & 5.03 & 1.10 & Service Intensiveness & 5.28 & 1.00 \\
\hline & Similarity & 4.66 & 0.68 & Similarity & 3.49 & 0.93 \\
\hline Parent product & Familiarity & 5.04 & $1 . \overline{62}$ & & & \\
\hline
\end{tabular}

\subsubsection{Experiment Findings}

Hypothesis 1 postulated that consumers would have more favourable extension evaluations for a less service-intensive extension compared to a more 
service-intensive extension. Hypothesis 1 was tested on the basis of the analysis of quality evaluations of extension products. ANOVA analysis of the quality perceptions of extensions revealed a significant main effect of service intensiveness, $F(1,236)=290.28, p<0.01$. The means show that consumers evaluate less service-intensive extensions (L) more favourably than more service-intensive extensions $(M)(L=5.38$ and $M=3.39)$. Hence, Hypothesis 1 is confirmed (results presented in Table 2.4, Part 1 ).

Hypothesis 2 investigated the main effect of perceived similarity on consumer evaluations of extension products, whereas Hypothesis 3 was concerned about the moderating effect of percelved similarity. As predicted, high-similarity extensions $(H)$ are evaluated more favourably than low-similarity extensions $(L)(H=4.49$ and $L=4.28), F(1,2.82)=3.46, p=0.064)$. However, Hypothesis 2 is only marginally supported at a $10 \%$ significance level. Furthermore, there is a significant interaction effect between perceived similarity and service intensiveness, $F(1,6.02)=7.40, p<.01$ ). Also, Table 2.5 (simple main effect) indicates that the impact of similarity on the service intensiveness effect is larger when similarity is high $(H)$ than when it is low $(L)(H=2.30$ and $L$ $=1.67$ ). Hence, Hypothesis 3 is also accepted.

Hypothesis 4 stated that consumers would attach more favourable evaluations to the parent product after being exposed to a more service-intensive extension compared to a less service-intensive extension. ANOVA results are reported in Table 2.4, where Part 2 shows that the impact of service intensiveness on the subsequent evaluations of the parent product is significant, $F(1,7.35)=6.48, p<0.05$. However, surprisingly, the effect pattern was reversed compared to what we hypothesized. Consumers" attitudes toward the parent product proved to be better after exposure to a less service-intensive extension (L) compared with a more service-intensive extension (M) $(L=4.40$ and $M=4.05$ ). We will discuss this finding further in the Discussion section.

For Hypothesis 5, we also found a significant interaction effect between similarity and the reciprocal effect, $F(1,5.10)=4.50, p<0.05$. It shows that the perceived similarity moderates consumers' post-evaluations of the parent brand due to extensions' relative service intensiveness. In addition, Table 2.6 (simple main effect) indicates that consumers' attitude change due to extensions ${ }^{\prime}$ different service intensiveness levels relative to its parent product is greater 
when it is in the high-similarity condition $(H)$ than in the low-similarity condition (L) $(H=0.64$ and $L=0.04)$.

Table 2.4: ANOVA Results for the Experiment Factors

\begin{tabular}{|c|c|c|c|c|c|}
\hline Source & Mean (SD) & df & Mean Square & $F$ & p \\
\hline \multicolumn{6}{|l|}{ Part 1. Extension Evaluations } \\
\hline A. Service Intensiveness & & 1 & 236.02 & 290.28 & 0.00 \\
\hline More service intensive extensions & $3.39(1.02)$ & & & & \\
\hline Less service interisive extenslons. & $5.38(0.81)$ & & & & \\
\hline B. Similarity & & 1 & 2.82 & 3.46 & 0.064 \\
\hline High similarity extensions & $4.49(1.46)$ & & & & \\
\hline Low similarity extensions & $4.28(1.23)$ & & & & \\
\hline$A^{*} B$ & & 1 & 6.02 & 7.40 & 0.007 \\
\hline \multicolumn{6}{|l|}{ Part 2. Parent Brand Evaluations } \\
\hline A. Service Intensiveness & & 1 & 7.35 & 6.48 & 0.012 \\
\hline More service intensive extensions & $4.05(1.05)$ & & & & \\
\hline Less service intensive extensions & $4.40(1.10)$ & & & & \\
\hline B. Similarity & & 1 & 2.82 & 2.48 & 0.116 \\
\hline High similarity extensions & $4.34(1.09)$ & & & & \\
\hline Low simillarity extensions & $4.12(1.08)$ & & & & \\
\hline$A^{*} B$ & & 1 & 5.10 & 4.50 & 0.035 \\
\hline
\end{tabular}

Table 2.5: The Mean of Quality Evaluations in Four Extensions

\begin{tabular}{|l|l|l|}
\hline & \multicolumn{2}{|c|}{ Similarity } \\
\hline & High & Low \\
\hline Treatment Conditions & Mean (SD) & Mean (SD) \\
\hline $\begin{array}{l}\text { Service Intensiveness } \\
\text { Less }\end{array}$ & $5.64(0.79)$ & $5.11(0.74)$ \\
More & $3.34(0.99)$ & $3.44(1.04)$ \\
\hline Mean Difference & 2.30 & -1.67 \\
\hline
\end{tabular}

Table 2.6: The Mean of Quality Evaluations for the Parent Product

\begin{tabular}{|l|l|l|}
\hline & \multicolumn{2}{|c|}{ Similarity } \\
\hline & High & Low \\
\hline Treatment Conditions & Mean (SD) & Mean (SD) \\
\hline Service Intensiveness & & \\
Less & $4.66(0.79)$ & $4.15(0.74)$ \\
More & $4.02(0.99)$ & $4.19(1.04)$ \\
\hline Mean Difference & 0.64 & -0.04 \\
\hline
\end{tabular}




\subsection{Discussion}

\subsubsection{Service Intensiveness Effect}

The service intensiveness of a parent product can induce more favourable evaluations of an extension when the extension is less service intensive than the parent product. Hence, when a clear distance in service intensiveness between an extension and the parent product exists, a parent product with relatively strong service intensiveness would be beneficial in contributing to the success of extensions. In this case, companies are recommended to emphasize the parent product's strong service intensiveness when communicating with potential customers. In contrast, when an extension is more service intensive than the parent product, a firm's capabilities of introducing a reliable product with consistent quality is doubted. This finding suggests that the use of the parent brand name might not be an optimal choice in this case.

Many industries have become increasingly service intensive. A very strong goods-intensive brand might become an obstacle in introducing successful brand extensions moving toward the service area. An examination of the communication strategies of several firms with strong goods intensiveness leads to the impression that they have been aware of this disadvantage. Some firms use advertisements to create and manifest more service-intensive associations for their brands. For example, Nokia does not focus on its strength in the production of mobile telephones in their communications to customers but emphasizes its ability to provide services to "connect people," such as the development of network solutions ( $w w w$. nokia.com). Hewlett Packard represents itself as a "leader in computing and imaging solutions and services" (www. hp.com). These strategies can be interpreted as aiming to attach more serviceintensive associations to the intrinsically goods-intensive parent brand. This reorientation has the implicit consequence that extensions toward the service direction can be more easily introduced.

\subsubsection{The Main and Moderating Effects of Perceived Similarity}

Consistent with previous findings, this study shows a positive main effect of perceived similarity on consumer evaluations of an extension (e.g., Aaker and Keller 1990). In other words, the fit of an extension automatically leads to more favourable extension evaluations. Moreover, this study also found that perceived 
similarity influences the extension evaluations indirectly by moderating the size of the service intensiveriess effect. Specifically, the opposite impacts of service intensiveness in the more-service intensive and less service-intensive extension scenarios are reinforced by the degree of similarity. Therefore, brand managers should emphasize the connection between an extension and the parent product in case of a less service intensive extension and dilute this linkage in a more service-intensive extension condition. For instance, the distance technique suggested by Kim, Lavack, and Smith (2001) could increase the perceived distance between an extension and the parent brand by the way their brand names are linguistically or graphically represented.

\subsubsection{Reciprocal Effects of Service Intensiveness}

We found that extensions' service intensiveness relative to their parent product had a significant impact on the post-evaluations of the parent product. However, unexpectedly, the impact pattern is reversed compared to what we hypothesized. Hypothesis 4 is based on the expectation that consumers would perceive a less service-intensive extension as a dilution of the firm's competence to produce complex products, in contrast to considering a more service-intensive extension as an accomplishment in this respect. An explanation of the rejection of Hypothesis 4 could be that consumers would perceive a less service intensive extension as a less complex and simpler product compared with the parent product, but not necessarily a lawer quality product that would lead to a lower evaluation (Bottomley and Holden 2001). Hence, it might not lead to a "dilution" Impression. Furthermore, the feeling of "accomplishment" or "dilution" hypotheslzed in Hypothesis 4 is strongly based on consumers' direct experience with the extension after it is actually launched in the market (Barwise 1993), which is not reachable by our research setting.

An additional finding is the observation of a relative small impact size of the reciprocal effect on the parent product. This is in line with Aaker's (1996) discussion that the averall brand perceptions can only be changed substantially after a long period of time and elaborate communication support.

\subsection{Limitations and Future Research}

There are several limitations of our research. First, given the experimental nature of our study, we could not examine the possible influence of extensions' 
actual performance on consumers' post-evaluations of the parent product. Future studies can use reall brand names and products to investigate the reciprocal effect. Next, the selected parent product is perceived by respondents as "moderate" in terms of service intensiveness level. It is also interesting to see whether the parent product's initial service intensiveness level would influence the findings in this study.

In addition, on the basis of previous literature, we assume that consumers will have a greater risk perception toward a more service-intensive extension than a less service-intensive extension. However, various consumers might react to risk differently depending on their personal traits. As it is beyond our research scope to test this latter effect in this study, it could be a good future research direction. By the same token, it is also valuable to test the second-order effect of the perception of "accomplishment" or "dilution" on extension evaluations among various consumers.

Finally, we took one product category for our parent brand. A study by Dacin and Smith (1994) has revealed the effect of brand portfolio characteristics on consumers' extension evaluations. Therefore, for future research, it might be valuable to investigate the service intensiveness effect in a brand portfolio scenario. 


\section{Chapter 3: Consumer Evaluations of Vertical SERvice Line EXTENSIONS}

Vertical service line extensions extend an established brand name to services at different quality/price levels. In this study, we examine the impact of a primary vertical line extension variable, the direction of extensions, on consumer responses to new extensions. Findings of an empirical study in the hotel industry indicate that consumers perceive higher risks in step-up extensions than in step-down extensions, which leads to lower consumer evaluations, perceived value, and purchase intensions in step-up than in stepdown extensions. Furthermore, the results also suggest that the effect of extension direction interacts with service guarantees and consumers' prior knowledge on consumer responses to vertical service line extensions. 
"Vertical extensions are sometimes a strategic imperative, but they can be dangerous. Tread carefully."

(Aaker 1997, p. 135)

\subsection{Introduction}

For many firms launching a new product ${ }^{3}$ is a risky endeavour because of high introduction costs and low success rates (e.g., Lee et al. 1996). One way of dealing with these risks is to leverage the existing brand equity for enhancing credibility and unobserved quality (Aaker 1991). The use of existing brand names involves mainly two strategies: brand and line extensions (e.g., Aaker and Keller 1990; Desai and Hoyer 1993). Brand extensions extend an original brand name into a completely different product category (e.g., Ivory Shampoo), whereas line extensions use the same or a similar brand name to launch new variants in the same product category (e.g., Cola-light). Though much research has focused on brand extensions (Aaker and Keller 1990; Broniarczyk and Alba 1994; Park, Miberg, and Lawson 1991), line extensions are much more popular in the marketplace. Aaker (1991) reported that $89 \%$ of new product introductions are line extensions and only $6 \%$ are brand extensions. Despite their prevalence in the marketplace, research on line extensions is very limited.

Among existing studies on line extensions, the focus has been virtually exclusively on extensions of tangible goods. Also, much of previous research on line extensions mainly studied horizontal line extensions when the original brand is extended by modifying features such as flavours or varieties (e.g. Diet Pepsi or Liquid Tide) (Lee et al. 1996). Not much is known about vertical service line extensions that introduce new offerings at different price/quality points. Yet, vertical service line extensions have been widely used in industries such as hotels and financial services. For instance, Marriott extended its hotel chains to "Courtyard Inn by Marriott" (step-down extension) for economic travelers; and American Express introduced "American Express Platinum" (step-up extension) to give important customers exclusive privilege. Although a service line extension can obtain introductory market share, gain efficiency in market commuinication, and strengthen brand equity through its penetration into different market segments (Kirmani, Sood, and Bridges 1999), such a strategy does not

\footnotetext{
"Product" is used in this study to indicate general consumption objects, incluiding both tangible goods and services.
} 
necessarly guarantee success. 27 percent of all line extensions fail, and even if they survive some of them do not generate extra profits (Nijssen 1999) Aaker and Keller (1990) indicate that the success of an extension predominately depends on consumers positive attitude toward the extension. This leads to the question on how consumers respond to vertical service line extensions and what factors influence their evaluations, and thus to the purpose of this research.

First, we examine the impact of a primary extension variable, the direction of extensions, on consumer responses to vertical service line extensions. Previous studies suggest that "fit" (between extensions and the parent product category) is a key influential factor in extension evaluations, as it captures the variation from the extension to the parent brand (e.g., Aaker and Keller 1990). In vertical line extensions where extensions are in the same category as the parent brand, the extension direction explains the changes of extensions compared to the parent brand.

Second, previous research has largely ignored the role of perceived risk in extension evaluations. Extensions are introduced to reduce the perceived risk associated with new products (Delvecchio and Smith 2005), as perceived risk produces uncertainties about product performance and therefore negative evaluations, especially in a service setting (Mitchell and Greatorex 1993). Thus, ignorance of the effect of perceived risk limits our understanding of consumer responses to service extensions. In this study, we examine the effects of two main types of risk, performance and financial risk.

Third, as perceived risk causes anxiety, consumers are said to depend on extrinsic cues such as service guarantees (e.g., Ostrom and lacobucci 1998) or their prior knowledge about the category (e.g., Allen and Bulter 1993) to increase confidence by predicting product performance. Specifically, service guarantees are considered a significant risk reliever (Ostrom and lacobucci 1998) and consumers with more prior knowledge are expected to have less risk perceptions (Allen and Bulter 1993). However, the extent to which these factors allaying risk depends on the level and type of risks perceived in different extension scenarios. Thus, we expect extension direction to interact with service guarantees and prior knowledge to affect consumers' risk perception toward extensions.

Fourth, perceived value is considered essential to purchase intentions as it "bundles" both benefits and sacrifices of an offering (e.g., Zeithaml 1988). 
Consumers are "value driven" (Sweeney, Soutar, and Johnson 1999), and extension evaluations do not provide sufficient "consumer voices" to guide managerial actions (Woodruff 1997). However, almost all previous studies only measured extension evaluations to reflect consumer reactions to extensions. Therefore, we measure both extension evaluations and perceived value to predict consumers' purchase intentions of extensions.

This study attempts to close the gap between the popularity of vertical service line extensions in practice and a lack of theoretical development. We investigate consumer responses to vertical service line extensions in the hotel industry and discuss the theoretical and managerial implications of our findings. Furthermore, different from many previous studies on extensions, we use regular consumers rather than students in the experiment to gain external validity.

\subsection{Development of a Conceptual Framework}

Our conceptual framework is summarized in Figure 3.1. We first introduce the extension direction factor and its impact on perceived risks. Second, we examine the interaction effects of extension direction with prior knowledge and service guarantees on perceived risks. Third, we discuss the impact of performance risk and financial risk on consumers' extension evaluations and perceived value. Fourth, we investigate the effect of extension evaluations and perceived value on consumers' behavior intention.

Figure 3.1: Conceptual Framework

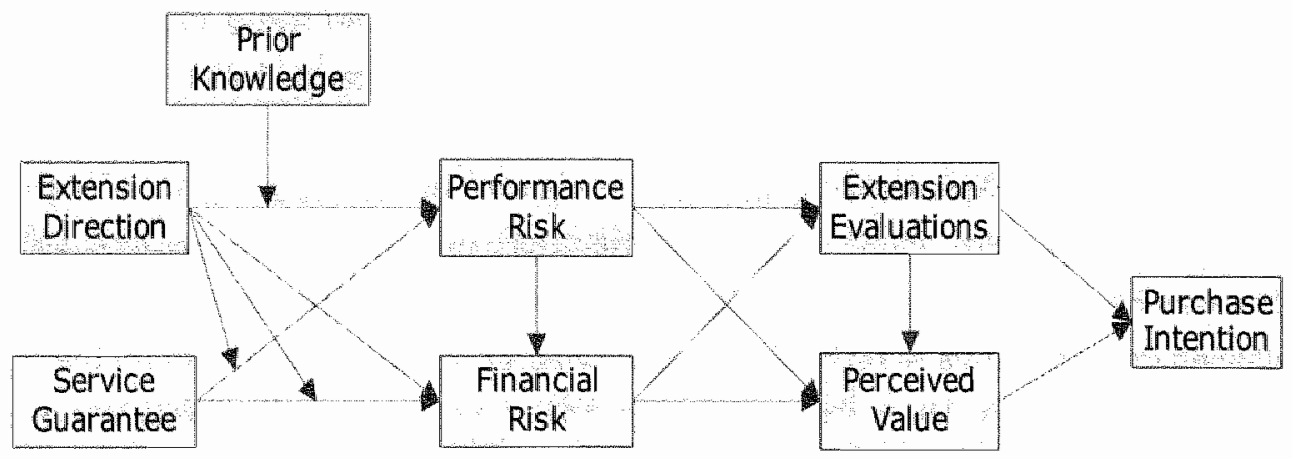




\subsubsection{Vertical Service Line Extensions}

Vertical line extensions extend the original or a similar brand name to different variants in the same product category, but usually at different price/quality points (Kirmani et al. 1999). The main attribute to categorize vertical ine extensions is the extension direction that can be either step-down or step-up from the core brand (Kim, Lavack, and Smith 2001; Randall, Ulrich, and Reibstein 1998). Note that step-down/up extensions do not infer "inferior" or "superior" quality compared to services in the same segment, but services with fewer/more features, amenities, and lower/higher level of service sophistication and complication compared to the original brand.

As Aaker (1997) indicated, vertical line extensilons have become an attractive strategy for companies to move into booming premium or value market segments. He also stated that, in some instances, "a vertical move is not merely justified but is actually essential to survive" (p.135). One primary advantage of vertical line extensions is to leverage the brand equity built up among its current customers to enter different market segments (Aaker 1996; 1997). An example of step-down extensions is "TUI", the largest European travel agency, that introduced "1-2-fly by TUI", to target economic travelers. Also, Internet provider "@Home" introduced "@Home Budge" and "Hilton" hotel chain introduced "Hilton Garden Inn" as step-down extensions for the lower-end customers. A rational for stepping down is to attract customers who can not afford the brand's current offerings in the hope that these customers eventually will trade up to the brand's more expensive offerings (Kirmanil et al. 1999). Consequently, the brand's equity will be enhanced by its penetration into multiple markets and increased revenue and market share. Similarly, stepping-up may reinforce or rejuvenate a brand's image for potential or current customers who are looking for more features/services, greater prestige, or higher quality (Kirman et al. 1999). The American Express Platinum card is an example of a step-up extension of American Express Credit Card. Another example is the Deutsche Bahn that came up with "Metropolitan", a luxury train with on-place service to serve the upscale market segment.

\subsubsection{Perceived Risks in Service Evaluations}

Consumer research defines perceived risk as a two-dimensional construct comprising uncertainties and consequences (e.g., Bettman 1973). Percelved risk 
Increases with higher level of uncertainties and/or the chance of greater associated negative consequences (Campbell and Goodstein 2001). Due to service's special characteristics, consumers perceive higher risks with the purchase of services than goods (Zeithaml and Bitner 1996). Specifically, intangibility makes services difficult to evaluate before and even after the purchase; heterogeneity increases consumers' uncertainties about the quality of service that they are offered; perishability may cause under-staffing or overdemand, increasing the uncertainty about the service delivery process; and inseparability increases consumers' involvement in a purchase decision, which Increases the degree of perceived risk (Mitchell and Greatorex 1993). Hence, consumers' risk perceptions are considered to be central to consumer evaluations (Dowling 1999), especially for newly introduced services in the marketplace.

In the current marketing literature, perceived risk has been operationalized by several specific risk dimensions, including performance, financial, physical, social, and psychological risk (Kaplan, Szybillo, and Jacoby 1974). The first three dimensions have been termed expected performance or non-personal risk and the latter two dimensions psychosocial or personal risk (Sweeney et al. 1999). In this study, we only consider financial risk and performance risk for two reasons. First, the relative importance of different risks varies in different consumer behaviours (Campbell and Goodstein 2001), and financial and performance risk are commonly associated with purchase decisions (Delvecchio and Smith 2005). Also, a number of studies have documented the influence of performance and financial risk on product acceptance, which provides empirical support for limiting the focus to these types of risk (Agarwal and Teas 2001; Bearden and Shimp 1982; Shimp and Bearden 1982; Sweeney, et al. 1999). Performance risk is defined as losses associated with the purchase if a product fails to meet the performance expectations, and financial risk refers to economic outlays that may occur if a product does not perform adequately (Horton 1976).

\subsubsection{Perceived Risks in Vertical Service Line Extensions}

Given service's special characteristics, the information about service quality is normally unknown to consumers prior to purchase (Kirmani and Rao 2000), which makes the purchase of new services even riskier (Guseman 1981; Murray and Schlacter 1990). According to signalling theory, consumers often rely 
on extrinsic cues or signals to overcome this information asymmetry between the service provider and the buyer (Boulding and Kimanl 1993; Rao and Ruekent 1994). Quality signals can be conveyed in various forms, and brand name is one of the most commonly used cues by consumers (e.g.; Agarwal and Teas 2001; Bearden and Shimp 1982; Mitchell and Greatorex 1999; Shmp and Bearden 1982). In the context of brand or line extensions, the parent brand name is served as such a signal for consumers to reduce their perceived performance and financial risk associated with the purchase of a new product.

However, the efficiency of such a signal transmitting quality information depends on the firm's previous investments in a certain market position (quality level) and consumers' previous experience (Dawar 1998). Hence, when a service provider promotes itself as a certain price/quality level company in the marker, its brand name will be associated with the corresponding image. These associations serve as a bond for future uses of this brand signal and consumers would infer the service quality of future offerings based on these associations (Dawar 1998; Wernerfelt 1988).

Performance risk increases with the uncertainty of whether a product will perform satisfactoriliy and the severity of performance-related losses if it fails to meet expectations (Bearden and Shimp 1982). Such losses include the potential reduced utility and physical or emotional harm resulting from substandard performance (DelVecchio and Smith 2005). Due to the diversity of customer dermands and customer involvement in the service delivery process, services with high level of sophistication require companies to obtain high competence and service handling capabillties (Larsson and Bowen 1989; Lovelock 1991; Sjoholt 1999). Meanwhile, such services also require employees to be more flexible and adaptable in performing service activities and solving problems interactively (De Bandt 1999; Ottewill et al. 2000). Therefore, when a step-up extension is introduced, based on their associations with the parent brand image, consumers may question whether a formerly mainstream brand will have the knowledge and capabllities to deliver the functional and emotional benefits expected in an upscale market (Aaker 1996; 1997). This increases the perceived performance risk, regardless of the firm's actual possession of the required competencies for extensions. In contrast, when a step-down extensilon is introduced, the parent brand associations can enhance consumers' confidence about the company's 
caipabillty to meet their service expectations, which in turn reduices performance risk. Therefore, we hypothesize that:

H1a: Consumers will have higher performance risk in step-up extensions than in step-down extensions (referred to as the effect of extension direction on performance risk).

Financial risk is positively related to the uncertainty of economic-related losses a product does not perform as expected (Agarwal and Teas 2001). Compared to step-down extensions, step-up extensions are usually positioned at a higher-price range (Kirmani et al. 1999). Since higher prices imply higher monetary sacrifices physically and emotionally. Such sacrifices increase the patential loss if a product does not perform as intended, and therefore the perceived financial risk (Shimp and Bearden 1982). Therefore, step-up extensions are expected to generate a higher financial risk perception than stepdown extensions.

H1b: Consumers will have higher financial risk in step-up extensions than in step-down extensions (referred to as the effect of extension direction on financial risk).

Furthermore, Peter and Tarpey (1975) suggest that performance risk and financial risk are likely to be related. Agarwal and Teas (2001) also indicate that higher risk of performance-related loss of a product can lead to higher anticipated monetary cost for product modification or replacement. Therefore, we argue that performance risk is positively related to financial risk.

H1c: Performance risk is positively related to financial risk.

\subsubsection{The Moderating Effect of Prior Knowledge on Performance Risk}

Consumers' risk perception is often influenced by individual-level factors such as consumers" prior knowledge about the product category. In this study, we expect prior knowledge to moderate the effect of extension direction on pelformance risk.

There has been a substantial amount of research on the role of prior knowledge or familiarity on various stages of consumer behaviour (e.g., Bettman and Park 1980; Rao and Monroe 1988; Sujan 1985). These studies conclude that prior knowledge facilitates the acquisition of new information as well as the use of existing information. Rao and Monroe (1988) state that consumers with different levels of prior knowledge have differentially developed "schema" about 
the attributes of a product, and thus will use different information in product evaluations. Also, consumers' knowledge of a product category increases the complexity of their cognitive structure, analytical capabilities, and ability to make elaborate inferences. Therefore, low-knowledgeable consumers (referred to as novices) (vs. high-knowledgeable consumers, referred to as experts) are more likely to use extrinsic cues (e.g., package, color) and less elaborate processes to evaluate a product. However, because of their more developed knowledge structure, experts are capable of using both extrinsic and intrinsic cues (e.g., service features), and their use of intrinsic cues will depend on the informative ability (i.e. diagnosticity) of the extrinsic information (Rao and Monroe 1988).

On the basis of these conclusions, Muthukrishnan and Weitz (1991) investigated the impact of prior knowledge on consume responses to brand extensions. They found that novices tend to relate the parent birand with the extension on the basis of extrinsic surface cues, such shape, color, and the perception of these two products in similar product categories. These factors usually do not directly relate to product performance. However, experts evaluate extensions based on deeper intrinsic cues. These cues are factors that account for performance in the original product and may also be related to performance in extensions. At the attribute level, these may include similarity in terms of technology, design, and competences required in the manufacturing and delivery process. They also concluded that, when the extension is similar to the parent brand on surface cues, novices (vs. experts) are more likely to rely on such a cue when evaluate extensions.

Research on extension evaluations suggests that the perceived simillarity between extensions and the parent brand has a positive influence on the perceived quality of extensions (Aaker and Keller 1990). In vertical line extensions, extensions are in the same category as the parent brand. Therefore, novices (vs. experts) are more likely to base their evaluations on this surface factor of service category similarity and perceive less performance risk for both step-up and step-down extensions. As a result, the difference of performance risk between the step-up and step-down extension condition is decreased when consumers are novices. However, experts may not perceive such a similarity diagnostic and hence may not use it as a positive signal to infer the quality of extensions. (MuthuKrishnam and Weitz 1991). In contrast, experts (vs. novices) are more likely to infer the quality of extensions based on elaborate inferences 
and analytical processes by looking into deeper cues such as service features, level of service complexity, and competence requirements for extensions. As we argued in hypothesis 1 , these processes make consumers question the firm's ability to deliver the expected service level when a step-up extension is introduced: Meanwhile, experts" capability of using deeper intrinsic cules to conduct elaborate inferences increases their confidence about the service quality of step-down extensions. Therefore, the difference of performance risk between the step-up and step-down extension condition is increased when consumers are experts. Hence, the different impact of step-up and step-down extensions on performance risk is strengthened when consumers are experts than when they are novices. We hypothesize that:

12: The impact of extension direction on performance risk will be stronger when consumers have higher prior knowledge.

\subsubsection{The Effects of Service Guarantees on Risk Perception in Different Extension Situations}

The difficulty in evaluating services due to the existence of credence quality prompts consumers to rely more on tangible and quality-consistent elements when evaluating the quality of services (De Chernatony and Dall'Olmo Riley 1999; Zeithaml and Bitner 1996). In addition to the quality signal of brand name, service guarantees are considered a tangible manifestation of the reliability of services - a quality dimension that is particularly important to consumers (Ostrom and Iacobucci 1998; Zeithaml, Parasuraman, and Berry 1990): Indeed, previous literature suggests that the use of service guarantees has become an important strategy for firms to reduce perceived risks in the purchase of services (Shimp and Bearden 1982; Tucci and Talaga 1997). However, the ability of service guarantees to reduce risk is affected by the extent to which risk is present (Ostrom and Iacobucci 1998). Given the previous arguments that there are different levels of performance and financial risk in step-down and step-up extensions, we expect the direction of line extensions, in addition to its main effect, to moderate the impact of service guarantees on consumers" risk concerns.

Research on guarantees suggests that guarantees only affect consumers" attitude indirectly through risk perception (e.g., Bearden and Shimp 1982; Boshoff 2002; Ostrom and lacobucci 1998). A service guarantee reduces 
performance risk by serving as a positive quality signal, as consumers feel it would be too costly for a firm to offer guarantees to low-quality products (Boulding and Kirmani 1993). A service guarantee also mitigates financial risk by offering substantial compensation (usually monetary) to minimize adverse consequences if the service fails (Wirtz, Kum; and Lee 2000). However, Ostron and Iacobucci (1998) suggest that a service guarantee has a less slignificant effect on risk perception when 1 ) other more direct positive signals are present (e.g., brand name, consumer report); 2 ) consumers do not perceive considerable risk in a purchase situation.

As we discussed earlier, consumers use the parent brand name as a quality signal to infer extension quality. Innis and Unnava (1991) found that when consumers already use an established brand name as a cue to quality, warranty information becomes a less influential risk-reducer (Innis and Unnava 1991). Since the parent brand name is used by consumers as a positive quality signal for step-down extensions but a negative signal for step-up extensions, we expect a more significant impact of service guarantees on performance risk in step-up extensions than in step-down extensions. Similarly, as consumers perceive more financial risk in step-up extensions than in step-down extensions, we expect a more significant impact of service guarantees on financial risk in step-up extensions than in step-down extensions. Furthermore, when consumers perceive little risk in a purchase situation, the presence of a service guarantee may even be interpreted as a signal for potential problems during the service delivery process (Wirtz 1998). This also weakens the impact of service guarantees on both performance and financial risk in the step-down extension condition (vs: step-up extension condition). Therefore, we hypothesize that:

H3a: The impact of service guarantees on performance risk will be stronger in step-up extensions than in step-down extensions.

H3b: The impact of service guarantees on financial risk will be stronger in stepup extensions than in step-down extensions.

\subsubsection{Perceived Risk, Extension Evaluation, Perceived Value, and Purchase Intention}

Consumers ${ }^{*}$ risk perception is considered to be central to their evaluations, choices, and behaviours (Dowling 1999). Mitchell and Greatorex (1993) also conclude that perceived risk is an even more useful construct in explaining 
consumer behaviour for the purchase of services than the purchase of goods: Both performance risk and financial risk cause anxiety and lead to negative evaluations of a product (Campbell and Goodstein 2001). Therefore, we hypothesize that:

H4a: Performance risk has a negative influence on evaluations of both step-up and step-down extensions.

H4b: Financial risk has a negative influence on evaluations of both step-up and step-down extensions.

Peter and Tarpey (1975) Identified three broad consumer decision-making frameworks. The first describes consumers motivation in reducing perceived risks by minimizing uncertainties and negative consequences of a purchase. The second describes consumers' orientation for positive evaluations before a purchase. The third assumes that consumers value the net valence of a purchase by comparing positive attributes with negative ones. This "met valence" was first Identified as the perceived value construct defined in Zeithaml's (1988) study. Zeithaml explored four diverse meanings of value: (1) value is low price; (2) value is whatever one wants in a product; (3) value is the quality one gets for the price one pays; and (4) value is one gets for what one gives. She concluded that these four consumer expressions of vallue can be captured in one overall definition: "perceived value is consumers" assessment of the utility of a product based on perceptions of what is received and what is given" (Zeithaml 1988). Speciflcally, perceived value is a trade-off between the expenses and sacrifices that consumers need to bear and the expected returns that they are supposed to get. The expected returns of a purchase can be influenced by a product's intrinsic and extrinsic attributes, perceived quality, and other high level of abstractions such as convenience, service, and appreciation. The sacrifices that consumers need to bear consist of not only monetary expenses but also any other type of sacrifices such as time, energy, and effort.

Performance risk and financial risk are potential sacrifices for consumers (Sweeney et al. 1999). This is because performance risk reminds consumers of the possible negative performance-related consequences and financial risk indicates the potential costs contingent upon the failure of the product to meet expectations. The higher the perceived risk, the more consumers "must gamble 
in buying" the service, and the lower the perceived value (Sweeney et al. 1999; p78). Therefore we hypothesize that:

H5a: Performance risk has a negative influence on perceived value for both stepup and step-down extensions.

H5b: Financial risk has a negative influence on perceived value for both step-up and step-down extensions.

Consumers evaluation of a product is based on attributes such as serviceability, features, performance, as well as affect that is not reflected in measurable attributes (Aaker and Keller 1990). Therefore, consumer evaluations summarize the overall quality, performance, and benefits that consumers expect to receive from a product. Thus, we propose that consumer evaluations of a line extension are positively related to the perceived value of the product.

H6: Extension evaluations have a positive influence on perceived value for both step-up and step-down extensions.

Consumers' behaviour intention is considered the most important predictor of consumers' actual behaviour (Fishbein and Ajzen 1975) "Consumers" extension evaluations as well as perceived value can have a positive impact on consumers' purchase intentions of new service extensions (e.g., Laroche, Kim, and Zhou1996; Sweeney et al. 1999). Therefore we hypothesize that:

H7a: Extension evaluations have a positive influence on purchase intentions for both step-up and step-down extensions.

H7b: Perceived value has a positive influence on purchase intentions for both step-up and step-down extensions.

\subsection{An Empirical Study}

\subsubsection{Experiment Design}

A $2 * 2$ between-subjects factorial design involving two factors was employed to test the aforementioned hypotheses. The first factor, extension direction, was manipulated at two levels: the step-up direction and step-down direction. The second factor, service guarantees, was manipulated at two levels: the presence of a service guarantee and no mention of a service guarantee. The third explanatory factor, prior knowledge, was measured amang respondents 
(Pedhazur and Schmelkin 1991). We use partial least squares to assess the reliability and validity of our measures. Furthermore, we also use partial least squares to test our hypotheses because of the experimental nature of our study and a series of causal relationships in the research model.

\subsubsection{Stimulus Development}

We choose the hotel industry as the focal service category in this study for four reasons: 1) the prevalence of vertical line extensions in the hotel industry allows us to develop realistic hypothetical extension scenarios; 2) the use of service guarantees is a common and important strategy in the hotel industry: 3) we assume that most respondents have more direct experiences with hotel services compared to other services; 4) the hotel industry has been used in many previous service studies as research stimull (e.g., McDougall, Levesque, and Vanderplaat 1998; Ostrom and Iacobucci 1998; Wirtz et al. 2000).

To select the parent brand, a small focus group was conducted with Dutch consumers. A desired parent brand should be 1) perceived as a middle-class hotel to prevent floor and ceiling effects in the step-down/up extension scenarios, and 2) familiar to consumers. We presented three pre-selected middle-class hotels (Best Western, Van der Valk, and Holiday Inn) to ten respondents in the focus group and asked them to answer whether they knew the brand, whether they ever stayed at these hotels, and how they would position the brand (budget, middle class, or (uxury). Based on the focus group results, Holiday Inn was selected as the parent brand.

\subsubsection{Questionnaire Development}

The scenarios of step-up and step-down extensions were developed by conducting desk research and in-depth telephone interviews with brand managers from major players in the European hotel market (e.g., Radisson SAS). We used fictitious extensions by adding descriptors to the parent brand name (i.e. Holiday Inn Eco \& Holiday Inn Empire). Fictitious extensions can avoid confounding effects and the use of descriptors is considered a common and safe way to introduce step-up/down extensions (Aaker 1997; Keller and Aaker 1992). In each extension scenario, respondents were asked to "role-play" a travel situation in which they had to book a luxury or a budget hotel in ordier to prevent 
the influence of personal preferences for a certain hotel category on their responises.

In line with Ostrom and Iacobucc (1998), we used two levels of service guarantees to simplify the research design and make the effect more salient and detectable from a methodological standpoint ${ }^{4}$. The service guarantee was designed based on five properties that constitute a successful guarantee: unconditional, easy to understand and communicate, meaningful, easy to invoke, and quick and easy to colllect (e.g., Hart 1988). Service guarantee availability was manipulated by having the hotel either offer a guarantee or there was no mention of a guarantee.

\subsubsection{Pretest}

A pretest was conducted with the following objectives: 1) to assess whether different scenarios are successfully manipulated; 2) to assess measurement reliability and validity; 3) to test whether the fictitious extensions are realistic and meaningful for the objective of our study, 4) to assess whether the back-translated Dutch questionnaire (from English to Dutch and back to English) is easily understandable by common consumers. 60 respondents who are familiar with the Holiday Inn brand name participated in the pretest. The results of the pretest show that the perceived market position of the parent brand is significantly higher than that of the step-down extensions (4.2 v5. 2.9, $p<0.001$ ) and significantly lower than that of the step-up extensions (4.2 vs. 5.8, $p<0.001$ ). Furthermore, the preliminary analysis shows that the measurement scales in terms of Cronbach's alpha are reliable.

\subsubsection{Experiment Procedure and Sampling}

One hundred and sixty Dutch consumers were randomly assigned to one of the four experimental scenarios. Respondents were told that the purpose of the study was to learn about their preferences for hotels in certain choice situations. In each experimental scenario, respondents were presented with a description of the extension (step-up or step-down) and a travel situation in which they would

\footnotetext{
"Some studies on service guarantees employed three levels of service guarantees in their research: unconditional, specific, and no guarantee (e.g. Boshoff 2002), whereas others opt for two levels: the presence of guarantee and no mention of guarantees (e.g. Ostrom and lacobucci 1998). Furthermote, Shimp and Bearden (1982) found that high warranty quality led to less risk perceptions, but moderate warranty quality was not different from a poor or nonexistent warranty.
} 
like to choose a budget/luxury hotel. After carefully reading the scenario, respondents were then asked to fill out the questionnaire and they received a pocket radio as compensation. In the sample, 53.1\% of the respondents were male, $46.9 \%$ were female. With respect to age, $38.1 \%$ of the participants were younger than $25,16.3 \%$ were aged between 25 and $35,21.9 \%$ between 36 and $45,16.3 \%$ between 46 and 55 and $7.5 \%$ were older than 55 . Concerning after tax yearly income, $29.4 \%$ respondents have an income of less than 612,000 , $21.8 \%$ between $€ 12,001$ and $€ 24,000,15.7 \%$ between 624,001 and $€ 36,000$, $16.9 \%$ between $€ 36,001$ and $€ 48,000$ and $13.1 \%$ of more than $€ 48,000$. Five participants $(3.1 \%)$ preferred to keep this information to themselves.

\subsubsection{Measurement}

Two prior knowledge constructs have been commonly conceptualized: subjective and objective knowledge (Brucks 1985). Consumers' subjective knowledge was measured through two items measuring self-assessed knowledge (Flynn and Goldsmith 1999; Muthukrishnan and Weitz 1991). In previous studies, this measure of subjective knowledge was found to be highly correlated with objective knowledge (Muthukrishnan and Weitz 1991). Furthermore, subjective knowledge has been shown to be a stronger motivation of purchase-related behaviour than objective knowledge (Gronhaug 2002). Thus we focus on subjective knowledge in this study. Risk perception was measured by performance risks (four items) and financial risks (three items) based on the study of Ostrom and Iacobucci (1998). Consumer evaluations of extensions were measured by three items ranging from very unfavourable to very favourable, very negative to very positive, and very unattractive to very attractive (e.g.s Boshoff 2002; Dawar 2000; Milberg, Park, and McCarthy 1997). A three-item measulement for perceived value was adapted from the validated scalle developed by Sweeney \& Soutar (2001) and Petrick (2002). Purchase intention was measured by a four-item measurement based on existing scales (Bloemer, de Ruyter, and Wetzels 1999). Furthermore, previous research on brand extensions indicates that parent brand evaluations affect consumer reactions to extensions, especially when the extension category is similar to the parent brand category (e.g., Aaker and Keller 1990). Therefore, we use parent brand evaluations as a covariate. Appendix B contains all measures, their sources, composite reliabilities, and loadings. 


\subsubsection{Manipulation Checks}

The manipulations have the intended effect. Respiondents in each extension condition were asked to evaluate the market position of the parent brand and the extensions on two items (budget/luxury, functional/prestige, Cronbach's alpha $=0.943$ ) of 7 point scales. The market position of the parent brand is perceived to be significantly lower than that of extensions in the step-up conditions (Mean step-up with service guarantee $=6.18$, Mean step-up without service guarantee $=6.24$, Mean parent brand $=4.62 ; p<0.001$ for all comparisons), but it is perceived to be significantly higher than that of extensions in the step-down conditions (Mean stepdown with service guarantee $=2.73$, Mean step-down without service guarantee $=2.63 ; p<0.001$ for all comparisons). Respondents in the "with service guarantee" group were asked to evaluate whether the guarantee was sufficient on a 7 point scale. The results show that respondents consider the offered service guarantee to be sufficient and there is no significant difference between the two "with service guarantee" conditions (Mean step-up $=6.11$, Mean step-down $=5.82, p>0.10$ ). Respondents in the "without service guarantee" condition were asked to state whether they have read a service guarantee statement in the end of the questionnaire. All respondents confirmed that there was no mention of service guarantee in the questionnaire.

\subsubsection{Data Analysis}

The measurement properties were estimated using partial least squares (PLS), specifically PLS-GRAPH $\vee 3.00$. In contrast to ANOVA, the use of partial least squares is more appropriate for our research model as it allows us to examine the experimental design with multiple causal relationships. Also, our primary concern is the prediction of dependent endogenous variables (Chin 1998; Fornell and Bookstein 1982). Furthermore, PLS has a minimal demand on measurement scales, sample size, and residual distributions (Chin 1998).

We assessed convergent validity by examining the factor loadings of construct indicators and the results show that all factor loadings are higher than 0.50 (Hulland 1999). Construct reliability was evaluated by using composite scale reliability (Fornell and Larcker 1981 ). Composite reliability ranged from 0.84 to 0.93 and exceeded the suggested cut-off value of 0.7 (Nunnally and Bernstein 1994). Furthermore, all average variances extracted are above the recommended cut-off value of 0.50 (Fornell and Larcker 1981), ranging from 0.59 to 0.85 . We 
assessed discriminant validity by checking 1) whether the square root of the average variance extracted exceeded the correlations of the construct with other constructs; 2) whether each correlation was less than 1 by an amount greater than twice its respective standard error (Bagozzi and Warshaw 1990); 3) whether all items loaded highest on their associated construct and not on another construct (Blazevic 2005; White, Varadarajan, and Dacin 2003). All constructs showed discriminant validity. Table 3.1 shows composite reliabilities; average variances extracted, and the inter-correlations between constructs.

Table 3.1: Reliabilities and Correlations among Constructs

\begin{tabular}{|c|c|c|c|c|c|c|c|c|}
\hline & CR & AVE & PK & PR & $\mathbf{F R}$ & EV & PV & PI \\
\hline Prior Kriowledge (PK) & 0.92 & 0.85 & 0.92 & & & & & \\
\hline Performance Risk(PR) & 0.85 & 0.59 & -0.086 & 0.77 & & & & \\
\hline Financial Risk (FR) & 0.84 & 0.64 & -0.125 & 0.558 & 0.80 & & & \\
\hline Extension Evaluation (EV) & 0.89 & 0.73 & $=0.022$ & 0.474 & 0.363 & 0.86 & & \\
\hline Perceived Value (PV) & 0.93 & 0.81 & 0.051 & 0.557 & 0.506 & 0.476 & 0.90 & \\
\hline Purchase Intention (PI) & 0.92 & 0.75 & -0.068 & 0.628 & 0.592 & 0.554 & 0.681 & 0.87 \\
\hline
\end{tabular}

For the interaction analysis, we standardized the indicators of all constructs to lower the correlation between the interaction and the original indicators (Chin, Marcolin, and Newsted 2003). We then used the calculated products between each indicator of the predicator and the moderator as indicators for the interaction construct. Furthermore, we investigated the added varlance explained by the interaction term in the endogenous construct through a comparison between the partial model and the full model. We used the bootstrapping method to test the beta coefficients and the corresponding $t$ values.

\subsection{Results}

Partial Model with only direct effects. We first test the partial model in which only the direct effects of extension direction, prior knowledge, and service 
guarantee are included in the model. The results for the direct effect model are provided in table 3.2 , along with the $\mathrm{R}^{2}$ for each endogenous construct.

Table 3.2: Partial model with only direct effects: beta coefficients ( $t$-values)

\begin{tabular}{|c|c|c|c|c|c|}
\hline & $\begin{array}{c}\text { Performance } \\
\text { Risk } \\
\end{array}$ & $\begin{array}{c}\text { Financial } \\
\text { Risk }\end{array}$ & $\begin{array}{l}\text { Extension } \\
\text { Evaluation }\end{array}$ & $\begin{array}{c}\text { Perceived } \\
\text { value } \\
\end{array}$ & $\begin{array}{l}\text { Purchase } \\
\text { Intention }\end{array}$ \\
\hline $\begin{array}{l}\text { Extension } \\
\text { Direction }\end{array}$ & $\begin{array}{c}0.164 \\
(2.52)^{* *} \\
\end{array}$ & $\begin{array}{c}0.447 \\
(9.02)^{2 * 3} \\
\end{array}$ & & & \\
\hline $\begin{array}{c}\text { Prilor } \\
\text { Knowledge }\end{array}$ & $\begin{array}{c}0.175 \\
(2.18)^{*}\end{array}$ & $\begin{array}{l}0.044 \\
(0.63) \\
\end{array}$ & & & \\
\hline $\begin{array}{c}\text { Service } \\
\text { Guarantee }\end{array}$ & $\begin{array}{c}-0.167 \\
(2.56)^{*}\end{array}$ & $\begin{array}{l}-0.107 \\
(1.92)^{*}\end{array}$ & & & \\
\hline $\begin{array}{c}\text { Performance } \\
\text { Risk } \\
\end{array}$ & & $\begin{array}{c}0.490 \\
(7.09)^{* * * *} \\
\end{array}$ & $\begin{array}{c}-0.269 \\
(2.46)\end{array}$ & $\begin{array}{c}-0.230 \\
(2.43)^{*}\end{array}$ & \\
\hline $\begin{array}{c}\text { Financial } \\
\text { Risk }\end{array}$ & & & $\begin{array}{c}-0.177 \\
(1.82)^{*} \\
\end{array}$ & $\begin{array}{c}-0.280 \\
(3.48)^{* * *}\end{array}$ & \\
\hline $\begin{array}{l}\text { Extension } \\
\text { Evaluation }\end{array}$ & & & 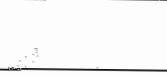 & $\begin{array}{c}0.208 \\
(2.15)^{*}\end{array}$ & $\begin{array}{c}0.297 \\
(5.33) * * *\end{array}$ \\
\hline $\begin{array}{c}\text { Perceived } \\
\text { Vallue } \\
\end{array}$ & & & & & $\begin{array}{c}0.540 \\
(10.07)^{* * 3 k}\end{array}$ \\
\hline Construct $\mathbf{R}^{2}$ & 0.299 & 0.541 & 0.275 & 0.428 & 0.532 \\
\hline
\end{tabular}

Key: *** $p<0.001 ; * * p<0.01 ; * p<0.05 ;$ all $R^{2} s$ were tested with an F-test and were all significant

Full model with moderating effects. We then test the full model with both the direct and the moderating effects. The results of the full model are provided in table 3.3, along with the $\mathrm{R}^{2}$ for each endogenous construct. First of all, our results show that the three-way interaction construct (extension direction*prior knowledge*service guarantee) does not have a significant influence on either the performance risk construct $(b=-0.034, t=0.21)$ or the financial risk construct $(b=0.132, t=1.00)$. Next, our results show that the moderating constructs of extension direction*prior knowledge and extension direction*service guarantee add to the amount of variance explained in the endogenous constructs, i.e. performance and financial risk. The $R^{2}$ change of performance risk is 0.026 and the $R^{2}$ change of financial risk is 0.018 . The F-test shows that the $R^{2}$ change on performance risk is marginally significant ( $F$ performance risk $=2.95, p=0.056$ ) and it is significant on financial risk at 0.05 level $\left(F_{\text {financial risk }}=3.10, p<0.05\right)$. 
Tlable 3.3: Full modell whth moderating effects: beta coefficients (t-vallues)

\begin{tabular}{|c|c|c|c|c|c|}
\hline & $\begin{array}{c}\text { Perfiormance } \\
\text { Risk }\end{array}$ & $\begin{array}{c}\text { Financial } \\
\text { Plsk }\end{array}$ & $\begin{array}{l}\text { Extemsion } \\
\text { Evaluation }\end{array}$ & $\begin{array}{c}\text { Perceived } \\
\text { Value } \\
\end{array}$ & $\begin{array}{l}\text { Purchase } \\
\text { Intention }\end{array}$ \\
\hline Extention Direction & $\begin{array}{c}0.169 \\
(1.87)^{7}\end{array}$ & $\begin{array}{c}0.592 \\
(8,30) \\
\end{array}$ & $\because \therefore$ & & \\
\hline Prior Knowledge & $\begin{array}{r}-0.004 \\
\quad(0.04) \\
\end{array}$ & $\begin{array}{c}0.043 \\
(0.71) \\
\end{array}$ & : & ; & \\
\hline Service Guarantee & $\begin{array}{l}20,152 \\
(197)^{*} \\
\end{array}$ & $\begin{array}{r}0.029 \\
(0.56) \\
\end{array}$ & & : & \\
\hline Performance Risilk & s. & $\begin{array}{c}0.490 \\
(7.31)^{*}\end{array}$ & $\begin{array}{c}-0.271 \\
(2.47)^{3}\end{array}$ & $\begin{array}{l}-0.233 \\
(2.27) * \\
\end{array}$ & \\
\hline Financial Risk & & & $\begin{array}{r}-0.1 .74 \\
(1.85)^{*}\end{array}$ & $\begin{array}{c}-0.277 \\
(3.48)\end{array}$ & \\
\hline Extension Evaluattion & & & & $\begin{array}{r}0.209 \\
(2.24)^{*} \\
\end{array}$ & $\begin{array}{c}0.297 \\
(5.06)^{*}\end{array}$ \\
\hline Perceived Value & & & & & $\begin{array}{r}0.540 \\
(9.98)^{*} \\
\end{array}$ \\
\hline $\begin{array}{l}\text { Extension Direction* } \\
\text { Prlor Knowledge }\end{array}$ & $\begin{array}{l}0.241 \\
(2.21)^{*} \\
\end{array}$ & $\begin{array}{r}-0.007 \\
(0.07) \\
\end{array}$ & & & 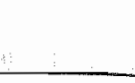 \\
\hline $\begin{array}{l}\text { Extensilon Direction* } \\
\text { Service Guarantee }\end{array}$ & $\begin{array}{l}-0.002 \\
(0.02) \\
\end{array}$ & $\begin{array}{r}-0.244 \\
(2.59)^{* *} \\
\end{array}$ & & & : \\
\hline $\begin{array}{l}\text { Exterision Direction } \\
\text { Prior Knowledge* } \\
\text { Service Guarantee }\end{array}$ & $\begin{array}{r}-0.034 \\
(0.21)\end{array}$ & $\begin{array}{l}0.132 \\
(1.00)\end{array}$ & & & \\
\hline Construct $\mathrm{R}^{2}$ & 0.325 & 0.559 & 0.275 & 0.427 & 0.532 \\
\hline
\end{tabular}

Key:*** $\mathrm{p}<0.001 ; * *<<0.01 ; * p<0.05$; all $\mathrm{R}^{2}$ s were tested with an F-test and were all significant

The first hypothesis predicts that consumers experience higher performance risk and financial risk in step-up extensions than in step-down extensions. Our results confirm both hypothesis 1 a and 1 b by showing that both performance risk $(b=0.169, t=1.87)$ and financial risk $(b=0.592, t=8.30)$ are positively influenced by extension direction $(1=10 \mathrm{w}$ risk, $7=$ high risk; $1=$ stepup extension, $0=$ step-down extension). Furthermore, we found a positive relationship between performance and financial risk ( $b=0.490, t=7.31)$. Hence, H1C is also supported. Hypothesis 2 proposes that the effect of extension direction on performance risk is positively moderated by consumers" priar knowledge. Our results confirm this hypothesis by showing a positive interaction term $(b=0.241, t=2.21)$ of extension direction*prior knowledge on performance risk. Hypothesis $3 a$ and $3 b$ predict that the effect of service guarantees on risk perception is moderated by extension direction. Our results show that the negative impact of a service guarantee is greater in step-up extensions than that in step-down extensions on financial risk $(b=-0.244, t=2.59)$, but the 
interaction term of extension direction*service guarantee has no significant influence on performance risk $(b=-0.002, t=0.02)$. Hence, hypothesis $3 a$ is rejected but $3 \mathrm{~b}$ is supported. Nevertheless, we found that the main effect of service guarantees on performance risk is significant $(b=-0.152, t=1.97)$. Furthermore, our results show that both performance risk $(b=-0.271, t=2.47)$ and financial risk $(b=-0.174, t=1.85)$ negatively influence consumers' extension evaluations. Thus, hypothesis $4 \mathrm{a}$ and $4 \mathrm{~b}$ are supported. Next, both performance risk $(b=-0.233, t=2.27)$ and financial risk $(b=-0.277, t=3.48$ ) have negative impacts on perceived value. This supports our hypothesis 5 a and $5 b$. Also, extension evaluations have a positive influence on perceived value $(b=0.209, t=$ 2.24). Therefore, hypothesis 6 is supported. Finally, both extension evaluation $(b=0.297, t=5.06)$ and perceived value $(b=0.540, t=9.98)$ positively influence consumers purchase intentions. Hence, hypothesis $7 \mathrm{a}$ and $7 \mathrm{~b}$ are both supported.

\subsection{Discussion and Implications}

\subsubsection{Implications for Theory and Research}

Despite the prevallence of line extensions in the marketplace, research on line extensions is very limited. Among the few studies on line extensions, Reddy et al. (1994) and Nijssen (1999) examined the success factors of line extensions by using aggregated profitability data as the dependent measure. Yet they did not examine a cognitive-level explanation for consumer reactions to line extensions. The current study examines a particular form of line extensions, vertical service line extensions, by looking at consumers' cognitive reactions to line extensions.

The key objective of this study is to analyze consumers' responses to vertical service line extensions and the role of perceived risk in formulating these responses. We examined the influence of a primary extension variable in vertical line extensions, the direction of extensions, on perceived risks of extensions. We found that consumers perceive higher performance and financial risks in step-up extensions than in step-down extensions. This can also be attributed to the fact that the increased possibillity for heterogeneity in step up services leads to high risk perceptions. Ostrom and Iacobucci (1998) state that there are several factors such as the complexity of services and extent of dependence on human labour that could potentially influence the perception of heterogeneity in service 
quality. Step-up extensions (vs. step-down extensions) involve more complicated service procedures and high involvement of service employees in the delivery process, which leads to higher risk perceptions in the step-up extension condition than in the step-down extension condition.

Athough perceived risk plays a central role in consumers evaluation and decision making process, it has not been examined as an antecedent of consumers cognitive responses to extensions. In this study, we found that perceived risk, as measured by elements of performance and financial risk, mediates the influence of line extensions on extension evaluations and perceived value. This finding further highlights the close relationship between risk and extemsion evaluations as well as perceived value, and how risk can be used conceptually and practically in generating more favourable evaluations and greater value for money. In addition, most of previous studies use a general risk construct (e.g., Ostrom and Iacobucci 1998). Although some studies measured specifled risk factors, they did not hypothesize their potentially different impacts in the model (e.g., Sweeney et al. 1999). We specified two dimensions of perceived risk, performance and financial risk, examining the unique antecedents of these two risk dimensions and their different roles in mediating the relationship between the influential factors of an extension and consumer responses to the extension. For instance, we found that prior knowledge affects performance risk but financial risk is not influenced by prior knowledge. Also, the impacts of service guarantees on the two dimensions of risk are also different. Our findings indicate that consumer-level factors (i.e. prior knowledge) as well as company-controlled factors (i.e. service guarantee) can mitigate performance risk, whereas consumers" financial risk perception is mostly influenced by an external monetary assurance.

When we examined the moderating effect of prior knowledge on performance risk, we found that more knowledgeable consumers (vs. less knowledgeable consumers) perceive a greater difference of performance risk between step-up and step-down extensions. This result corroborates the previous finding that consumers with varying level of prior knowledge use different information cues when evaluating products. Our results also show that the impact of prior knowledge on financial risk is completely mediated by performance risk. This finding can be explained by the fact that financial risk reflects the monetary loss incurred when a product does not perform as expected 
(Sweeney et al. 1999), while consumers with varying levels of prior knowledge mainly use different information cues as product quality indicators (Ra⿳亠 and Monroe 1988).

In addition, we also found that the impact of service guarantees on financial risk is greater in step-up than in step-down extensions. This resutt highlights the importance of service guarantees when the risk perception is substantial and there are no other positive signals to reduce it. However, we found that there is no significant interaction between service guarantees and extension direction on performance risk. We then checked the direct effect of service guarantees on performance risk, and we found a significant direct effect of service guarantees on performance risk. This result might be explained by the fact that both step-up and step-down extensions involve a considerable amount changes from the parent brand offering. Therefore, even though consumers perceive relatively less performance risk in step-down extensions than in step-up extensions, the overall performance risk level in both extension scenarios is high. As a consequence, compared to the overall performance risk level, the difference of performance risk between step-up and step-down extensions is relatively small. This decreases the impact difference of service guarantees between the step-up and the step-down extension condition. Furthermore, the significant direct effect of service guarantees on performance risk differs from Shimp and Bearden's (1982) finding that high warranty quality could only significantly reduce consumers' financial risk but not performance risk. They explained that service guarantees may not increase consumers' confidence about the quality of a product but consumers realized that they would be financially compensated if the product failed. Our finding supports the argument of other previous studies (e.g., Ostrom and Iacobucci 1998) that service guarantees reduce risk perceptions by both serving as a positive quality signal to reduce uncertainties and by minimizing adverse consequences if services fail (Wirtz et al. 2000).

Furthermore, we measured both extension evaluations and perceived value to reflect consumer responses to extensions whereas most previous studies only measured extension evaluations. Our results show that perceived value indeed had a much stronger influence on consumers' purchase intention than extension evaluations, highlighting the critical role of perceived value for consumers to make purchase decisions and for companies to gain competitive advantage (Parasuraman 1997; Parasuraman and Grewal 2000; Petrick 2002). 


\subsubsection{Implications for Brand Management}

These results have important implications for marketing practitioners. Consumers have lower risk perceptions in step-down extensions than in step-up extensions. Hence step-down extensions are expected to receive higher evaluations, perceived value, and purchase intentions compared to step-up extensions. This result can help us understand the phenomenon that step-down extensions are much more prevalent in the marketplace than step-up extensions. Aaker (1996) also pointed out that consumers ${ }^{*}$ increasing value orientation may make step-down extensions a competitive necessity. Hence, step-down extensions seem to be a more effective strategy if brand managers aim to leverage the existing brand equity and extend the brand profitability into different market segments. However, in some cases, step-up extensions are introduced not for gaining profitability in the extension offerings, but for reinforcing the parent brand image and therefore attracting more customers in the current market segment. Our study provides managers a better understanding on how consumers react to different line extensions, which helps managers develop different extension strategies for different managerial purposes.

Next, different branding and promotion strategies may facilitate the acceptance of step-up and step-down extensions. For instance, experts (vs. novices) are more likely to rely on deeper intrinsic cues (e.g., competency requirements) to infer the quality information of extensions, which makes them perceive higher risks than novices in the step-up extension condition. In such a situation, it is important to emphasize these intrinsic cues in brand communications to convince consumers that the parent brand has the required capability and competency to delivery the extension service. Managers may also use a strategy similar to the sequential introduction technique introduced by Keller and Aaker (1992) to facilitate the step-up extension acceptance. Keller and Aaker state that the brand image established in consumers' mind through previous marketing activities influences their extension evaluations. They argue that successful intervening extensions lead to more favourable evaluations for subsequent extensions, even if these extensions are dissimilar to the parent brand. Thus, we suggest that firms can take incremental steps in extending the original brand upwards to a higher-end market. For instance, an economy hotel chain, Van der Valk, first introduced 4 star Van der Valk hotels in its process of 
the upward extension. On the other hand, in the step-down extension condition, it is advisable to emphasize the linkage between the parent brand and the extension to receive more favourable extension evaluations. Furthermore, brand communications should emphasize the expressive values of the extension for customers (i.e. extrinsic cues such as affordable price and well-known brand) rather than focusing on technical service values and detalled service amenities.

The results of this study also show that service guarantees have limited effects on risk perceptions in some extension conditions. Managers may consider using other risk rellievers besides service guarantees. For instance, companies can provide free-upgrade opportunities or free coupons for loyal customers to experience the step-up or step-down extensions. These methods can reduce consumers' risk perceptions through their experiences with the extension services and help firms spread positive word-of-mouth to potential customers.

\subsection{Limitations and Future Research}

We identified several limitations in this research and we take them as points of direction for future research. First, we choose to concentrate on one industry rather than perform a cross-sectional analysis. Future research should select a broader set of services, as the impact of the extension direction may behave differently depending on the type of services and specific consumer variables in that service category. Furthermore, although we use a real brand name as the parent brand and the manipulation check reveals successful manipulations, the hypothetical line extensions and imaginary purchase situations may hinder respondents from expressing their true reactions to extensions. This may also contribute to the relative effect size in the results of our study. Therefore, although such an experiment provides important findings on the way consumers evaluate extensions, further research may go beyond an experiment work, using real purchase situations and market data to verify the findings of this study.

This study focuses on consumer responses to service extensions. However, the success of an extension strategy depends on not only how an extension is evaluated but also whether the parent brand will be diluted or harmed (e.g., KIm et al. 2001). Furthermore, a company introducing line extensions may not aim to generate extra sales and profits but to simply improve the strategic positioning of the parent brand (Hardle and Lodish 1994). Hence, it is important for future 
research to investigate how consumers respond to the parent brand when a vertical line extension is introduced, whether different types of parent brands (functional vs. prestige) will receive different effects from the introduction of line extensions, and whether different marketing strategies (e.g., distancing strategy, Kim et al. 2001) moderate the impact of extensions on the parent brand.

Furthermore, this study focuses on performance/financial risk and the role of prior knowledge and service guarantee in increasing/reducing such risks. Roselius (1971) and Settle and Alreck (1989) argued that different risk relievers may influence different types of risks in different purchase situations, such as time loss risk and psychosocial loss. Greatorex and Mitchell (1994) also suggest that the effect of risk relievers is not generalizable across product groups. Hence further research may consider including different or more dimensions of risks in investigating the issues introduced in this study in a different service and manipulation setting. 


\section{Chapter 4: MAPping Cognitive BRAnd}

\section{ARCHITECTURE BY EXAMINING THE SPILLOVER Effects of Product-harm Crises}

Consumers" cognitive representation of brands is of central importance to the understanding of consumer behaviour and marketing. Yet; little is known about the cognitive representation of brand architecture. We investigate an associative network conceptualization of brand architecture. To validate this conceptualization, we examine a critical network property that has significant implications for marketing: spillover effects from one node to others in the network. We hypothesize that if brand architecture can be conceptualized as an associative network, then the key binding principle of associative networks, the strength of association between nodes, should predict the pattern of spillover effects. Three experiments provide tests of hypotheses related to spillover effects. Results support an associative network conceptualization as spillover effects conform to predicted patterns. Implications are drawn for the nature of brand representation and its consequences for the spillover of market-related information from one brand to others within the network. 
"Building a coherent international brand architecture is a key component of the firm's overall international marketing strategy, because it provides a structure to leverage strong brands into other markets, assimilate acquired brands, and integrate strategy across markets." (Douglas, Craig, and Nijssen 2001, p. 97)

\subsection{Introduction}

The conventional single-brand company is increasingly a rarity (Laforet and Saunders 1999). Complex brand architectures with multiple brands, subbrands, endarsed brands, and co-brands are ubiquitous because brand relatedness helps sellers fulfil market segmentation, brand strategy, and marketing efficiency objectives (Aaker and Joachimisthaler 2000). Relatedness is cultivated through a variety of means including the use of common brand names and logos, similar trade dress and design, similar or related advertising, promotion of complementary usage, and even proximate shelf location (Aaker and Joachimsthaler 2000; Rajagopal 2004). Once established, perceptions of relatedness influence the processing of external information. Indeed, a brand cannot be isolated from exposure to information about related brands. For instance, Kellogg's Cornflakes advertising may have spillover effects on other Kellogg's brands, such as Specialk and Vector. Similarly, if the Cornflakes brand is subject to severe quality problems prompting product recalls, consumers might update their evaluations not just of Cornflakes, but also of other Kellogg's subbrands. In other words, relatedness makes the brands subject to 'spillover' effects in which external information (e.g., advertising, or a negative news) about a brand can change evaluations of brands that are not directly implicated (Roehm and Tybout 2005). For researchers and marketers alike, the implication is that neglecting indirect effects on related brands limits our understanding of the antecedents of important marketing constructs such as brand evaluations and purchase likelihood, and may lead to inappropriate managerial actions.

Yet little research has addressed the impact of external information on related brands. One reason for this gap may be the lack of a coherent conceptualization of the cognitive representation of brand architecture. This is not to say that the construct of brand representation has been ignored. Indeed, studies of the cognitive representation of individual brands and their market 
environment abound. These conceptualizations include brands as elements of a graded product category structure (Alba and Chattopadhyay 1985; 1986; Broniarczyk and Alba 1994; Nedungadi 1990; Nedungad, Chattopadhyay, and Muthukrishnan 2001), semantic brand categories (Boush and Loken 1991; Dawar 1996; Park, Milberg and Lawson 1991), schemas (Sujan and Bettman 1989), and bundles of associations (Broniarczyk and Alba 1994; Keller 1993; Krishnan 1996; Lawson 2002). Common to these conceptualizations is that they place the representation of individual brands in the context of a larger cognitive structure (for example, a category structure), and examine how such representation influences the processing of new information.

However, despite examining individual brands as embedded in larger structures, past studies have largely neglected the interdependency between brands and overlooked the possible network effects that arise from the linkages between them. In particular, there has been little research on cognitive networks in which brands are interrelated (as opposed to cognitive networks that link brands to products or product categories). An important class of effects that result from embededness in a network is spillover effects by which the impact of positive or negative information can spread from one node in a network to others.

The objectives of this study are to explore and map the cognitive representation of brand architecture by examining patterns of spillover. The term brand architecture was coined to help managers organize and manage portfollios of brands by specifying "brand roles and the nature of relationships between brands" (Aaker and Joachimsthaler 2000, p8; Rajagopal 2004). In this study, we examine consumers" cognitive brand architecture, whilich we define as consumers" mental representation of relatedness between brands. Borrowing from memory research, we develop an associative network conceptualization of brand architecture. Evidence of systematic spillover effects, predictable on the basis of features of an associative network such as the strength of association, would lend considerable credence to an associative network conceptualization of brand architecture.

For a typicall brand portfolio, brand architecture consists of a parent brand and sub-brands as nodes, and linkages of varying strength between the nodes as the basic elements. We explore the structure of this cognitive network by introducing negatively valenced information at varying nodes within a presumed 
network, and predicting and observing the indirect negative consequences at other locations. The primary feature of an associative network, the strength of association between nodes, is used to predict the magnituide and pattern of spillover effects. Findings from three experiments designed to test these predictions are reported. The first experiment tests spillover effects that are hypothesized on the basis of measured strength of association between brands within a well-defined brand architecture. The second tests for spillover effects by experimentally manipulating the strength of association. The third experiment is designed to compare spillover within a brand portfollo against spillover to other brands in the same product category. We conclude with the discussion of the theoretical implications for brand representation and spillover effects, and suggestions for the management of brand portfolios.

\subsection{Conceptualizing Cognitive Brand Networks}

Among the various conceptualizations of cognitive structure, associative network theory (Anderson 1983; Collins and Loftus 1975) has been favored by marketing researchers for its parsimony and generality (Cowley and Mitchell 2003; Keller 1987; Lawson 2002; Morrin 1999) "It suggests that knowledge is stored as a network consisting of "cognitive units" or nodes, where each node representing a piece of information is connected to other nodes via linkages of varying strength (Anderson 1983; Morrin 1999; Nedungadi and Hutchinson 1985).

In such a network, a node may represent a brand name, a product, a product category or an attribute (Keller 1987; Krishnan 1996). Formation of these information nodes depends on the encoding format and learning goals during information acquisition (Craik and Lockhart 1972; Tulving 1979; Tulving and Thomson 1971; 1973). Several researchers have suggested that in the marketing environment, the brand serves as a cognitive organizing principle because the typlcal information presentation format including advertising, product packages, and shelf displays, is brand based, and because the majority of consumers' consumption experiences are also brand-based (Biehal and Chakravarti 1982; Johnson and Edward 1978). The resulting cognitive structure is conceptualized as a collection of brand nodes that consist of brand-related information, describing brand claims, evaluations, and attributes (Keller 1993; Till and Shimp 1998). 
An extension of this conceptualization of brands as nodes captures the relatedness between brands by positing linkages between nodes. For example, a Kellogg's sub-brand, FrootLoops, is advertised explicitly as "a brand from Kellogg. Similarly, Unilever's ice cream brand in Europe "Ola". is associated with several sub-brands that are often presented together in a single print advertisement. We suggest that these relationships, to the extent they are represented in consumer memory, take the form of linkages between brand nodes.

Within a brand portfolio, firms" family branding initiatives can be seen as attempts to establish or influence cognitive linkages between the parent brand and its sub-brands or among sub-brands. Once established, these links can gain strength through repeated exposure and additional liearning opportunities. Furthermore, as sub-brands within a brand portfolio often share similar quality standards, brand image, and advertising execution elements, consumers may also use these additional cues to organize their representation of brand architecture. Accordingly, we conceptualize a brand network as a set of brand information nodes that are interrelated via associative linkages. This is not to say that brands that are not part of the same portfolio cannot be linked in an associative network. But rather that linkages between brands in a portfolio that are established and influenced by marketing activities have not been examined in previous studies: Our purpose is to map these linkages and study their consequences for consumers' processing of external information. A key effect in the interaction of external information with the cognitive representation of a brand network is the spillover effect.

\subsection{Spillover Effects and the 'Retrieval-Updating' Process}

The term "spillover effect" is used to describe a variety of phenomena in marketing, including the "halo effect" in umbrella branding (DeGraba and Sullivan 1995), inter-attribute correlations in inference making (Ahluwalia, Unnava, and Burnkirant 2001; Bronlarczyk and Alba 1994), dilution of the parent brand and flagship products due to unsuccessful brand extensions (e.g., Keller and Sood 2003; Deborah Roedder et al. 1998), and the impact of external information (e.g., an advertisement, a news item) on associated objects (e.gn, brands, products) that are not directly involved (Balachander and Ghose 2004). We adhere to this last definition of the "spillover" effect in our study. In this 
stream of literature, much of the research, with the exceptions of Roehm and Tybout's (2005) study, focuses on market-level analysis, such as spillover as measured in the impact on sales (Erdem and Sun 2002; Sullivan 1990). In contrast, our objective is to examine the cognitive process underlying spillover effects at the individual consumer level, Roehm and Tybout (2005) examine the effects of category typicality on spillover to competitive brands in an industry using the categorization model. They focus on brand membership in a product category, and the role of the category in conveying spillover to competitor brands. In contrast, we focus on an associative network representation of brand architecture, and use its features to study the pattern of spillover effects conveyed through brand linkages within a brand portfolio.

Cognitively, spillover effects can be viewed as the combination of two consecutive processes: retrieval of related nodes and their updating. Retrieval is seen as the result of "spreading activation" in an associative network (Anderson 1983; Collins and Loftus 1975). Exposure to external information pertaining to a brand node (we refer to this node as the origin node), leads to node stimulation. Stimulation spreads through the associative network to related nodes. We refer to these as destination nodes. When a node is stimulated above a given threshold, it is said to be "activated," in that information represented by this node (e.g., brand evaluations) is retrieved into working memory (Anderson 1983). Retrieval allows the information to be processed and, if required, updated. We take the updating of information in a destination node due to indirect activation from the origin node as evidence of spillover (Till and Shimp 1998).

Interestingly, existing research in both psychology and marketing has either focused on retrieval or on updating. Studies that simultaneously examine both processes are rare. Studies of the retrieval process show that when the origin node is activated by an external prime, the probability of retrieving a destination node (destination node accessibility) is a function of the strength of association between the origin and destination nodes (Morrin 1999; Nedungadi 1990; Nedungadi, Chattopadhyay, and Muthukrishnan 2001). These studies are concerned with the influence of brand priming on brand accessibility and choice, and not with the updating of associations of the primed or related brands. Therefore, the primes are designed to be neutral. For instance, in order to show that retrieval can influence brand cholce without affecting evaluations, Nedungadi (1990) primed brands with primes that were evaluatively neutral. In other 
studies (Balachander and Ghose 2003; Fazlo, Herr and Powell 1992), persuaslve messages such as advertisements were used as primes, and therefore could potentially lead to updating (Mackenzle, Lutz, and Belch 1986): But since these studies focused on understanding memory accessibility of the primed brand, they measured consumers' ease of categorization, recognition, recall and choice, but not evaluations.

Updating has received considerable attention in the real $m$ of attitude and information integration research (e.g., Chaiken and Stangor 1987; Cooper and Croyle 1984; Lutz 1975; Olson and Zanna 1993; Petty, Wegener, and Fabrigar 1997: Smith and Swinyard 1982). This body of research suggests that brand evaluation updating occurs when consumers are exposed to 1) persuasive messages, such as advertising (e.g., Mackenzie et al. 1986; Rossiter and Percy $1980)$, 2) negative or positive personal experiences, such as product testing and usage (e.g., Gaeth et al. 1997; Smith 1993), or 3) negative or positive external information, such as word-of-mouth (e.g., Day 1970). Attitudes are vilewed as summary evaluations of objects along a dimension ranging from positive to negative (Olson and Zanna 1993; Petty et al. 1997). The extent of updating depends on message memory and the amount of elaboration triggered by the message (Petty et al. 1997; Petty, Priester, and Wegener 1994).

The separation of retrieval and updating research has meant that the relationship between the strength of association of cognitive nodes and the magnitude of spillover has not previously been examined. We examine both, and measure the extent of updating at a destination node once it is retrieved from memory. Based on previous literature, we propose that the retrieval of a destination brand node depends on the strength of association between this brand and the origin brand. Once retrieved, the destination brand node information (e.g., brand evaluations) may be updated. The pattern of updating of destination nodes is predicted on the basis of the strength of association between brand nodes. A stronger link facilitates affect transfer (Chapman and Ayleworth 1999) and therefore a greater extent of updating in the destination brand node may be expected. A strong link also makes the message (on the origin brand) more salient and relevant for the destination brand, encouraging greater elaboration at the destination node. Therefore, we expect strength of association to predict the extent of updating in the destination brand node. 


\subsection{Product-Harm Crises as a Prime}

Research on attitudes and valenced information primes (e.g., Ahluwalia, Burnkrant; and Unnava 2000; Ito et al. 1998) suggests that negative information is more influential and diagnostic than positive information in the formation and updating of consumer evaluations. We employ negative information as a prime because we expect these characteristics will make spillover effects more salient and therefore more easily detectable from a methodological standpoint.

Product-harm crises are well-publicized instances of defective or dangerous products that have been shown to have a significant impact on consumers' brand evaluations (Dawar and Pillutla 2000; Klein and Dawar 2004). Prior research provides some evidence for a product-harm crisis negatively affecting sales of the affected brand and other related brands (Sullivan 1990). Sullivan (1990) investigated the effect of a sudden acceleration problem with the Audi 4000 automobile on demand for the Audi 5000 and Audi Quattro subbrands: She found significant negative effects on demand for the Aud 5000 and Quattro sub-brands. Furthermore, the influence on the Audi 5000 was larger than that on Quattro. A speculative explanation for this differential effect is that Audi had created strong associations between its Audi-5000 and Audi-4000 models through its marketing communications, whereas the Quattro was positioned as a more autonomous and distinct sub-brand by, for example, excluding the Audi name from Quattro's print advertisements. This finding may suggest a positive correlation between the extent of spillover and the strength of association, but it has never been empirically tested. Furthermore, Sullivan's (1990) study looked at aggregate demand as the dependent measure and did not examine a cognitive-level explanation for the spillover effects.

\subsection{Hypothesis Development}

We lllustrate the predicted effects with the brand architecture presented in Figure 4.1. The parent brand is labelled brand $P_{t}$ and its three sub-brands are labelled $A, B$ and $C$. 
Figure 4.1: An example associative brand network representing a biand portfolio

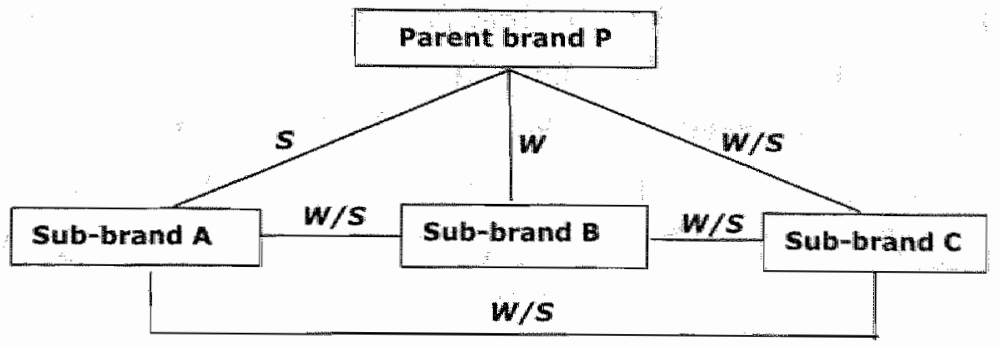

The sub-brands vary in their strength of association with the parent brand. In the structure of Figure 4.1, sub-brand $A$ has a stronger association with parent brand $P$ than does sub-brand $B$. The strength of the $C$ - $P$ association is equivalent to either A-P or B-P. The inclusion of this third sub-brand in the structure serves both as a replicate and a control to eliminate potential confounding factors in the spillover from the sub-brands to the parent brand.

We first focus on the links between each of the sub-brands ( $A, B$ and $C$ ) and the parent brand (P). These links are presumably established as part of consumers' learning of brand portfolio structure. The established links can be thought of as varying in strength. For example, the Cornflakes sub-brand may have a stronger association with the Kellogg parent brand than does the subbrand Vector. Based on the theoretical arguments presented above, we expect that information about a product-harm crisis at one of the sub-brands activates this sub-brand node, and that this activation spreads to the parent brand, potentially contaminating parent brand evaluations. The extent to which parent brand evaluations are updated is predicted to be a function of the strength of association of the origin sub-brand to the parent brand. Our first set of hypotheses captures this predicted relationship:

H1a: Brand evaluations of the parent brand suffer greater negative spillover when a crisis occurs at a strongly associated sub-brand than when an identical crisis occurs at a weakly associated sub-brand.

H1 $\mathbf{b}$ : Crises at sub-brands of equivalent strength of association to the parent brand have equivalent spillover on parent brand evaluations.

Linkages between sub-brands exist due to the common parent brand, but also due to similar product features, complementary usage situations, and other 
commonalities. In other words, sub-brand to sub-brand linkages may be qualitatively different from the silmple filial relationship between a sub-brand and the parent brand. Therefore, we expect that a destination sub-brand can be activated via multiple linkages from the origin sub-brand node. The level of activation that reaches the destination brand is said to be the sum of activation through each link (Collins and Loftus 1975). We predict spillover on the basis of this sum total, and do not differentiate on the basis of the source of the activation (via the parent brand or the other linkages between sub-brands).

H2a: A crisis at an origin sub-brand (e.g., sub-brand A) will have a greater spillover effect on brand evaluations of a strongly associated destination subbrand (e.g., sub-brand B) than on brand evaluations of a weakly associated destination sub-brand (e.g., sub-brand C).

H2b: Brand evaluations of destination sub-brands ( $B$ and $C$ ) of equivalent strength of association to the origin sub-brand (A) suffer equivalent spillover effects from a crisis at the origin sub-brand $(A)$.

\subsection{Experiment 1}

The purpose of Experiment 1 is to examine whether spillover effects in a brand network can be predicted on the basis of the strength of association between brand nodes, as stated in $\mathrm{H} 1$ and $\mathrm{H}_{2}$. A total of 340 undergraduate student subjects enrolled at a European university participated in a series of pretests and the main study in exchange for participation in lotteries with small prizes. Of the 185 student subjects who participated in the main study, $47.6 \%$ were female, $59.5 \%$ were business students, and $40.5 \%$ were law students. Subjects in the pretests were drawn from the same pool as the main study.

\subsubsection{Pretests}

Four pretests were conducted with the following objectives: 1) to select a sultable brand portfolio with an architecture similar to that described in Figure $\mathbb{1}_{\text {; }}$ 2) to test the fictitious crisis stories that were used as stimuli for readability and realism; 3) to assess baseline familiarity and brand evaluations for brands in the selected portfolio; and 4) to test the effectiveness of the crisis manipulation.

Several consumer packaged goods brand portfolios were tested as part of the initial stimulus pool. Pretest 1 measured the strength of association between the sub-brands and the parent brand using a computer-based response time 
sequential priming methoid. Response time sequential priming is well established in social psychology and consumer research as a method of measuring the strength of association between nodes in a cognitive structure (Bargth and Chartrand 2000; Dawar 1996; Fazio, Herr, and Pawell 1992; Herr, Farquhar, and Fazio 1996; Houwer et al. 2002; Morrin 1999). Righthanded respondents were asked to respond to the question of "relatedness" between two brands that appeared on the screen by pressing " $M$ " key (Yes) or " $Z$ " (No) key as rapidly as possible while remaining accurate in their responses. Left-handed respondents used the reverse pattern of keys. Thirty respondents participated in Pretest 1. The task consisted of four practice questions, followed by five blocks of eight questions (four experimental questions and four filler questions) in a randomized order. The priming program yields two elements of data for each pair of brands: the accuracy and the latency of the response. Subjects who incorrectly answered the relatedness question apparently do not associate sub-brands to the parent brand and therefore were not included in further analysis. For subjects who correctly answered the relatedness question, response latency is taken as an inverse indicator of the strength of association between the two brands. As preliminary analyses of the response time measure revealed positive skewness, we employed natural logarithmic transformations to normalize the data (Boush and Loken 1991). Although the analysis was conducted with the transformed data, for ease of comparability the means are reported in the original metric (milliseconds). Based on the results, two feasible brand portfolios (the Ola brand and Nestle brand portfolios) were selected for the subsequent pretests. Results of the Ola architecture are described here, and those of the Nestle architecture are described in Experiment 2. In the Ola brand portfolio, the sub-brand Raket is more weakly associated with parent brand Ola than are the sub-brands Magnum (RT [response time] Raket-ola $=1484 \mathrm{~ms}$ [millisecond], $R T_{\text {Magnum-0la }}=836 \mathrm{~ms}, \mathrm{p}<0.05$ ) and Cornetto (RT Corrietto-0la $=880 \mathrm{~ms}, \mathrm{RT}_{\text {Raket-Ola }}=1186 \mathrm{~ms}, \mathrm{p}<0.05$ ). Magnum and Cornetto are equivalent in their strength of association with parent brand Ola (RT cornetta-0la $=902 \mathrm{~ms}$, and RT Magnum-ola $=855 \mathrm{~ms}, p>0.10$ ). In addition to the sequential priming task, subjects were also asked to evaluate six fictitious newsstyle stories with different crisis scenarios. One was selected for its realism and readability. The selected story described a severe quality problem with one of the sub-brands that causes consumers to fall ill. 
Pretest 2 measured the strength of association between sub-brands with 28 respondents. The reaction time measurement used in Pretest 1 is ideally suited to measuring single relationship recognition; such as filial relationship or category membership. Since links between sub-brands are multi-faceted, the strength of association between sub-brands was measured using a paper and pencil measure of "relatedness" (Herr, Farquhar, and Fazio 1996). Prior to this task, respondents read instructions suggesting that sub-brands could be related in a number of ways, including through common brand families, similar features, similar usage occasions, etc. and that they should consider these types of linkages when making their judgments (Herr et al. 1996). The results indicate that Magnum has a significantly stronger association with Cornetto than with Raket (Mean Magnum-Cornetto $=5.00$, Mean Magnum-Raket $=2.34, p<0.001$ ), and reciprocally, Cornetto has a significantly stronger association with Magnum than with Raket (Mean Cornetto-Magnum $=5.00$, Mean conetto-Raket $=2.69, p<0.001$ ). Finally, the strength of the Cornetto-Raket and Magnum-Raket associations is equivalent $(p>0.10)$. Based on these results, the Ola brand architecture is presented in Figure 4.2 ;

Figure 4.2: The network structure of the Ola parent brand and sub-brands

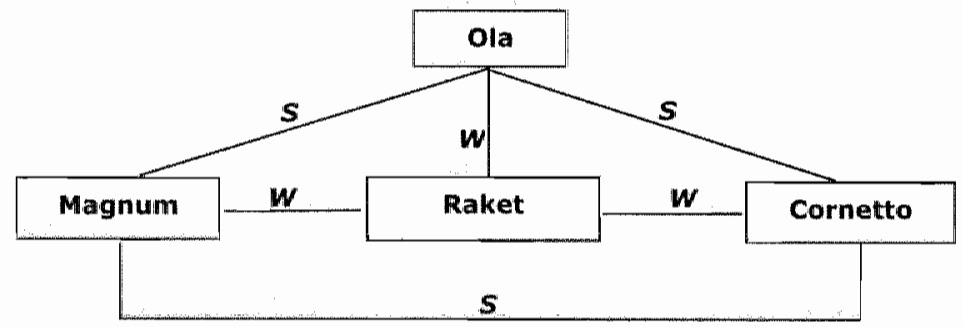

Pretest 3 established baseline brand familiarity and initial brand attitude. Seventy-four subjects rated their familiarity and brand attitude for a set of brands that were part of packaged goods brand portfolios. The results show that subjects were highly familiar with the parent brand Ola (Mean $=5.59$ ) as well as its sub-brands (Means $=5.91,5.91$, and 5.53 for sub-brands Cornetto, Magnum and Raket, on seven-point scalles where " 7 " is extremely familiar; $p>0.10$ for all pairs of comparisons). Furthermore, subjects have similar initial brand attitude for the parent brand Ola (Mean $=5.62$ ) and its sub-brands (Means $=5.89,5.53$, and 5.52 for sub-brands Magnum, Raket and Cornetto, on seven-point scales 


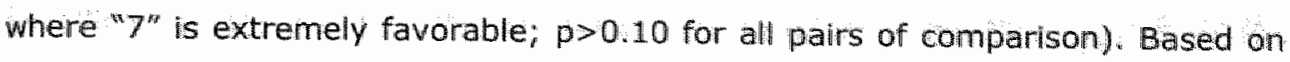
the results of Pretests 1,2 , and 3, three sub-brands of Unilever's European ice cream brand Ola (sub-brands: Raket, Cornetto and Magnum) were selected as stimuli for Experiment 1.

Pretest 4 is a calibration test with the objective of confirming that the fictitious crisis manipulation has the intended negative effect on evaluations of the origin brand. Twenty-three respondents were randomly assigned to an experimental and a control group. In the experimental group, the pre-selected fictitious crisis story was primed at the sub-brand Magnum. The results show that the crisis at Magnum significantly influences the brand evaluations of Magnum (Mean difference $=3.47, p<0.001$ ), relative to the control group where no crisis was primed at Magnum. Brand evaluations were measured using the same tenitem scale as in the main study.

\subsubsection{Experiment Procedure}

One hundred and eighty five respondents were randomly assigned to one of the three experimental groups and one control group. Respondents in each experimental group were exposed to the same crisis story about one of the three sub-brands (Magnum, Cornetto or Raket). In this manner, the locus of the product-harm crisis was manipulated, as a means of varying strength of association.

After carefully reading the crisis story, respondents were asked to evaluate the three sub-brands Magnum, Cornetto and Raket (the order in which these were presented was randomized across respondents). Respondents were then asked to evaluate the parent brand Ola. Next, respondents reported their knowledge of whether Ola and the three ice cream sub-brands presented are related. Respondents who answered in the negative were not included in further analysis for two reasons. First, people who do not associate sub-brands to the parent brand were excluded in measuring the strength of association (the independent variable) in the pretest. It is therefore consistent to exclude people who do not associate sub-brands to the parent brand in measuring brand evaluations (the dependent variable). Second, it is expected that people who do not associate sub-brands to the parent brand will have little or no spillover on the parent brand when a sub-brand is exposed to negative information. Therefore, inclusion of these respondents could spuriously magnify the differences between 
strong (large spillover expected) and weak (small spillover or no spillover expected) strength of association scenarios. The resulting sample size is 146 . Next, respondents evaluated the perceived severity of the crisis story on a seven-point scale (Not at all severe - Very severe), and provided demographic information. Respondents were then debriefed and thanked for their participation.

\section{4,6.3 Dependent Variables}

Consistent with previous research on brands and negative information, we employ a composite measurement of brand evaluations, including dimensions of brand attitude (negative-positive, bad-good, unfavourable-favourable), brand trust (not at all trustworthy-trustworthy, not at all reliable-very reliable, not at all dependable-very dependable), perceived quality of the brand and the product (high quality-low quality), brand purchase likelihood (not at all likely-very likely) and brand desirability (not at all desirable-very desirable) (Cronbach alpha = 0.94) (Agarwal and Rao 1996; Ahluwalia, Burnkrant, and Unnava 2000; Dawar and Pillutla 2000; Klein and Dawar 2004). The mean of the ten-item scale serves as the dependent variable.

\subsubsection{Manipulation Checks}

The manipulations had the intended effect. Crises at Cornetto, Magnum, and Raket significantly lowered consumer evaluations of these three sub-brands (Mean reduction $=2.90,2.62$, and 2.43 respectively, all $p^{\prime} s<0.001$ ). There were no significant differences between each of the experimental groups and the control group in terms of perceived severity (all p's $>0.10$ ). Furthermore, there were no systematic differences across gender and student majors.

\subsubsection{Resu/ts}

Compared to the control group in which respondents were not exposed to a product-harm crisis, the Ola parent brand's evaluations were significantly lower after the crisis at each sub-brand (Mean Difference [M.D. $]_{\text {Raket crisis }}=-1.17$, $p<0.001$; M.D. Magnum crisis= $-1.70, p<0.001$; M.D. Cometto crisis $=-2.13, p<0.001$ ), This result supports the associative linkages between sub-brands and the parent brand Ola, and indicates that Ola was subject to significant spillover from a crisis at each sub-brand. 
H1a proposes that crises with loci at strongly associated sub-brands will have a greater negative impact on parent brand evaluations than crises at weakly associated sub-brands. The sub-brand Raket has relatively weaker associations with Ola than sub-brands Magnum and Cornetto. One-way ANOVA with planned contrasts reveals significantly higher influences of crises at the strongly associated sub-brands Cornetto and Magnum on Ola brand evaluations than a crisis at Raket (Ola Evaluation Raket crisis Magnum crisis $=0.53, p<0.05$; Ola Evaluation Raket crisis- Cornetto crisis $=0.97, p<0.01)$. Hence, H1a is supported. The mean difference of brand evaluations (compared witith the control group) for each brand is presented in Table 4.1 .

Table 4.1: Mean differences (Standard Error) of brand evaluations in Experiment 1

\begin{tabular}{|c|c|c|c|c|}
\hline & \multicolumn{3}{|c|}{ Mean Differences of Brand Evaluations between the control and crisis groups } \\
\hline Crisis Locus & Raket & Magnum & Cornetto & Ola \\
\hline Raket & $2.43^{*}(0.2548)$ & $0.74 *(0.1913)$ & $0.64 *(0.1884)$ & $1.17 *(0.2445)$ \\
\hline Magnum & $0.07(0.2082)$ & $2.62^{*}(0.2665)$ & $1.10^{*}(0.1955)$ & $1.70^{*}(0.2558)$ \\
\hline Cornetto & $0.36(0.2525)$ & $1.85^{* *}(0.2347)$ & $2.90^{*}(0.2058)$ & $2.13^{*}(0.2749)$ \\
\hline p $<0.05$ & & & \\
\hline
\end{tabular}

H1b proposes that crises at sub-brands of equivalent strength of association should have equivalent impact on the parent brand. We know from the pretests that the strength of the Magnum Ola association is equivalent to the strength of the Cornetto-Ola association $(p>0.10)$. The results indicate that the influence of the crisis at Cornetto is not significantly different from the influence of the crisis at Magnum (Ola Evaluation Magnum crisis-Connetto crisis $=-0.43, p=0.098$ ). Therefore, $\mathrm{H} 1 \mathrm{~b}$ is also supported. These results suggest that the influence of subbrand crises on parent brand evaluations is positively related to the strength of association between the brands.

H2 explores spillover effects among sub-brands. H2a proposes that spillover effects depend on the strength of association between the destination and origin sub-brands. We first take the crisis at Magnum as the reference point and test its impact on Raket and Cornetto sub-brand evaluations. Since the spillover effect is measured by subtracting the brand evaluations in the control group from the brand evaluations in the experimental group, we test for the following interaction: whether the difference in brand evaluations (between the 
control and the experment group) is greater when the strength of association between the harmed sub-brand and the destination sub-brand is strong than when it is weak. A $2 * 2$ (strength of association * crisis) mixed ANOVA with the repeated measure for the strength of association (strong vs. Weak) and a between subject factor for crisis (crisis group vs. control group) yields a significant interaction term (M.D. Raket evaluation $=-0.07, \mathrm{M} . \mathrm{D}$. cornetto evaluation $=-1.10, \mathrm{~F}$ $(1,11.894)=15.62, p<0.001)$. It confirms that the crisis at Magnum has a greater spillover effect on the strongly associated Cornetto (Cornetto control $=5.34$, Cornetto experment $=4.24, p<0.01$ ) than on the weakly alssociated Raket (Raket control $=5.06$, Raket experiment $=4.99, p>0.10$ ). Next, using the crisis at Cornetto as the reference point, we find that the Cornetto replicate shows a similar pattern of results. The crisis at Cornetto has a greater spillover effect on the strongly associated Magnum than on the weakly associated Raket (M.D. Magnum evaluation= 1.85 , M.D. Raket evaluation $=-0.36, F(1,23.768)=25.73, p<0.001)$. Furthermore, planned contrasts show that the spillover of the Cornetto crisis on Magnum is significant (Magnum control $=5.65$, Magnum experiment $=3.80, p<0.001$ ) and that on Raket is not significant (Raket control $=5.06$, Raket experiment $=4.70, p>0.10$ ). Therefore $\mathrm{H} 2 \mathrm{a}$ is supported.

For validation, $\mathrm{H} 2 \mathrm{~b}$ checks whether equivalent strength of association results in approximately equivalent spillover effects between sub-brands. We take the Raket crisis as the reference point to examine whether the crisis at Raket (weakly associated with both Magnum and Cornetto) has equivalent spillover on Magnum and Cornetto sub-brand evaluations. The results confirm this expectation (M.D. Maxnum evaluation $=-0.74, p<0.001 ;$ M.D. Connetto evaluation $=-0.64$, $p<0.01 ; F(1,0.097)=0.409, p>0.10)$, and support $\mathrm{H} 2 b$, with the usual caution involved in interpreting a null result. Overall, these results suggest that the greater the strength of association between the origin and destination subbrands, the greater the spillover on brand evaluations of destination brands.

\subsubsection{Discussion}

The results of Experiment 1 support our conceptualization of cognitive representations of brand architecture as an associative network. As for all networks, the key feature of the brand network is the linkages between nodes that convey the impact of external information at one node to related nodes. In Experiment 1, we measured the strength of these links, and used the implied 
structure of the network to predict the extent of updating that would occur at related brand nodes. The results indicate that strength of association is a significant predictor of spillover effects of a product-harm crisis, both from the sub-brand to the parent brand and from sub-brand to sub-brand. The implications of this result for the cognitive representation of brand structures and the interaction with new information are discussed in the general discussion section. Before we draw those general conclusions, we turn our attention to addressing some limitations and eliminating alternative explanations for the results in Experiment 1.

One potential limitation of the results from this experiment is that the strength of association was measured rather than manipulated. We used crises at sub-brands of varying strength of association with the parent brand as proxies for the strength of association construct. While this provides a valuable test of the hypotheses in a "naturalistic" setting, it also raises two criticisms. First, the evidence presented is correlational, not causal. And second, the potential for confounds exists, particularly if the specificities of sub-brands in some way interact with the independent variable. Although the similar pattern of results across replicates in Experiment 1 alleviates some of these concerns, it is not as conclusive as results from a manipulated independent variable might be. Experiment 2 is designed to address these weaknesses by manipulating the strength of association.

\subsection{Experiment 2}

Experiment 2 was conducted to examine whether the effects observed in Experiment 1 can be experimentally induced by manipulating the strength of association between brands. Therefore, the hypothesis under investigation here is whether increased strength of association leads to increased spillover effects in a brand portfolio (Hypothesis 3). Furthermore, the experiment uses a different set of brands in a different product category than the stimuli in Experiment 1, to alleviate potential confounds and to provide additional validation for the results through a replication of the findings.

\subsubsection{Experiment Procedure}

We selected this second brand portfolio based on pretests described earlier with the criteria that two selected sub-brands (Nuts and Crunch) have 
approximately equivalent strength of association with the selected parent brand Nestlé $(M . D$. Wutg-crinch $=-26 \mathrm{~ms}, p>0.10)$. Ninety-eight subjects were randomly assigned to one experimental group and one control group. In memory research, the rehearsal task is commonly used to strengthen the association between concepts (e.g., Nedungadi and Hutchinson 1985; Posavac et al. 2001). Therefore, in the experimental group, respondents were first asked to perform a computerassisted priming task in which the strength of Nuts-Nestle and Crunch-Nestle association was enhanced through repeated exposure. The priming task consisted of two parts. In the first part, 43 filler questions (some of these were also repeated) were interspersed randomly with 23 experimental trials, where the Nuts-Nestlé and Crunch-Nestlé pairs appeared 11 and 12 times respectively). Each repetition required respondents to respond to a question about the "relatedness" between two brands, and an incorrect response triggered a feedback message. The second part consists of 23 questions ( 21 of them are filler questions) and serves as a manipulation check where both testing pairs only appeared once each. After a break, a questionnaire with a crisis (the same crisis used in Experiment 1) at the "Nuts" brand was presented to respondents. The rest of the procedure was similar to that of Experiment 1. In the control group, respondents completed the same procedure as respondents in the experimental group, but the strength of association between the sub-brands (Nuts and Crunch) and Nestlé was not manipulated by the repeated exposure task.

\subsubsection{Manipulation Check}

Manipulation checks show that the Nuts-Nestlé association is significantly stronger in the experimental group than in the control group (R.T. Nuts control = $1240 \mathrm{~ms}, R_{\text {. T. Nuts axperiment }}=413 \mathrm{~ms}, p<0.01$ ); as is the strength of Crunch-Nestle association (R.T. erunch control $=1258 \mathrm{~ms}$, R.T. crunch experiment $=470 \mathrm{~ms}, p<0.01$ ). The two sub-brands are equally strongly associated with the parent brand (R.T. Nutscrunch $=-37 \mathrm{~ms}_{x} \mathrm{p}>0.10$ ) in the experimental group.

\subsubsection{Results}

The results show that compared with the control group, the decline in the brand evaluations of the parent brand Nestle is greater when the strength of association was experimentally increased through rehearsal (Mean Nestie controi = 4.29, Mean Nestle experiment $=3.24, p<0.05)$. This result supports the prediction that 
the increased strength of the Nuts-Nestlé association leads to greater spillover from the sub-brand Nuts to the parent brand Nestle. The inclusion of the second sub-brand, Crunch allows us also to gauge the spillover across sub-brands. The results show that sub-brand Crunch is more severely impacted by the crisis at sub-brand Nuts in the experimental group than in the control group (Mean crumeh $c_{\text {contro! }}=4.42$, Mean crumth experment $=3.29, p<0.01$ ). We surmise that this is because the strength of the Nuts-Crunch association includes associations via the parent brand, and that an increase in both the Nuts-Nestle association and the CrunchNestlé association increases the Nuts-Crunch spillover.

\subsubsection{Discussion}

We manipulated the strength of association between brand nodes in consumers' memory through a repeated exposure procedure. The results indicate that the manipulated increase in strength of association between a sub-brand and the parent brand leads to greater crisis spillover effects from the sub-brand to the parent brand. This finding increases our confidence in the findings of Experiment 1 about the relationship between the strength of association and the magnitude of spillover effects. Fulthermore, we also found that the increased strength of association between the sub-brands and the parent brand leads to a greater spillover effect between sub-brands.

The sub-brands in both Experiments 1 and 2 represent products within the same product category (ice cream for Experiment 1; chocolate bars for Experiment 2). This raises a potential alternative explanation: that spillover effects occur not because the sub-brands are elements of a brand network with a common parent brand, but because they are linked via a common product category: The manipulation of the strength of association in Experiment 2 does suggest that brand architecture is the conduit for at least some of the spillover between sub-brands and the parent brand. To test the extent of this intra-brand architecture spillover (between sub-brands) relative to the spillover due to a common product category, we conduct Experiment 3.

\subsection{Experiment 3}

The product category model suggests consumers organize product information hierarchically from the basic product category up to super-ordinate categories, and down to more specific or subordinate categories (Loken and Ward 
1990, Sujar 1985). Given these linkages, the category structure can function as an organized retrieval plan, and when a brand is primed by external information, other brands in the same category might be retrieved, activated and contaminated (Nedungadi 1990; Roehm and Tybout 2005). Roehm and Tybout (2005) for example, show how the typicality of brands within a category moderates the spillover of negative information about a brand onto competing brands. This suggests an alternative conduit for the observed spillover: not through brand linkages but via product category linkages.

When sub-brands in a portfolio happen to be in the same product category, they are associated via the product category as well as through the shared brand architecture. It is plausible, therefore, that a destination brand node is activated via multiple linkages from the origin brand node, including product category linkages. Our approach in Experiments 1 and 2 has been to measure the total strength of association to predict the magnitude of spillover effects in a poitfolio. If cognitive brand architecture represents a theoretically productive characterization, we need to demonstrate that spillover through both the brand architecture linkages and common category linkages is at least as significant as the spillover through the common product category link alone.

However, as we saw in experiment 1 and 2, the extent of spillover between sub-brands in a portfolio depends on the strength of association. When the strength of association between a destination and origin brand is not strong enough to retrieve or update the destination brand, little spillover is seen. In this case, the spillover between sub-brands in a brand portfolio might be no different than the spillover between brands that are part of the same product category. Therefore, we hypothesize that spillover between sub-brands within a brand portfolio is stronger or equivalent to spillower between brands within the same product category (Hypothesis 4). To test this hypothesis, we conduct an experiment using the three sub-brands of the ola parent brand and two ice cream brands of varying typicality outside the ola portfolio.

\subsubsection{Pretests}

Pretests were conducted to select two brands in the ice cream product category that were not part of the Ola portfolio. The extent to which a brand is representative of the product category is referred to as its typicality (Loken and Ward 1990; Nedungadi and Hutchinson 1985). Previous studies indicate that a 
variety of factors may influence brand typicality, such as usage frequency, evaluation, and familiarity (Loken and Ward 1990). They also suggest that brand typicality influences retrieval (Nedungadi 1990) and can lead to more updating (Roehm and Tybout 2005).

A two-step pretest sought to identify candidate brands for the experimental stimuli. First, a focus group of eight participants discussed ice cream brands with respect to their familiarity, usage, and brand liking as indicators of brand typicality. Based on the focus group, two brands of different presumed levels of typicality were identified: Häagen Dazs as a typical ice cream brand, and Fruitjoy as somewhat less typical. In the second step, 18 subjects participated in a free-elicitation task in which they were asked to produce five ice cream brands in the order in which they came to mind. In accordance with Nedungadi and Hutchinson (1985) and Fazio, Herr, and Powell (1992), we expect that the order of brand recall positively correlates with typicality. The analysis coded the brands Raket, Cornetto, Magnum, Häagen Dazs, and Fruitjoy, assigning the ordinal rank in the elicitation task as a proxy measure of typicality, if the brand was mentioned, and a rank of ' 10 ' if it was not mentioned among the five brands elicited ${ }^{5}$. Results of a Wilcoxon Signed Ranked test show that there is no significant difference between Raket, Cornetto, Magnum and Häagen Dazs in terms of their typicality ( $p>0.10$ for all pairs), and Fruitjoy is significantly less typical than Magnum, Cornetto, Raket and Häagen Dazs ( $p<0.01$ for all pairs). Häagen Dazs and Fruitjoy were selected as the two external brands. The relationship between brands in experiment 3 is depicted in figure 4.3 .

Figure 4.3: The spillover within and across the Ola brand portfolio

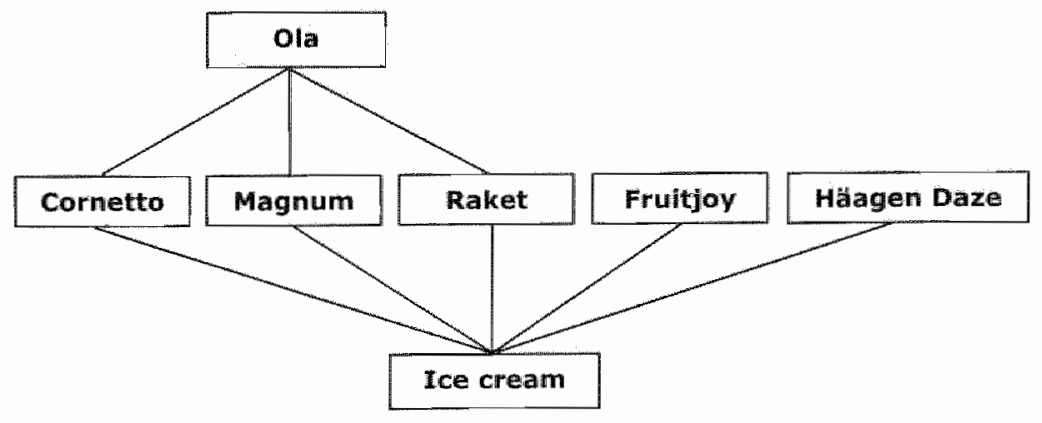

\footnotetext{
"A sensitivity test using different walues (6-10) for the absent brands shows that the difference of typicality between the selected brands is robust.
} 


\subsubsection{Experiment Procedure}

Sixty-six subjects were randomly assigned to either an experimental or control group. Respondents in the experimental group were exposed to the crisis story at the Cornetto brand. Subjects then responded to a questionnaire that included evaluations of the Magnum, Raket, Fruitjoy and Haagen Dazs brands in a counter-balanced order. In the control group, subjects were asked to evaluate the same brands without exposure to the crisis story. Next, subjects reported the percelved relatedness of each of the five brands to Ola. Only respondents who correctly identified the members of the Ola portfollo (Raket, Magnum and Cornetto) were included in the data analysis. The resulting sample size ranges from 35 to 41 for the pair-wise comparisons of the spillover effect of the Cornetto crisis on the Magnum, Raket; Häagen Dazs and Fruitjoy brands.

\subsubsection{Results}

A 2*2 (strength of association * crisis) mixed ANCOVA was used to assess the influence of the Cornetto crisis at Raket and Magnum, with repeated measures for strength of association (strongly/weakly associated with Cornetto) and a between-subjects factor for crisis (crisis/control). Familiarity with Raket and Magnum serve as covariates. In a replication of the results of Experiment 1 , the results show that the Cornetto crisis has a significantly greater influence on Magnum than on Raket (M.D. Raket $=-0.54, p=0.057$; M.D. Magnum $=-1.97$, $p<$ $0.001 ; F(1,12.866)=8.94, p<0.01)$.

Next, similar ANCONA tests were conducted for Magnum-Haagen Dazs, Raket-Haagen Dazs, Magnum-Fruitjoy, and Raket-Fruitjoy pairs. The results show that the crisis at Cornetto has a significantly greater influence on Magnum than on Haagen Dazs (M.D. Magnum $=-2.06, p<0.001 ;$ M.D. Haggendas $=-0.30, p>$ $0.10 ; F(1,15.407)=16.40, p<0.001$ ) and Fruitjoy (M.D. Magnum $=-2.01, p<$ 0.001 ; M.D. Fuitjoy $=0.32, p>0.10 ; F(1,20.676)=12.46, p<0.01)$. This supports our proposition that brands within the portfolio of the harmed brand are subject to greater spillover than brands outside the portfolio. The influence of the Cornetto crisis on Raket is not significantly different from that on Häagen Dazs (M.D. Raker $=-0.65, p=0.069 ;$ M.D. Haagendasz $=-0.33, p>0.10 ; F(1,0.362)=0.41$, $p>0.10$ ). This is consistent with the prior that Raket is weakly associated with Cornetto. However, the results show a significant difference between the impact 
an Raket and Fruitjoy (M.D. Raket $=-0.71, p=0.05 ;$ M.D. Finitjoy $=0.58, p=0.086 ; F$ $(1,6.722)=4.89, p<0.05)$

\subsubsection{Discussion}

In this experiment, we sought to examine the extent of spillover within a brand portfolio relative to brands within the same product category, but outside the brand portfolio. If spillover through the product category provides a benchmark for the extent of spillover within versus outside the brand portfolio (Roehm and Tybout 2005), our results suggest that spillover within a brand portfolio is at least as copious as highly typical brands outside the brand portfolio. This indicates that brand linkages are strong, that they convey activation, and that the resulting spillover effects are at least as strong as those that occur through category networks. These findings underscore the utility of conceptualizing cognitive representations of brand architecture.

\subsection{General Discussion}

\subsubsection{Theoretical Implications}

Research on brands has provided a valuable understanding of the cognitive structure, as well as the antecedents and consequences of the representation of stand-alone brands (Aaker and Keller 1990; Keller 1993; Shocker, Srivasatava, and Reukert 1994; Sullivan 1990; Weinberger and Romeo 1991). However, despite the prevalence of portfolio brands, little emplrical research has examined how these might be cognitively represented, and what the consequences of such representation might be for consumer behaviour. From a theoretical standpoint, it is worthwhile to conceptualize a cognitive couinterpart to the marketplace construct of brand architecture because it allows us to examine the antecedents and consequences related to the brand portfolio. The utility of positing such a representation resides in our ability to make predictions about the interaction of external information with the cognitive representation, and on this basis, to be able to predict changes in the representation and consequent consumer behaviour.

The research reported here constitutes a first attempt to explore these cognitive structures, and examine how they interact with external information. Experiment 1 provides evidence of spillover effects and supports our initial 
proposition that associative linkages between brands form a brand network. We found that the extent of the spillover, defined as the updating of the destination node, depends on the strength of association between the destination and origin brand nodes. Experiment 2 underscores the causal role played by the strength of association. By manipulating the strength of association between the sub-brand and the parent brand, greater spillover is induced. The results of Experiment 3 show that spillover effects within a brand portfolio are at least as strong as spillover within the same product category, but outside the portfolio. This helps corroborate the existence of associative linkages between brands, and supports the conceptualization of the construct of "cognitive brand architecture."

The principal advantage of network representations is that they provide the conceptual framework for the study of indirect effects. Indirect exposure effects are rarely examined as antecedents of consumer behaviour related to brands. Spillover of positive and negative information is one type of indirect effect. Our results illustrate that such indirect effects may account for substantial variance in brand evaluations. We employed negatively valenced information as a stimulus to examine how its effects spread through the network, but our findings about the structure of brand networks can equally apply to examining the effects of positive or persuasive messages, which are more prevalent in the marketing environment. The investigation of positive spillover effects such as advertising efficiencies (Balachander and Ghose 2003) and attitude transfer of rave reviews (Chapman and Aylesworth 1999) is gaining research attention due to its promising managerial benefits. The understanding of the cognitive process of splllover developed in our research provides a process explanation for a phenomenon that has previously mainly been examined at the macro level.

We conceptualize spillover as resulting from retrieval and updating of associations in a destination node. This suggests that determinants of retrieval such as the strength of association in a network may influence the extent of updating. While earlier research has pointed to the strength of association as a determinant of the probability of retrieval, our findings suggest that strength of assoclation may also be predictive of the extent of elaboration and updating. This result may also be corroborated by the accessibility-diagnostic framework (e.g., Ahluwalia and Gurhan-Canli 2000). Specifically, a destination brand should be first retrieved from consumers' memory to be accessible, and the extent of updating depends on whether the information on the origin brand is relevant for 
the destination brand (e.g., Keller and Sood 2003). A stronger link lncreases the probability that the destination brand is accessed, and makes the message on the origin brand more relevant for the destination brand. These findings suggest a broader role for the key descriptor of the network property of linkages between nodes, and illustrate the value of a network conceptualization of cognitive brand architecture.

A conceptualization of brand architecture may also carry implications for other consumer behaviour phenomena such as inferences about missing attribute information, perceptions of similarity of brands based on strength of association within a network, categorization and sub-typing of brands, as well as brand consideration and choice. For example, the literature on missing information (e.g., Ahluwalia, Unnava and Burnkrant 2001; Broniarczyk and Alba 1994) indicates that consumers rely on inter-attribute correlations to infer the value of missing attributes. If subjective assessments of correlation are a function of co-activation of brand nodes in a network, then the strength of associative linkages between brands will help determine the brands from which information is "borrowed" to fill in missing attributes. By a similar mechanism, perceptions of similarity may be influenced by repeated co-activation, leading to the prediction that brands that with greater strength of association will also be perceived as more similar, independently of feature similarity of the products that they represent. Finally, categorization, sub-typing, consideration and choice have been shown to be subject to retrieval effects based on a category structure representation (Alba and Chattopadhyay 1985; 1986; Nedungadi 1990; Sujan and Bettman 1989). The results presented here suggest that retrieval effects due to brand architecture may influence these phenomena in a similar fashion. Mapping the brand network is worthwhile for a complete understanding of their antecedents.

\subsubsection{Managerial Implications}

Managerially, this study carries implications for the design of brand architecture. Several consumer goods companies, including Nestlé, Unilever and S.C. Johnson have in recent years pursued an umbrella-branding strategy, placing the corporate parent brand on product packages and advertisements of their sub-brands. This conscious increase in the strength of association of the sub-brands to the parent brand is driven by the potential benefits of marketing efficiency. However, the results presented here suggest that these need to be 
welghed against the risks of negative spillover when one sub-brand suffers an adverse event. As part of a network, brands are vulnerable not just to the risks inherent in their own products and actions, but also to those of other brands in the network. The likelihood of such adverse events that can have spillover effects may be low, but the risk is exacerbated due to the greater salience of negative information.

Experiment 3 carries managerial implications for broad brands. The results showed that spillover within the brand architecture is at least as great as the spillover to other brands within the product category. From a practical standpoint it is important to examine the relative strength of brand-related spillover to category spillover because many brands consist of portfolios of products and subbrands that span multiple product categories. These broad brands are premised on "conceptual' similarity rather than product-based fit (Meyvis and Janiszewski 2004; Park, Milberg and Lawson 1991). Indeed, one explanation for the existence of these brands is that they benefit from the positive spillover through the brand architecture. The findings reported here point to the potential for negative spillover through the same architecture.

A cognitive brand architecture conceptualization may also provide valuable understanding in a variety of branding phenomena that are receiving increasing attention in the marketing literature, including advertising alliances (Samu, Krishnan and Smith 1999), brand alliances (Simonin and Ruth 1998), and cobranding (Swaminathan and Reddy 2003). Osselaer and Janiszewski (2000; 2001) suggest that consumers' learning of associations between brands is established and strengthened as the frequency of brand co-appearance increases. In other words, several types of brand relatedness deliberately created by marketers may help construct cognitive brand architecture, and a conceptualization of brand architecture in cognitive terms may be necessary to shed light on phenomena that implicate brand relatedness.

\subsection{Limitations and Future Research}

In the research reported here we controlled for or kept constant several factors that might potentially moderate the relationship between independent and dependent variables. In this section, we describe some of these, as they provide avenues for future research. 
As a first approach to mapping cognitive brand architecture, our focus was on exploring the role of the key network property of strength of association. It is important to note, however, that in examining the effects of external information on existing cognitive structures, the characteristics of the information itself can also potentially influence outcomes. Network association theory (e.g., Anderson 1983) states that the activation of a linked node depends on the strength of links as well as the strength of activation at the origin node. The strength of activation may vary as a function of the salience of brand priming, which itself might be influenced by factors such as crisis severity, and even the attribution that consumers make about the crisis. For instance, previous research has shown that severe crises and crises perceived to be avoidable cause more feelings of anger and stronger emotional reactions to the harmed brand (Folkes 1984; Weiner 2000). Next, we investigate the impact of a primary network feature, strength of association, on the spillover effect. However, other features of a network, such as the strength of the nade itself, may also influence the nature and extent of spillover. An analogous effect can be found in Deborah Roedder et al's (1998) study. They investigate the dilution of flagship products due to unsuccessful brand extensions. They found that even though the flagship product is strongly linked to the parent brand, it is resistant to dilution because strong bellefs held in the flagship product node are not easily updated. Therefore, further research on factors such as information characteristics and other network features that might moderate negative information processing will provide a more complete understanding of the spillover effects in a brand network.

Attitude research indicates that attitude characteristics and structures can also influence the interpretation of attitude-relevant information and the extent of updating (e.g., Olson and Zanna 1993). For instance, Fazio and colleagues (1986, etc) indicate that the strength of object-evaluation association (i.e., the accessibility of attitudes) influences the speed of attitude activation from memory upon merely encountering an attitude object. Therefore, it might be worthwhile exploring this second arder retrieval process that occurs prior to updating. Specifically, the stronger the object evaluation association, the more accessible evaluations are once the object is retrieved. This might lead either to a higher probability of updating, more updating, or both. In our studies, we controlled for this potential background factor by using brand stimuli with which subjects are highly familiar. However, future research may select brands with different 
strength of object-evaluation associations by measuring the response latency of an attitude inquiry (Fazio et al. 1986), and examine the impact of the second order retrieval (attitude accessibility) on the spillover.

one finding in memory research is that, "relations can bie asymmetrical in strength and that the direction processed more frequently develops stronger relations (Barsalou and Sewell 1985, p650). Collins and Loftus (1975) also indicate that links between conceptual nodes are "pointers" that may go in both directions. Farquhar, Herr and Fazio (1990) discuss the difference between category-brand association (dominance) and brand-category association (typicality), and the implications for brand extension (see also Herr, Farquhar and Fazio 1996; Holden and Lutz 1992). The results of Experiment 1 show some evidence of asymmetric spillover. This finding might indicate asymmetry in the strength of association. If present, asymmetry would suggest that spillovers occur more in one direction than the other. Determining the antecedents of asymmetry might help design brand architectures that benefit from positive spillover of a parent brand to sub-brands, but insulate the parent brand from risks of negative occurrences at the sub-brand.

In a marketing environment in which complex brand architectures are prevalent, neglecting the cognitive representation of these architectures provides an incomplete understanding of the effects of external information on consumer behavior. This paper attempts an initial step toward understanding these cognitive representations by proposing and testing an associative network model of brand architecture. 


\section{ChAPTER 5: Information AND PROCESSING}

\section{ChaRACteristics as Moderators of Negative}

\section{SPILLOVER EFFECTS}

The impact of negative information on consumer evaluations has been shown to be a function of the cognitive structure within which it is processed. In this study we examine two additional factors that contribute to the spread of negative information in a network: (a) information characteristics; (b) processing characteristics. Three experiments test the moderating role of information characteristics and processing characteristics on the pattern of spillover within the cognitive structure. The results suggest boundary conditions for the impact of negative information in a brand network, and in particular describe when negative spillover is likely to be strengthened, attenuated, and even diminished. 


\subsection{Introduction}

Negative information is gaining great concerns among marketing managers due to its increased prominence in the marketplace (Weinberger and Lepkowska-White 2000) and the fast dissemination speed to a wide scope of consumers (Klein and Shiv 1996). While much of previous research investigates the impact of negative information on the cognitive entity (e.g., a brand) directly implicated in the information (e.g., Kurzbard and Siomkos 1992), the strength of the effects of negative information suggests that the consequences are unlikely to be limited to the directly implicated entities alone. For example, a wellpublicized "sudden acceleration" problem with the Audi 4000 automobile negatively affected the demand for its sister brand, the Audi Quattro (Sullivan 1990). In general terms, such spillover phenomena can be conceptualized as the impact of external information (e.g., a product-harm crisis) on associated objects (e.g., brands) that are not directly involved (Balachander and Ghose 2003).

The cognitive process that governs these spillover effects on related entities have received little attention. The few studies that attempted to examine such spillovers have shown the extent of spillover to be a function of the relatedness between cognitive nodes. For example, Roehm and Tybout (2005) demonstrated that the spillover of a brand's corporate scandal onto competitor brands in the same product category is a function of the typicality of the affected brand and related brands. Similarly, in the study 3 (chapter 4 ), we found that a product-harm crisis influences the affected brand as well as related brands in a brand portfolio, and that such spillovers are a function of the strength of assoclative linkages between brands. In both studies, the focus on inter-brand structure stems from the conceptualization of spillover as a network effect, in which properties of the network structure play an important role in predicting the pattern of spillover effects.

In this study, we examine two additional factors that may predict the extent of spillover. Specifically, we suggest that the extent of spillover is likely to be a function of not only the properties of the cognitive structure through which negative information spreads, but also the characteristics of the information travelling through the metwork and the nature of processing that negative information undergoes. Hence, the objective of this study is to investigate the impact of information characteristics, processing characteristics, and their 
interaction with the cognitive structure representing brand networks on the pattern of spillover effects.

We study these effects by introducing product-harm crises at varying subbrands in a brand portfolio, predicting and observing the indirect consequences on the parent brand and other sub-brands. Findings from three experiments designed to test predictions about patterns of spillover are reported. The first experiment tests the impact of information characteristics, specifically crisis severity, and its interaction with the primary feature of inter-brand structure, the strength of association between brands, on the pattern of spillover effects in a brand portfolio. The second experiment examines the corresponding effects for processing characteristics, namely the attribution of negative information. The third experiment is designed to investigate a three-way interaction between crisis severity, attribution, and strength of association. We conclude with the discussion of theoretical and managerial implications for spillover effects of negative information in a brand portfolio.

\subsection{Negative Spillovers in Brand Portfolios}

As we discussed in study 3 (chapter 4), brands in a portfolio are not cognitively independent in the way that consumers represent them in memory. Based on network association theory (e.g., Anderson 1983), we view brands in a portfolio as information nodes in an associative network. In such a network, the stimulation of a brand node (referred to as the origin node) can spread to other brand nodes (referred to as the destination node) through associative linkages. When a node is stimulated above a given threshold level, it is "activated" in that information represented by this node is retrieved into working memory. Retrieval allows the information to be processed, and if necessary, updated. The extent of updating at destination nodes can be predicted on the basis of the primary feature of an associative network, namely the strength of association between brand nodes. Strength of association is a function of the extent of associative relatedness between two concepts, for example a brand-brand relationship (e.g., Morrin 1999).

Roehm and Tybout (2005) and our study 3 have investigated the nature of spillover of negative information in such cognitive networks. In these studies the properties of negative information were kept uniform and invariant across experimental scenarios. However, the nature of information may well influence 
how it is processed in a network and therefore the pattern of its spillover. For instance, one important attribute of negative information is its severity (Herr, Kardes, and $\mathrm{Kim}$ 1991). Extremely negative information draws more attention and a greater level of cognitive elaboration on the information. This in turn leads to a greater extent of cognitive activation at the affected brand and consequently greater updating of beliefs about related brands, or in our terminology, greater spillover.

Furthermore, although both studies examined the effects of processing negative information in terms of their impacts on brand evaluations, the processes involved in arriving at those outcomes, such as the nature of attributions about negative information, were not considered. Attribution is "part of the process" (Kelley 1973, p.107) by which consumers form beliefs about an object based on incoming information, especially when the information being processed is negative and unexpected (e.g., Folkes 1988; Jorgensen 1994). Research in attribution theory demonstrates that consumers are rational information processors and their reactions to negative information are influenced by causal inferences (Folkes 1984). Hence, different attributions of a negative incident can induce different emotional reactions that could be generalized to related products/brands (Weiner 2000), in other words, leading to different spillover effects. Hence, building on prior studies, we expect the characteristics of the information itself (e.g., severity) and the characteristics of processing (e.g attribution) to moderate the spillover effect between brands.

\subsection{Impact of Crisis Severity on Spillover Effects}

Negative information has been shown to be more influential than positive information in forming consumers' overall product evaluations (e.g., Skowronski and Carlston 1989). This phenomenon is termed the negativity effect and has been documented in a variety of streams of literature, including impression formation, persuasion, and decision making, in both the person perception and product evaluation contexts (Ahluwalia, Burnkrant, and Unnava 2000; Klein and Shiv 1996; Skowronski and Carlston 1989; Weinberger, Allen, and Dillon 1981).

A common explanation for the negativity effect is that negative information is considered more diagnostic and informative than positive information. Diagnosticity refers to as the relevance or usefulness of information that helps consumers to categorize an object into the implied category and 
distinguish it from other non-category members (Feldman and Lynch 1988; Keller and Sood 2003). However, it is important to note that the greater diagnosticity of negative information (vs. positive information) is not due to its negative valence, but rather because it is statistically rare, distinctive, and nonmodal (Scott and Tybout 1981). This is particularly true for information about brands in the marketplace. Much information in the marketplace about brands is positive (e.g., positive brand evaluation, appraisai), persuasive (e.g.; advertisements), or neutral (e.g., price information). Building on these arguments, we argue that the potential impact of negative information is influenced by features determining its rarity and distinctiveness. One such feature is the severity level of negative information (Herr, Kardes, and Kim 1991).

The results of our study 3 have shown that, in a presumed brand network (Figure 5.1), a crisis at an origin brand (e.g., sub brand A) has greater spillovers on brand evaluations of a strongly associated destination brand (e.g., sub-brand B) than on brand evaluations of a weakly associated destination brand (e.g., subbrand $C$ ). In this study, we are interested in examining whether such a structural effect will be magnified or attenuated by the characteristics of the information spreading through the network. Specifically, we examine how the level of crisis severity influences the positive relationship between strength of association and spillover.

\section{Figure 5.1: An Example Associative Brand Network}

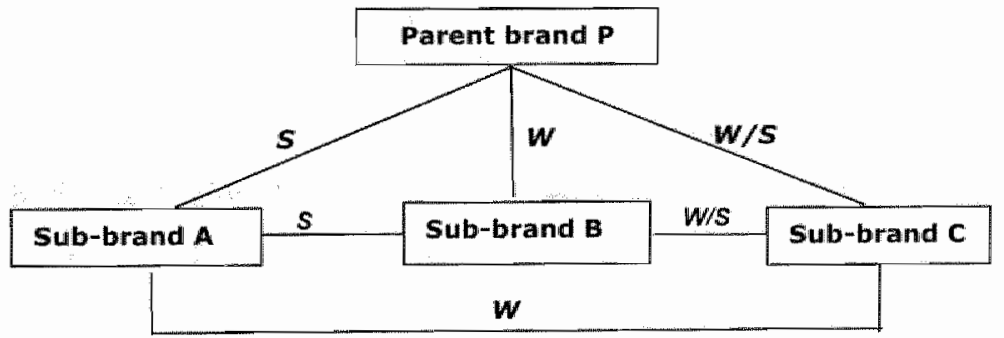

The extent of spillover at a destination node positively relates to the strength of its associative linkage with the origin node, as strong links facilitate the transfer of activation from the origin node to the destination node. However, based on network association theory (e.g., Anderson 1983), the efficiency of these associative linkages in conveying activation depends on the level of 
activation initiated at the origin node. The level of initiated activation is a function of the frequency, recency, and salience of the priming information (Nedungadi 1990) that affects the level of information processing at the origin brand. A severe crisis (vs. non-severe crisis) attracts greater cognitive attention and leads to considerable information elaboration at the origin brand (Nedungadi 1990; Peter and Olson 2005; Skowronski and Carlston 1987). Thus a severe crisis will stimulate a lhigher level of activation at the origin node than does a non-severe crisls. A high level of activation at the origin node can strengthen the positive relationship between strength of association and spillover by magnifying the differences of spillovers between strongly associated nodes (high activation transmitted, large spillover expected) and weakly associated nodes (low activation transmitted, small spillover or no spillover expected). On the contrary, a low level of activation at the origin node weakens the effect of strength of association on spillovers as the amount of activation that could be potentially transferred to the destination node via associative linkages is limited. Therefore, we expect that the positive relationship between strength of association and spillover will be stronger when the crisis is severe than when it is non-severe. We hypothesize that:

H1: The positive relationship between strength of association and spillover on brand evaluations is stronger when a crisis is severe than when it is not severe. This hypothesis holds for

a) the spillover of crises at a sub-brand to brand evaluations of the parent brand; b) the spillover of crises at a sub-brand to brand evaluations of other sub-brands.

\subsection{Impact of Crisis Attribution on Spillover Effects}

Consumers' cognitive and affective reactions to a negative incident have been shown to be central to understanding consumers' subsequent behavior (Folkes and Kotsos 1986; Manrai and Gardner 1991). For instance, Weiner and Handel (1985) indicate that there is general positive or negative emotion following the outcome (e.g., the success or failure) of an event. These "outcomedependent" emotions can exert a significant influence on subsequent consumer evaluations and behavior (Folkes 1988; Weiner 2000). For example, the negative outcome of product failure will cause negative emotions regardless the causes of the incident. 
Besides these outcome-dependent emotions, consumers' causal inferences of the incident will generate attribution-dependent emotional reactions (e.g., anger, pity, feeling hurt; Folkes 1984, Weiner and Handel 1985). Attribution theory suggests that consumers spontaneously engage in attributional activities (Harvey and Weary 1984), especially when the event is negative and unexpected, such as product failure (Folkes $1984 ; 1988$ ). In their attempt to understand the causes of product failure, consumers are saild to rely on causal inferences to form an overall judgment of responsibility or blame, which influences their subsequent behavior toward the focal brand or company (Folkes 1984; Folkes, Koletsiky and Graham 1987; Folkes and Kotsos 1986; Jorgensen 1994). Therefore, it is not merely the judgment that the product has failed that determines consumer responses, but also consumers' attribution or causal inferences about the failure (Folkes 1984).

In Weiner's (1980) widely used version of attribution theory, consumers' causal inferences are classified along three complementary dimensions. Locus of causality describes the extent to which the incident is internal or externall to the focal company; Controllability is the extent to which the incldent is within the company's control; and Stability captures whether the incident is likely to recur or is an isolated event. The three dimensions are said to differ in their impact on consumer behavior. Folkes (1984) argues that Controllability and Locus influence whether consumers blame the company and are angry with the company. Weiner (2000) also suggests that these two dimensions enable consumers to determine responsibility for the incident. Stability, on the other hand, influences consumers" expectancy of whether the incident will occur again in the future. Attributions to unstable reasons lead to uncertainties about future outcomes, whereas attributions to stable reasons make consumers expect the same outcome in the future (Folkes 1984; Weiner 1980).

In a brand network, a crisis that is considered by consumers to be internal and controllable increases attributions of blame and generates negative emotions (such as anger, regret, and desire for revenge) toward the brand (Folkes 1984 ; Tsiros and Mittal 2000). The attribution of blame and negative emotions will stimulate a high level of cognitive activation at the origin brand. As we argued earlier, a high level of activation at the origin node can increase the efficiency of strength of association in conveying activation from the origin node to the destination node, and therefore strengthens the positive relationship between 
strength of association and spillover. On the other hand, if consumers attribute a crisis to external and uncontrollable causes, they will have less affective reactions toward the origin brand (vs. internal and controllable attribution). In this situation, the effect of strength of association on spillover will be weakened as the maximal activation that could be possibly transferred to the destination brand is limited, regardless of the strength of associative links. Furthermore, consumers kend to blame the actor (the consumer who causes the incident) or the situational factor (e.g, the weather, a retailer) when the crisis is attributed to external and uncontrollable causes, which makes consumers believe that the incident is situation or consumer specific. This distracts consumers' attention from the origin brand and weakens the impact of inter-brand structure ( $i_{\text {. }}$. strength of association) on the spillover effects at the destination brand. Therefore, we hypothesize that:

H2: The positive relationship between strength of assaciation and spillover on brand evaluations is stronger when a crisis is attributed to be more internal and controllable than external and uncontrollable. This hypothesis holds for

a) the spillover of crises at a sub-brand to brand evaluations of the parent brand; b) the spillover of crises at a sub-brand to brand evaluations of other sub-brands.

\subsection{Experiment 1}

The purpose of Experiment 1 is to examine whether crisis severity moderates the impact of strength of association on spillover. 197 students participated in the main experiment, $50.5 \%$ were female, and no systematic gender differences were found.

\subsubsection{Pretests}

We used the same brand portfollo of Ola with three sub-brands (Raket, Magnum, and Cornetto) for experiment 1 based on the pretests in our study 3 (chapter 4). In the Ola portfolio, the parent brand Ola has weaker associations with the sub-brand Raket than with both the sub-brands Magnum (RT [response time]: $1484 \mathrm{~ms}$ vs. $836 \mathrm{~ms}$ [millisecond], $p<0.05)$ and Cornetto $(1186 \mathrm{~ms}$ vs. $880 \mathrm{~ms}, p<0.05)$. Magnum and Cornetto are equivalent in their strength of association with Ola ( $902 \mathrm{~ms}$ vs. $855 \mathrm{~ms}$, $\mathrm{p}>0.10$ ). Furthermore, Magnum has stronger associations with Cornetto than with Raket $(5.00$ vs. 2.34, $p<0.001$; $7=$ strong), and reciprocally, Cornetto has stronger associations with Magnum 
than with Raket (5.00 vs. $2.69, p<0.001$ ). Finally, the strength of the Cornetto Raket and Magnum-Raket association is equivalent $(p>0.10)$.

We conducted an additional pretest to test the manipulation of crisis severity. After carefully reading the stories, 64 respondents were requested to answer whether the described incident was severe, dangerous, and serious on seven-point scales $\left(" 7^{\prime \prime}=\right.$ severe, dangerous, and serlous, Cronbach's alpha $=0.88$ ). The results show that severe crises were perceived significantly more severe than non-severe crises ( 5.68 vs. $3.71, p<0.001$ ). The non-severe crisis described a minor quality problem that caused consumers to feel light uneasiness whereas the severe crisis described a major quality problem that caused consumers to fall ill.

\subsubsection{Experiment Procedure}

A $2 * 2$ between subject factorial desigm was employed in the experiment, with one between subject factor for severity (severe vs. non-severe) and the ather factor for strength of association (strong vs. weak). The locus of productharm crises was manipulated (expose crisis stories at the sub-brand Raket or Cornetto), as a means of varying strength of association.

197 respondents were randomly assigned to one of the four experimental scenarios and one control group. In each experiment group, after carefully reading a crisis story, respondents were then asked to evaluate the sub-brand Magnum, Cornetto, and Raket in a randomized order, and then they were asked to evaluate the parent brand Ola. Next, respondents reported their knowledge of whether Ola and its sub-brands are related. Finally, respondents evaluated perceived severity of crisis stories on a seven-point scale (Not at all severe Very severe), and provided demographic information. Respondents were then debriefed and thanked for their participation.

\subsubsection{Dependent Variables}

We employ the same composite measurement of brand evaluations as we used in the study 3 as the dependent variable in this study. The measurement includes dimensions of brand attitude, brand trust, perceived quality of the brand and the product, brand purchase likelihood, and brand desirability (Cronbach alpha $=0.92)$ (Dawar and Pillutla 2000; Klein and Dawar 2004). The mean of the ten-item scale serves as the dependent variable. 


\subsubsection{Results}

The manipulation check shows that severe crises at both Cornetto and Paket are perceived significantly more severe than non-severe crises (Cometto: 4.95 vs. 3.24, $<<0.001$; Raket: 4.63 vs. 2.96, p<0.001). There are no significant differences between each severe crises and between each non-severe crises (all $\left.p^{\prime} s>0.10\right)$. The result also shows that Cornetto and Raket both receive lower evaluations when the crisis exposed at the two brands is severe than when it is not severe (Cornetto: 2.39 vs. 3.94, p<0.001; Raket: 2.64 v5. 3.96, p<0.001). These results indicate that our manipulation of crisis severity has the intended effect.

H1a proposes that severity moderates the impact of strength of association on the spillover of sub-brand crises at the parent brand. Since the effect of strength of association on spillover is measured by comparing brand evaluations in different crisis conditions with brand evaluations in the same control group, we test for the following interaction: whether the difference of parent brand evaluations (between the Raket and the Cornetto crisis condition) is greater when the crisis is severe than when it is not severe. A $2 * 2$ between subject ANOVA (severity * crisis) yields a significant interaction term ( $F(1,4.859)$ $=3.91, p=0.05)$. It confirms that the difference of ola brand evaluations (between the Raket and the Cornetto crisis) is greater when the crisis is severe (4.57 vs. 3.64, p<0.01) than when it is not severe $(4.58$ vs. $4.46, p>0.10)$. Hence, $\mathrm{H} 1 \mathrm{a}$ is supported. The mean differences of Ola brand evaluations are presented in figure 5.2 (panel 1).

$\mathrm{HIb}$ proposes that severity moderates the impact of strength of association on spillover between sub-brands. We test the hypothesis by examining the impact of Raket and Cornetto crises with different severity manipulations on Magnum brand evaluations. A $2 * 2$ between subject ANOVA (severity * crisis) yields a significant interaction term $(F(1,11.756)=8.93$, $p<0.05$ ). It confirms that the difference of Magnum brand evaluations (between the Raket and the Cornetto crisis) is greater when the crisis is severe (4.91 vs. $3.77, p<0.001$ ) than when it is not severe (4.75 vs. $4.72, p>0.10)$. Therefore $\mathrm{HIb}$ is supported. The mean differences of Magnum brand evaluations are presented in figure 5.2 (panel 2). 
Figure 5.2: Mean Differences of Brand Evaluations in Experiment 1

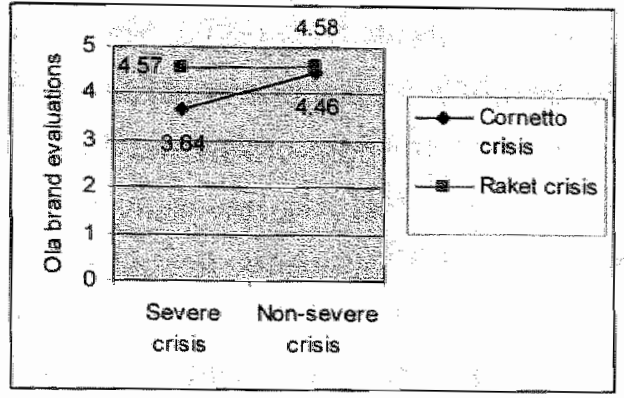

Panel 1

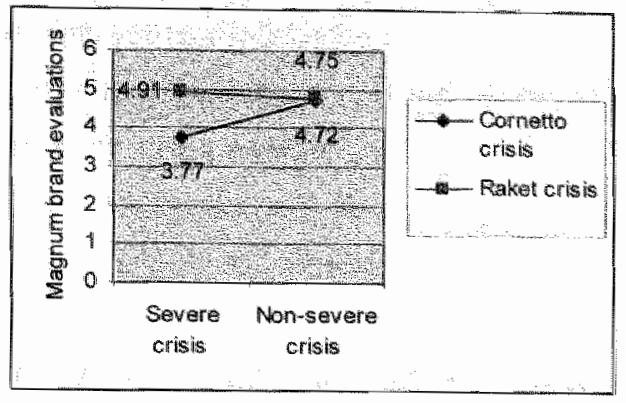

Panel 2

\subsubsection{Discussion}

The results of Experiment 1 show that when the crisis is severe, it has a greater spillover effect on the strongly associated sub-brand than on the weakly associated sub-brand. However, when the crisis is not severe, the strength of association between the origin brand and the destination brand does not influence the magnitude of spillover effects. This result indicates that the positive relationship between strength of association and the magnitude of spillover in a brand network is conditioned to information characteristics such as the level of crisis severity.

\subsection{Experiment 2}

The purpose of Experiment 2 is to examine whether crisis attribution moderates the impact of strength of association on spillover. We focus on the locus and controllability dimension for the manipulation of attribution for two reasons. First, these two dimensions determine the perception of responsibility (Folkes 1984; Jorgensen 1994; Tsiros, Mittal, and Ross 2004) and therefore consumers' brand evaluations (Klein and Dawar 2004) that are measured as the indicator of spillover. Second, due to the unexpected nature of product harm crises used as experimental stimuli in this study, respondents found it difficult to differentiate stable causes from unstable causes and crises with obviously stable causes unrealistic.

\subsubsection{Pretests}

We selected the Nestle brand portfolio (with sub-brand Nescafe, Nestea, KitKat) for experiment 2 based on the results of pretests in study 3 (chapter 4 ). 
In the Nestle brand portolio, the parent brand Nestle has weaker associations with the sub-brand Nescafe than with both the sub-brands Nestea (RT [response time]: $1814 \mathrm{~ms}$ vs. $1314 \mathrm{~ms}$ [millisecond], $p<0,05)$ and KitKat (1676ms vs, $1313 \mathrm{~ms}, \mathrm{p}<0.05)$. Nestea and KitKat have equivalent strength of association with Nestle (1324ms vs, $1322 \mathrm{~ms}$, p $>0,10)$. Furthermore, Nescafe has significantly stronger associations with Nestea than with KitKat (4.52 vs. $3.17, p<0.05)$, and reciprocally, Nestea has significantly stronger associations with Nescafe than with Kitkat (4.52 vs. 3.14, $p=0.01)$. Finally, the strength of the Nescafe-KitKat and Nestea-KitKat association is equivalent $(p>0.10)$.

An additional pretest was conducted to design the manipulation of attribution. Four versions of questionnaires with two fictitious crises for each level of attribution (internal/controllable, internal/uncontrollable, external/controllable, and external/uncontrollable) were randomly distributed to 118 respondents. After carefully reading the stories, respondents were requested to answer 1) whether the described incident was internal or external to the brand; 2) whether it was controllable or uncontrollable by the brand; 3) whether it was realistic and imaginable. Based on the pretest results, we excluded the external/controllable scenario as crises with external but controllable causes were considered unrealistic and hard to imagine. Hence we took three levels of attribution manipulation in the main experiment. The external/uncontrollable scenario described a quality problem caused by weather (storm), the internal/uncontrollable scenario described a quality problem caused by an employee who unintentionally made a mistake, and the internal/controllable scenario described a quality problem caused by the poorly-maintained machinery.

\subsubsection{Experiment Procedure}

A $3 * 2$ between subject factorial design was employed in this experiment, with one between subject factor for attribution (internal/controllable, internal/uncontrollable, and external/uncontrollable) and the other factor for strength of association (strong vs. weak). The locus of the product-harm crisis was manipulated (expose crisis stories at the sub-brand Nescafe or Nestea), as a means of varying strength of association. 285 respondents were randomly assigned to one of the six experimental scenarios and one control group. The rest of the experiment procedure was similar to experiment 1. 


\subsubsection{Results}

The manipulation check shows that the perceived locus is significantly different (all p's<0.001; $1=$ internal attribution) between both external attribution conditions $(5.62,5.73)$ and four internal attribution conditions $(2.43,2.61,2.25$; 2.58). Furthermore, the perceived controllability is significantly different (all p's<0.001; 1=uncontrollable attribution) between both controllable attribution conditions $(5.71 ; 5.77)$ and four uncontrollable attribution conditions $(2.48 ; 2.62$; $2.65 ; 2.61$ ). The results also show that there are no significant differences between scenarios with the same manipulation with respect to perceived locus, controllability, and crisis severity (all $p$ "s $>0.10$ ).

$\mathrm{H} 2 \mathrm{a}$ proposes that crisis attribution moderates the impact of strength of association on the spillover of sub-brand crises at the parent brand evaluations. A $3 * 2$ between subject ANOVA (attribution * crisis) vields a marginally significant, interaction term $(F(1,3.816)=2.80, p=0.063)$. It shows that the difference of Nestle brand evaluations (between the Nescafe and the Nestea crisis condition) is the largest when the attribution is internal/controllable ( 3.37 vs. $2.39, p<0.01$ ), moderate when the attribution is internal/uncontrollable ( 3.43 vs. $2.94, p>0.10$ ), and the smallest when the attribution is external/uncontrollable (3.90 vs. 3.86 , $p>0.10$ ). Hence, $\mathrm{H} 2 \mathrm{a}$ is marginally supported. The mean differences of Nestle brand evaluations are presented in figure 5.3 (panel 1 ).

$\mathrm{H} 2 \mathrm{~b}$ predicts the moderating effect of crisis attribution in the strength of association-spillover relationship among sub-brands. We test this hypothesis by examining the difference between Nestea brand evaluations and Kitkat brand evaluations in Nescafe crises with different attribution manipulations. A $3 * 2$ (strength of association * attribution) mixed ANOVA with the repeated measure for strength of association and the between subject factor for attribution yields a significant interaction term $(F(1,2.964)=4.58, p<0.05)$. It confirms that the difference of brand evaluations (between Nestea and Kitkat) is the largest when the Nescafe crisis is attributed as internal/controllable ( 2.92 vs. $4.17, \mathrm{p}<0.001$ ), moderate when the crisis is attributed as internal/uncontrollable (3.29 vs. 4.49, $p<0.001$ ), and the smallest when the crisis is attributed as external/uncontrollable ( 4.10 vs. $4.67, \mathrm{p}<0.01$ ). Hence, $\mathrm{H} 2 \mathrm{~b}$ is supported. The mean differences of Nestea and KitKat evaluations are presented in figure 5.3 (panel 2). 
Figurie 5.3: Malean Differences of Brand Evaluations in Experiment 2

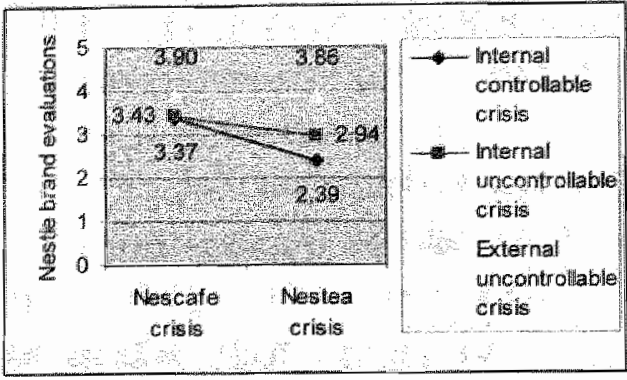

Panel 1

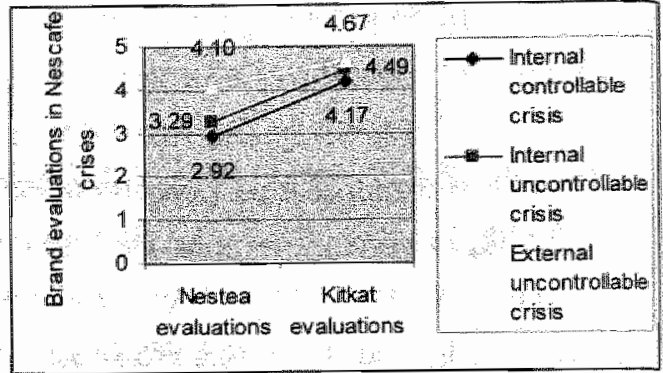

Panel' 2

\subsubsection{Discussion}

The results of Experiment 2 show that the effect of strength of association on spillover becomes stronger as the crisis is attributed to be more internal and controllable. Experiment 1 and 2 examine the moderating effect of severity and attribution in the strength of association-spillover relationship respectively. However, severity and attribution may have a multiplicative moderating effect on this relationship. For instance, a severe crisis with internal and controllable causes may generate a greater amount of activation at the origin brand than the additive effect of two crises with either severe consequences or internal/controllable causes. Therefore we conducted experiment 3 to test the three-way interaction of severity, attribution, and strength of association on spillover.

\subsection{Experiment 3}

As we discussed earlier, conscious attribution of responsibility stimulates high level of activation at the origin brand, which increases the impact of strength of association on spillovers. However, Lord and Smith (1983) argue that not all attribution activities involve a controlled cognitive process. On the contrary, in some instances, individuals may respond to external cues in an automatic or "mindlless" manner with little effort and attention. Lord and Smith indicate that these different types of attribution activities are resulted from different levels of information processing when the information is encoded. When the level of information processing is high (vs. low), attributors are more likely to 1) actively make causal assessments rather than passively; 2) consciously attribute responsibility rather than heuristically. One of the important factors that 
influence the level of information processing is extent to which the stimuli exposed to attributors are salient (Harvey and Weary 1984; Taylor and Fiske 1975). The salience of stimuli (e.g., crises) could be influenced by information characteristics that are prominent in consumers' view, such as severity, vividness, etc (Peter and Olson 2005). Thus, a severe crisis (vs. non-severe crisis) can stimulate a higher level of information processing, which evokes a more effortful attribution process and therefore more intense activation at the origin brand. Therefore, we expect crisis severity to influence the effect of attribution in moderating the strength of association-spillover relationship.

H3: Crisis severity moderates the effect of crisis attribution in the strength of association-spillover relationship. Specifically, the moderating effect of crisis attribution is stronger when a crisis is severe than when it is not severe.

\subsubsection{Experiment Procedure}

To simplify the experimental procedure, we focus on the spillover between sub-brands in this experiment. A $2 * 2 * 2$ between-within subject mixed design was employed in the experiment, with one between subject factor for severity (high vs. low), one between subject factor for attribution (internal/controllable vs. external/uncontrollable), and one within subject factor for strength of association (strong vs. weak). 171 respondents were randomly assigned to one of the four experimental scenarios in which crises with varying levels of severity and attribution manipulations were exposed at the sub-brand Cornetto in the Ola brand portfolio. The rest of the experiment procedure is similar to that in experiment 1.

\subsubsection{Results}

The manipulation check shows that the perceived locus is significantly different between the internal and the external attribution condition for both severe crises ( 2.41 vs. $5.56, p<0.001 ; 1=$ internal attribution) and non-severe crises ( 2.23 vs. $5.52, p<0.001$ ). Furthermore, the perceived controllability is significantly different between the controllable and the uncontrollable condition for both severe crises ( 1.91 vs. $5.20, p<0.001 ; 1=$ controllable attribution) and non-severe crises $(2.05$ vs. $5.48, p<0.001)$. The results also show that the perceived severity is significantly different between the severe and the nonsevere condition for both internal/controllable crises ( 4.86 vs. $3.45 ; p<0.01$; 
$1=10 w$ severity) and external/uncontrollable crises (4.24 vs. $3.41, p<0.05$ ). Finally, there are no significant differences found between crises with the same manipulation in terms of locus, controllability, and severity (all $p$ "s $>0.10$ ).

$\mathrm{H} 3$ expects that severity strengthens the moderating effect of attribution in the strength of association-spillover relationship. We test this hypothesis by examining the moderating effect of crisis attribution on the influence of Cornetto crises on Raket and Magnum evaluations in different crisis severity manipulations. A mixed $2 * 2 * 2$ (severity*attribution*strength of association) ANOVA yields a significant three way interaction term $(F(1,3.553)=4.50, p<0.05)$. Our results show that the moderating effect of attribution in the strength of associationspillover relationship is much stronger when the crisis is severe than when it is non-severe. In panel 1 of figure 5.4 where the crisis is severe, the effect of strength of association on spillover is stronger when the attribution is internal/controllable than when it is external/uncontrollable. A contrast $(4.26-$ 3.70 vs. $4.44-4.83)$ is significant $(p<0.05)$ and confirms this. Conversely, in panel 2 of figure 5.4 where the crisis is not severe, there is no significant effect of attribution in the strength of association-spillover relationship. We conducted the contrast (4.66-4.27 vs: 5.16-4.62) and found it to be non-significant $(p>0.10)$. Hence, our hypothesis 3 is supported.

\section{Figure 5,4: Mean Differences of Brand Evaluations in Experiment 3}

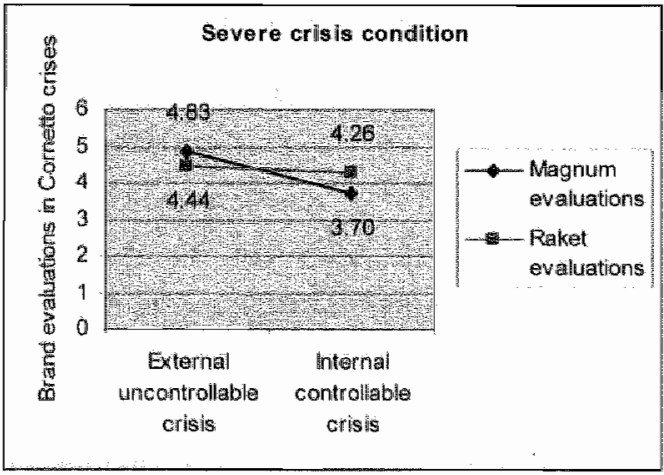

Panel $\mathbf{t}$

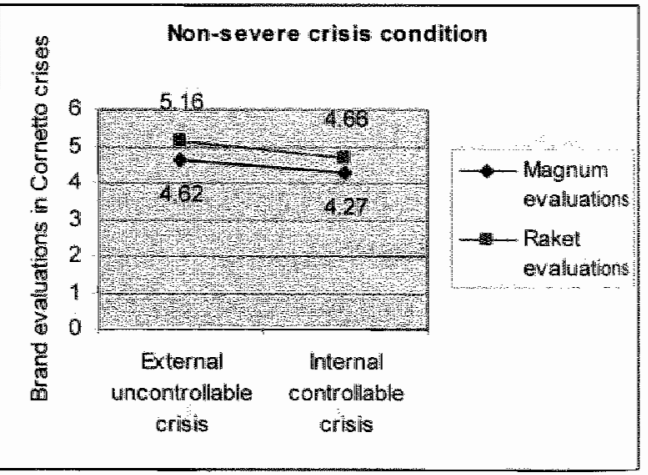

Panel 2

\subsection{General Discussion}

The results of our study 3 (chapter 4) have shown that negative information at a brand may negatively influence related brands in a cognitive 
brand network, and the magnitude of such spillover is positively influenced by the strength of associative linkages between brands. In this study, we examine the boundary conditions of this positive relationship between strength of association and spillover and we find that the influence of strength of association on spillover is conditioned to the nature of information spread through the network and the characteristics of information processing evoked.

We find that the strength of association-spillover relationship is positive when the crisis is severe and non-significant when the crisis is not severe. This corroborates Scott and Tybout's (1981) statement that the strength of priming is not determined by the valence of information but the distinctiveness of information. A severe crisis is more rare and distinctive; and therefore it is more diagnostic than a non-severe crisis. More diagnostic information attracts more attention and stimulates a stronger priming effect and therefore a higher level of activation at the origin brand, which strengthens the impact of strength of association on spillover effects between brands. In addition, our results suggest that a crisis attributed to be more internal and controllable (vs. external and uncontrollable) will cause more intense negative emotions and therefore strengthen the spillover conveyed via inter-brand linkages. Furthermore, in the analysis for spillover between sub-brands, we found that locus has a greater influence than controllability in strengthening the impact of strength of association on spillovers. This result might be due to the fact that perceivers often assign responsibility for "role-related" outcomes to role occupants (Lord and Smith 1983). In other words, consumers may assume that companies involved in the crisis incident, through different actions, could have produced different outcomes and therefore should be responsible for the consequences, as long as the incident is caused by an internal reason.

Furthermore, the multiplicative moderating effect of severity and attribution in the strength of association-spillover relationship indicates that the nature of information and how the information is processed can influence the magnitude of spillover simultaneously. This result may also be explained by Petty and Cacioppo's (1986) central-peripheral framework that discusses consumers' cognitive activity during the causal attribution process. Specifically, when a crisis is not severe, consumers feel that the situation is under control and therefore have less motivation to collect information when making attributions (Folkes and Keisler 1991). However, when the crisis is severe, consumers feel the pressure to 
Understand the situation and therefore have higher motivation to make causal attributions. According to Petty and Cacioppo, motivation as one of the causal antecedents affects both the attributions made by consumers and the processing path that consumers use. In particular, consumers will take the peripheral path in the non-severe crisis situation and the central path in the severe crisis situation. OMalley Jr.(1996) indicates that consumers who use a central processing path when making attributions will experience more intense emotions (e.g., anger) and will attribute more causal responsibility to companies than consumers who use a peripheral processing path. The more intense emotions and stronger attribution of responsibility in the severe crisis situation (vs . non-severe crisis situation) will consequently strengthen the impact of strength of association on spillower between brands.

In conclusion, this study suggests boundary conditions for the impact of negative information, and therefore provides marketers with knowledge of situations in which spillover is likely to be strengthened, attenuated, or even diminished. The results of this study indicate that although spillover is conceptualized as a network effect, whether the properties of network structure predict the pattern of spillover is dependent on the characteristics of information and information processing. Currently, most companies use a "mass approach" in responding to negative publicity (Ahluwalia et al. 2000). The results of this study indicate that, when a crisis is severe and/or attributed to internal and controllable causes, it is very likely that brands in a portfolio receive different levels of spillover from the affected brand, depending on the level of perceived relatedness among brands in the portfollo. Therefore, managers should use different response strategies to remedy the crisis situation safely and effectively. On the contrary, when the crisis is not severe and/or attributed to external and uncontrollable causes, it is maybe more efficient to address all related brands in a portfolio with a general response.

\section{5:9 Limitations and Future Research}

Despite the interesting findings of this study, we need to acknowledge a few limitations. First, we manipulated crisis severity by describing different consequences of product quality problems on consumers" health safety. However, the level of severity may be interpreted in other ways such as the level of monetary and time-wise consequences (Craighead, Krawan, and Miller 2004). 
Future research may select different forms of negative information with different severity manipulations to investigate their impacts on the spillover effect.

One of the critical aspects in consumer-oriented attribution is the choice of an attributional focus, such as the object-perception (e.g., attributions about why a product performs the way it did) or person-perception (e.g., why a person says what 5 /he said) (Mizerski, Golden, and Kernan 1979). In this study, we focused on the object-perception when examining the impact of attribution on spillover. However, in many situations, the attribution of negative information involves person-perception or a mix of object- and person-perception. For example, when negative word of mouth about a brand spreads, consumers may first apply principles of person-perception to assess beliefs concerning source credibility, and then apply object-perception to make causal inferences. Such a complex attribution process may have different impacts on the spillover effect than what we have examined in this study. Therefore, future research could investigate whether different attribution focuses lead to different moderating effects of attributions.

Furthermore, besides the characteristics of information and information processing, the goal of information processing may also influence the impact of strength of association on spillover. For instance, outcome-goal driven consumers are more risk-averse and likely to perceive negative information to be more diagnostic than impression- and position-involved consumers (Ahluwalia 2002). The perceived diagnosticity of information in turn determines the pattern of spillover conveyed via associative linkages. Thus, future studies may also investigate the impact of different processing goals on the spillover effect spread through a brand network via associative linkages. 

CHAPTER 6: CONCLUSION 
"The great thing in this world is not so much where we are, but in what direction we are moving (Oliver Wendell Holmes, in Aaker 1996, p27)

"Brands have become the barrier to entry, but they are also the means to entry." (Edward Tauber, in Aaker 1991, p27)

\subsection{Synopsis}

For year 2005, Coca-Cola once again is the top one brand on the Interbrand's list of the World's most valuable brands, with an estimated value of 68 billion US dollars. This value is more than half of Coca-Cola's market value, and 10 times of its book value. However, the mere introduction of such a brand can involve an investment of from 50 million to well over 150 million US dollars (Aaker 1991), not to mention the huge amount of effort and money spent on building performance, personality, and trust in the brand. Yet none of these guarantees success. Therefore various brand leveraging strategies become important resources for companies to capitalize on the existing successful brands. Companies may use an established brand to penetrate new product categories (i.e. brand extensions) or introduce new variants in the same product category (i.e. line extensions). They may also associate a strong brand with newly introduced or weak brands to strengthen their market performance (i.e. brand architecture). However, as Aaker (1991) indicated, "it is not all peaches and

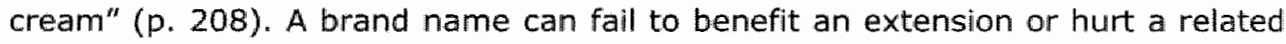
brand, and these beneficiary entities (extensions and related brands) can also dilute or damage the original brand image, cannibalize its sales, and weaken its market position by increasing competition in its product category (e.g., Kumar 2005). Even though studies have been conducted to investigate the optimal ways to leverage a brand and avoid the negative consequences, they maimly focused on the goods context, limited formats of extensions, and scenarios of single brand equity leveraging. In order to provide a broader and deeper understanding of brand leveraging strategles, the central research question of this dissertation was:

What are the benefits and risks of brand leveraging strategies in different contexts, formats, and market scenarios? 
This main research question was addressed in four research projects. Each project was described in one chapter of this dissertation. Chapter 2 (studv 1) investigated consumer responses to cross-extended products (1.e. extending from services to goods or vice versa). In chapter 3 (study 2), we examined consumer reactions to vertical line extensions in a service setting. These two studies aim to validate current extension models in different contexts and extension formats. These two studies also complement the existing extension studies through identifying additional influential factors on consumer evaluations of extensions. Given the increasingly complex market situation, brand managers often have to manage brand portfolios involving multiplie brands and sub-brands. A brand architecture strategy leverages the equity of multiple brands by specifying brand roles and relationships between brands. In order to study the leveraging effects of brand architecture, Chapter 4 (study 3 ) conceptualized the cognitive structure of brand architecture as an associative network and examined the spillover effect of negative information in such networks. Chapter 5 (study 4) identified the boundary conditions of the negative spillover effects discussed in chapter 4 through examining the moderating effect of information characteristics and processing characteristics.

Overall; this dissertation focused on three types of brand levering strategies in terms of their benefits and risks: (1) brand extension, (2) line extension, and (3) brand architecture. The remainder of this chapter provides an overview of the four studies' findings including theoretical and managerial implications. Finally, the chapter concludes with general suggestions for future research in the area of brand leveraging strategles.

\subsection{The Influence of Service Intensiveness on Brand Extension Evaluations}

Brand extensions have been the source of strategic growth for many firms (Aaker 1991). Past research on extension evaluations has traditionally focused on the perceived similarities between extensions and the parent brand in terms of product features, usage situations, user types, product/brand images, and technology levels. We focused on another important dimension, the relative service intensiveness of extensions compared to the parent brand, and examined its effect on consumer evaluations of brand extensions. The service component has become an important part of a product, and it influences how consumers 
evaluate the quality of the product. Many extensions contain different levels of service components compared to their parent brands, regardless of the product category similarities between these extensions and their parent brands. This dimension is particularly relevant for cross-extensions in which service-intensive extensions are developed from goods-intensive parent brands, or vice versa. In an experimental setting, we found that evaluations of brand extensions were influenced by the relative service intensiveness of extensions and the parent brand. When a parent brand is more service intensive than its extensions, consumers perceive less risk and therefore have higher evaluations toward the extensions. Thus, a high service level associated with the parent brand can be an important source of brand equity. Companies intending to diversify their product portfollos through intraducing more goods-intensive products can emphasize the parent brand's service aspect as a means of creating favourable brand extension evaluations: However, the use of a parent brand name may not be helpful when companies extend from a low service intensive parent brand to a high service intensive extension. Companies may overcome this limitation by either using a sub-brand name or providing potential buyers with additional information to reduce their risk perceptions associated with the purchase of extension products. In addition, we also found that the parent brand's service level plays a stronger rolle when the extension category is similar than when it is dissimilar to the parent brand category. This result validates the previous finding that brand affect is transferred more easily when there is a greater similarity between the parent brand and extension product categories. Based on these findings, we can see that, besides the traditionally examined fit dimensions (e.g., category similarity), the relative service intensiveness is an additional dimension on which a parent brand and an extension can be related. Even when the two product categories are judged to be similar, consumers can perceive the two products to be different due to their different levels of service components.

\subsection{The Role of Risk Perceptions in Vertical Line Extension Evaluations}

In contrast to their prevalence in the marketplace, research on line extensions is much less than research on brand extensions. Two underlying assumptions in the extension literature may have led to this phenomenon. First, compared to line extensions that introduce new variants in the same product categary, brand extensions help companies enter a new product category. 
Therefore, brand extensions are considered riskler, more problematic, and therefore need more strategic planning. Second, given the similarities between brand and line extensions, consumers are expected to evaluate line extensions in the similar way as they evaluate brand extensions. However, these two assumptions may not hold if researchers have given more attention to vertical line extensions beside horizontal line extensions that have been the focus of most previous studies on line extensions. Vertical line extensions, although in the same product category as the parent brand, may involve great changes from the parent product. Furthermore, extending a brand to an upscalle or downscale market is a very challenging strategy and needs careful planning (Aaker 1997).

We studied vertical line extensions in a service setting to close the gap between their popularity in practice and a lack of theoretical development. We found that the direction of extensions (step-up or step-down) influences how consumers respond to an extension, and this effect is mediated by consumers" risk perceptions toward the extension. Consumers consider a step-up extension to a more premium market riskier than a step-down extension to a more valueoriented market compared to the parent brand. This risk perception involves both performance and financial risk perspectives. As a consequence, consumers evaluate step-down extensions more positively than step-up extensions and perceive more value in the former than the latter. Furthermore, step-up extensions are perceived even riskier than step-down extensions when consumers are famillar with the parent brand and extension category.

Based on these findings, it seems that brand managers need to extend brands downward to gain the ultimate efficiency of such a strategy. However, as Kirmani et al. (1999) indicated, step-up and step-down extensions are both important means for strategic growth in many companies. Aaker (1997) also argued that, in some instances, a vertical move is more than justified because it is actually essential to survive. Therefore, it is important to know how companies may reduce consumers' risk perceptions in step-up extensions. We studied the effect of service guarantees, one of the most effective risk relievers in general service settings, on the risk perception of vertical line extensions. We found that a service guarantee can significantiy reduce consumers' financial risk perception in step-up extensions but it has no effect on financial risk in step-down extensions. A more encouraging result is that a service guarantee mitigates performance risk in both step-up and step-down extensions. In light of these 
results, companies are suggested to employ service guarantees as an effective risk reliever in vertical ine extensions, especially in step-up extensions. Once we know companies can influence consumers responses to vertical line extensions by introducing company-controlled marketing variables (e.g., service guarantees), another question becomes relevant: should companies apply the same marketing variable to all consumers? To answer this question, we investigated the effect of service guarantees on perceived risk for consumers with varying levels of prior knowledge. We found that the level of prior knowledge did not influence the effectiveness of service guarantees. This again shows that providing service guarantees is a powerful marketing tool for alleviating risk perceptions in vertical service lïne extensions.

\subsection{Negative Spillovers în Brand Architecture}

Extension strategies enable companies to capitalize on single brand equity for new product introductions. However, by using a brand architecture strategy, managers can achieve clarity and synergy among multiple brands in a brand portfolio. However, one of the negative consequences of the brand architecture strategy is that negative information (e.g., product-harm crises) about one brand in a portfolio can harm consumer evaluations of other brands that are not directly involved in the information.

We have shown that the extent of this spillover effect is positively related to the strength of associative linkages between brands in a portfolio. Many firms intentionally increase the strength of associations between brands in a portfolio to achieve the potential benefits of marketing efficiency. For instance, Procter \& Gamble presents all major sub-brands in an extensive commercial in the Asia market, and claims, "we are all family members of Procter and Gamble". Unilever and S.C. Johnson also intend to build associations between brands by placing the corporate parent brand on product packages and advertisements of their subbrands. Our studies have shown that the potential benefits of brand architecture (Aaker and Joachimsthaler 2000) need to be weighted against the risks of negative spillovers when one brand suffers an adverse event. As part of an associative brand network, brands are vulnerable not just to the risks inherent in their own products and actions, but also to those of other brands in the network.

Furthermore, this negative consequence is not limited to the impact of negative events occurred at brands in a portfolio. For instance, consumers may 
infer the attributes of one brand based on the hformation of other brands in the portfolio. The inferred product attribute information may not be accurate and can even lead to unfavourable product evaluations. For example, if a consumer perceives the taste of Kellogg's Cornflakes to be sweeter than other cereal brands, s/he may think that the taste of other Kellogg's sub-brands is also sweeter than other brands. This perception can consequently influence the evaluations of these sub-brands depending on consumers" preference for sweetness.

When two brands in a portfolio happen to be in the same product category, they are associated via the product category as well as through the shared brand architecture. Therefore the spillover between brands can spread through brand linkages and/or product category linkages. We compared the spillover through bath brand linkages and common category linkages with the spillover through common category linkages alone. We found that brand linkages have a significant contribution to the spillover between brands in a portfollo which is over and above the spillover effect brought by common category linkages. This finding underscores the important impacts of associative linkages between brands on the benefits and risks related to brand architecture.

In addition to the impact of strength of association on spillover between brands in a portfolio, we also examined two additional factors that may predict the extent of spillover. In particular, we found that the impact of strength of association on spillover is positively moderated by how severe the negative incident is and how consumers attribute the causes of the incident. A severe incident that is attributed to be internal to and controllable by the company has the strongest influence on the positive relationship between strength of association and spillover. In this situation, companies should employ different remedy strategies for brands that are associated with the harmed brand in different levels of strength of association, instead of using a "mass approach" in responding to negative publicity. However, when a crisis is not severe and attributed to be external and uncontrollable, all related brands in the portfolio will receive the same extent of spillover. In this situation, it will be more efficient to address all brands that are related to the harmed brand in a general way in stead of responding to each brand individually. 


\subsection{A Perspective on Future Research}

We have discussed specific suggestions for future research at the end of each chapter. In this final section, we would like to provide some general directions for future research in the area of brand leveraging strategies.

We have identified influential factors on consumer evaluations of brand/ine extensions in different extension formats and contexts. These factors are more concerned with how extensions should be designed in order to facilitate the transfer of affect and knowledge from the parent brand to extensions. However, the way through which extensions are communicated to consumers plays an important role in facilitating or impeding the transfer (Martin, Stewart; and Matta 2005). For instance, marketing communications can influence the perception of similarity between extensions and the parent brand, which consequently influences the transfer of brand affect. Therefore, future research should approach extension strategies from an integrated perspective that considers not only the design of extensions but also the appropriate way to communicate the product information of extensions to consumers.

We have shown that the introduction of extensions may have negative consequences on the parent brand. We studied the consequences of extensions through measuring consumers subsequent evaluations of the parent brand after the introduction of extensions: In addition to the possible negative influence on parent brand evaluations, extending a brand (especially line extensions) can also cannibalize the sales of the parent brand. This negative consequence may even occur when the evaluations of the parent brand are not influenced or positively influenced by the introduction of extensions. Nevertheless, very few studies (exceptions are Lomax et al. 1997; Reddy et al. 1994) have investigated the effect of the cannibalisation of extensions on the parent brand. For brand managers, it is important to ensure that extensions are additions to the product portfolio rather than substitutes for existing products of the parent brand. Therefore, future research should conduct systematic investigation on questions such as how companies deal with the risk of cannibalisation? What factors determine or moderate the level of cannibalisation? Are there situations where cannibalisation is particularly encouraged and what is an acceptable levell of cannibalisation in the light of the overall increase of brand profitability?

We mainly used experimental designs in our studies. As we can observe from previous studies, experimental studies have largely dominated the research 
on brand and line extensions. Yet such a confinement may limit the generalizability of research findings. For instance, in an experimental setting, subjects are often forced to pay attention to the proposed extension product. This procedure can artificially inflate the effects of extensions. On the other hand, consumers' lack of direct experience with the proposed extension in experimental studies may reduce the salience of product cues, which deflates the effects of extensions. Therefore, future studies could conduct research in a real consumption environment and use panel data from the market to validate findings from previous studies. Furthermore, the confinement to experimental studies may limit researchers to the constraints of their research paradigms. Therefore, future studies could use more qualitative methodologies, such as indepth interviews with consumers, brand managers, and case studies, to broaden the scope of our knowledge about extensions. These qualitative methods may challenge dominant cognitive paradigms and help us test alternative theoretical perspectives on consumeir responses toward extensions (Czellar 2004).

We conceptualized the cognitive structure of brand architecture as an associative network. The principle advantage of such conceptualization is that it provides the conceptual framework for the study of spillover effects in brand architecture. We examined the negative spillover effect between brands, which is one type of negative consequences of the brand architecture strategy. Based on the conceptual framework presented in our studies, future research could study other types of negative consequences of brand architecture or the effects of positive spillover effects in a brand portfolio. Furthermore, we have shown that the cognitive structure of brand architecture influences the extent of spillover" effects between brands in a portfolio. This finding leads to other interesting questions such as what factors influence the cognitive structure of brand architecture. Is the cognitive structure of brand architecture relatively stable in consumers" memory? Therefore, future research could investigate how consumers establish the associative linkages between brands, what factors influence the strength of these linkages, and under which situations the cognitive structure of brand architecture might be changed. Findings of these studies can help managers design their brand architecture in a more efficient way and have a better understanding of the effects of brand architecture in terms of its benefits, risks, and influences on consumer behaviour. 


\section{REFERENCES}


A

Aaker, David A. (1997), "Should You Take Your Brand to Where the Action Is?" Harvard Business Reviem, Vol. 75 (5), 135-43.

Aaker, David A. (1996), Building Strong Brands. New York: Free Press,

Aaker, David A. (1991), Managing Brand Equity. New York: The Free Press.

Aaker, David A, and Erich Joachimsthaler (2000), "The Brand Relationship Spectrum: The

Key to the Brand Architecture Challenge, "Calfornia Management Review, Voll 42

(4), 8-23.

Aaker, David A. and Kevin L. Keller (1990), "Consumer Evaluations of Brand Extensions," Journal of Marketing, Vol. 54 (1), 27-41.

Agarwal, Manoj K. and Vithala R. Raio (1996), "An Empirical Comparison of Consumer-

Based Measures of Brand Equity", Marketing Letters, Vol. 7 (3), 237-48.

Agarwal, Sanjeev and R. Kenneth Teas (2001), "Perceived Value: Mediating Role of Perceived Risk", Journal of Marketing Theory \& Practice, Vol. 9 (4), 1-14.

Ahluwalia, Rohini (2002), "How Prevalent is the Negativity Effect in Consumer

Environments?" Journal of Consumer Research, Vol. 29 (2), 270-79.

Ahluwalla, Rohirii, H. Rao Unnava, and Robert E. Burnkrant (2001), "The Moderating Role of Commitment on the Spillover Effect of Marketing Communications." Journal of Marketing Research, Vol. 38 (4), 458-71.

Ahluwalia, Rohini, Robert E. Burnkrant, and H. Rao Unnava (2000), "Consumer Response to Negative Publicity: The Moderating Role of Commitment, "Journal of Marketing Research, Vol. 37 (2), 203-15.

Ahiluwallia, Rohini and Zeynep Gurhan-Canli (2000), "The Effects of Extensions on the Family Brand Name: An Accessibility-Diagnosticity Perspective" ,Journal of Consumer Research, Vol.27 (3), 371-81.

Alba, Joseph W. and Amitava Chattopadhyay (1986), "Salience Effects in Brand Recall," Journal of Marketing Research, Vol.23 (4), 363-69.

Alba, Joseph W. and Amitava Chattopadhyay (1985), "Effects of Context and Part-

Category Cues on Recall of Competing Brands, Journal of Marketing Research, Vol.22(3), 340-49.

Allen, Jeff and Daniel D. Butler (1993), "Assessing the Effects of Donor Knowledge and Perceived Risk on Intentions to Donate Blood", Journal of Health Care Marketing. Vol. $13(3), 26-33$.

Anderson, John R. (1983), "A. Spreading Activation Theory of Memory," Journal of Verbal Learning and Verbal Behaviour, Vol.22, 261-95. 
Bagozzi, Richard P. and Paul R. Warshaw (1990), "Trying to Consume, Joumal of Consumer Research, Vol. 17 (2), 127-40.

Balachander, Subramaniain and Sanjoy Ghose (2003), "Reciprocal Spillover Effects: A Strategic Benefit of Brand Extensions," Journal of Marketing, Vol.67 (1), 4-1.4.

Bargh, John A. and Tanya L. Chartrand (2000), "Studying the Mind in the Middle: A. Practical Guide to Priming and Automaticity Research". In $\mathrm{H}$. Reis and $\mathrm{C}$. Judd (Eds.), Handbook of Research Methods in Social Psychology (pp253-285). New York: Cambridge University Press.

Barone, Michael 1., PaulW. Miniard, and Jean B. Romeo (2000), "The Influence of Positive Mood on Brand Extension Evaluations, Journal of Consumer Research, Vol.26 (4), 386-400.

Barsalou, Lawrence and Damiel Sewell (1985). "Contrasting the Representation of Scripts and Categories", Journal of Memory and Language, Vol. 24, 646-65.

Barwise, Patrick (1993), "Brand Equity: Snark or Boojum?" International Journal of Research in Marketing, Vol. 10 (1), 93-104.

Batt, Rosemary (1999), "Work Organization, Technology, and Performance in Customer" Service and Sales, ${ }_{i}$ Industrial and Labour Relations Review, Vol.52 (4), 539-64.

Bearden, William O. and Terence A. Shimp (1982), "The Use of Extrinsic Cues to Facilitate Product Adoption", Journal of Marketing Research, Vol.19 (2), 229-39.

Berry, Leonard L. (1984), "Service Marketing Is Different," in Service Marketing: Text, Cases and Readings, C. H. Lovelack. Englewood Cliffs, NJ: Prentice Hall, 29-37.

Bettman, James R. (1973), "Perceived Risk and Its Components: a Model and Empirical Test" ${ }^{\prime}$, Journal of Marketing Research, Vol. 10 (2), 184-90.

Bettman, James $R_{x}$ and $C$. Whan Park (1980), "Effects of Prior Knowledge and Experience and Phase of the Choice Process on Consumer Decision Processes", Journal of Consumer Research, Vol. 7 (3), 234-48.

Biehal, Gabriell J. and Dipankar Chakravarti (1982), "Information-Presentation Format and Learning Goals as Determinants of Consumers' Memory Retrieval and Choice Processes," Journal af Consumer Research, Vol.8 (4), 431-41.

Blazevic, Vera (2005). The Fascination of Knowledge Creation-Studies on Knowledge Interfaces in High-Tech Services, Doctoral Dissertation, Maastricht.

Bloemer, Josee, Ko de Ruyter, and Martin Wetzels (1999), "Linking Perceived Service Quality and Service Loyalty: a Multi-Dimensional Perspective" "European Journal of Marketing, vol. $33(11 / 12), 1082-106$.

Boshoff, Christo (2002), "Service Advertising: An Exploratory Study of Risk Perceptions", Journal of Service Research, Vol.4 (4), 290-98. 
Bottomley, Paul A. and John R. Doyle (1996), "The Formation of Attitudes towards Brand Extensions: Testing and Generalizing Aaker and Keller's Model, International Journal of Research in Marketing, Vol. $13(4), 365-77$.

Bottomley, Paul A. and Stephen 3. S. Holden (2001), "Do We Really Know How Consumers Evaluate Brand Extensions? Empirical Generalizations Based on Secondary Analysis of Eight Studies," Journal of Marketing Research, Vol. 38 (4), 494-500.

Boulding, William and Amna Kirmani (1993), "A Consumer-Side Experimental Examination of Signalling Theory: Do Consumers Perceive Warranties as Signals of Quality?" Journal of Consumer Research, Vol. 20 (1), 111-23.

Boush, David M. and Barbara Loken (1991), "A Process-Tracing Study of Brand Extension Evaluation," Journal of Marketing Research, Vol. 28 (1), 35-50.

Boush, David M., S. Shipp, B. Loken, E. Genturck, S. Crockett, E. Kennedy, B. Minshall, D. Misurell, L. Rachford, and J. Strobel (1987), "Affect Generalization to Simillar and Dissimilar Brand Extensions", Psychology and Marketing, Vol. 4(3), 225-37.

Bridges, Sheri, Kevin L. Keller, and Sanjay Sood (2000), "Communication Strategies for Brand Extensions: Enhancing Perceived Fit by Establishing Explanatory Links," Journal of Advertising, Vol.29 (4), 1-11.

Broniarczylk, Susan M. and Joseph W. Alba (1994), "The Importance of the Brand in Brand Extension," Journal of Marketing Research, Vol. 31 (2), 214-28.

Brucks, Merrie (1985), "The Effects of Product Class Knowledge on Information Search Behaviour", Journal of Consumer Research, Vol. 12 (1), 1-16.

C

Campbell, Margaret C. and Ronald C. Goodstein (2001), "The Moderating Effect of Perceived Risk on Consumers' Evaluations of Product Incongruity: Preference for the Norm,"Journal of Consumer Research, Vol. 28 (3), 439-50.

Chapman, Kenneth 1. and Andrew Aylesworth (1999), "Riding the Coat-Tails of a Positive Review: Rave Reviews and Attitude Transfer," Journal of Consumer Marketing, Vol. $16(4 / 5), 418-41$.

Chaiken, Shelly and Charles Stangor (1987), "Attitudles and Attitude Change," Annual Review of Psychology, 575-630.

Chin, Wynne W. (1998), "The Partial Least Squares Approach to Structural Equation Modeling," in Modern business research methods, G.A. Marcoulides, Ed. Mahwah, New Jersey: Lawrence Erlbaum Associates

Chin, Wynne W., Barbara L. Marcolin, and Peter R. Newsted (2003), "A Partiall Least Squares Latent Variable Modeling Approach for Measuring Interaction Effects: Results from a Monte Carlo Simulation Study and Voice Mail Emotion/Adoption Study", Information System Research, Vol.14 (2), 189-218. 
Cohen, Joel B. and Kunal Basu (1987), "Altemative Models of Categorization: Towards a Contingent Processing Framework,"Journal of Consumer Research, Vol 13 (4), 455-72.

Collins, Allan M. and Elizabeth F. Loftus (1975), "A Spreading-Activation Theory of Semantic Processing," Psychological Bulfetin, Voll.82 (6), 407-28.

Cooper, Joel and Robert T. Croyle (1984), "Attitudes and Attitude Change, "Annual Review of Psychalogy; 395-426.

Court, David C., Mark G. Leiter, and Mark A. Loch (1999), "Brand Leverage", MCKinsey Quarterly, Issue 2, 100-10.

Cowley, Elizabeth and Andrew A. Mitchell (2003), "The Moderating Effect of Product Knowledge on the Learning and Organization of Product Information, "Journal of Consumer Research, Vol. 30 (3), 443-54.

Craik, Fergus I.M. and Robert S. Lockhart (1972), "Levels of Processing: A Framework for Memory Research," Joumal of Verbal Learning and Verbal Behaviour "Vol. 11, $671-84$.

Craighead, Christopher W., Kirk R. Karwan, and Janis L. Miller (2004), "The Effects of Severity of Failure and Customer Loyalty on Service Recovery Strategies", Production \& Operations Management, Vol. 13 (4), 307-21.

Czellar, Sandor (2003), "Consumer Attitude toward Brand Extensions: An Integrative Model and Research Propositions", International Joumal of Research in Marketing, vol. $20(1), 97-116$.

D

Dacin, Peter A. and Daniel C. Smith (1994), "The Effect of Brand Portfolio Characteristics on Consumer Evaluations of Brand Extensions," Journal of Marketing Research, Vol.31 (2), 229-42.

Dawar, Niraj (1998), "Product-Harm Crises and the Signaling Ability of Brands", International Studies of Management and Organization, Vol. 28 (3), 109-19.

Dawar, Niraj (1996), "Extensions of Broad Brands: The Role of Retrieval in Evaluations of Fit, "' Journal of Consumer Psychalogy, Vol.5 (2), $189-207$.

Dawar, Niraj and Madan M. Pillutla (2000), "Impact of Product-Harm Crises on Brand Equity: The Moderating Role of Consumer Expectations," Journal of Marketing Research, Vol.37 (2), 215-26.

Day, George S. (1970), "Using Attitude Change Measures to Evaluate New Product Introductions " Journal of Marketing Research, Vol. 7(4), 474-82.

De Bandt, Jacques (1999), "The Concept of Labor and Competence Requirements in a Service Economy," The Service Industries Journal, Vol.19 (1), 1-11. 
Deborah Roedder, John, Barbara Loken, and Christopher Joiner (1998), "The Negative Impact of Extensions: Can Flagship Products Be Diluted?" Journal of Marketing, Vol. $6.2(1), 9-32$.

De Chernatony, Leslie and Francesca Dall'Olmo Riley (1999), "Experts" View about Defining Senvices Brands and the Principles of Services Braniding Journal of Business Research, Vol, 46 (2), 181-92.

de Ruyter; Ko and Martin Wetzels (2000), "The Role of Corporate Image and Extension Similarity in Service Brand Extensions," Journal of Economic Psychology, Val. 21 $(6), 639-59$.

DeGraba, Patrick and Mary W. Sullwan (1995), "Spillover Effects, Cost Savings, R\&D and the Use of Brand Extensions,"Intemational Journal of Industrial Organization, Vol. $13(2), 229-49$.

DelVecchio, Devon and Daniel C. Smith (2005), "Brand-Extension Price Premiums: the Effect of Perceived Fit and Extension Product Category Risk", Journal of the Academy of Management Science, Vol. 33 (2), 184-96.

Desai, Kajpesh K. and Wayne D. Hoyer (1993), "Line Extensions: A Categorization and an Information Processing Perspective" ,Advances in Consumer Research, Vol.20 (1), 599-606.

Douglas, Susan P., C. Samuel Craig, and Edwin J. Nijssen (2001), "Executive Insights: Integrating Branding Strategy Across Markets: Building International Brand Architecture" "Journal of International Marketing, Vol.9 (2), 97-114.

Dowling, Grahame R. (1999), "Perceived Risk," in The Elgar Companion to Consumer Research and Economic Psychology, Peter E. Eart and Simon Kemp, eds. Cheltenham, UK: Edward Elgar, 419-24.

Dowling, Grahame R. and Richard Staelin (1994), "A Model of Perceived Risk and Intended Risk-Handling Activity," Journal of Consumer Research, Voll. 21 (2), 119 34.

$\mathbf{E}$

Erdem, Tulin and Baohong Sun (2002), "An Empirical Investigation of the Spillover Effects of Advertising and Sales Promations in Umbrella Branding," Journal of Marketing Research, Vol. $39(4), 408-20$.

\section{$\mathbf{F}$}

Farquhar, Peter H., Julia Y. Han, Paul M. Herr, and Yuji Ijiri (1992), "Strategies for leveraging master brands", Marketing Research, Vol. 4 (3), 32-43.

Farquhar, Peter $H_{\text {, }}$ Paul M. Herr, and Russell H. Fazio (1990), "A Relational Model for Category Extensions of Brands," Advances in Consumer Research, Vol. 17 (1), $856-60$. 
Fazio, Russell H., David M. Sanbonmatsu, Martha C. Powell, and Frank R. Kardes (1985), "Orn the Automatic Activation of Attitudes, Joumal of Personality and Social Psychology, Vol. 50 (2), 229-38.

Fazio, Russell H., Paul M. Herr, and Martha C. Powell (1992), "On the Development and Strength of Category-Brand Associations in Memory: The Case of Mystery Ads," Journal of Consumer Psychology, Vol.1 (1), 1-13.

Feldiman, Jack M. and John G. Lynch, Jr. (1988), "Self-Generated Validity and Other Effects of Measurement on Belief, Attitude, Intention, and Behaviour", Journal of Applied Psychology, Vol. 73 (3), 421-35.

Fishbein, Martin and Icek Ajzen (1975), Believe, attitudes, intentions, and behaviour: an introduction to theory and research. Reading: Addison-Wesley.

Flynn, Leisa R. and Ronald E. Goldsmith (1999), "A short, Reliable Measure of Subjective Knowledge ${ }^{*}$, Journal of Business Research, Vol. 46 (1), 57-66.

Folkes, Valeris S. (1984), "Consumer Reactions to Product Failure: An Attributional Approach", Journal of Consumer Research, Vol. 10 (4), 398-409.

Folkes, Valeris S. and Tina Kiesler (1991), "Social Cognition: Consumers' Inferences about. the Self and Others" In: Robertson, T.S., Kassarjian, H.H. (Eds.), Handbook of Consumer Behaviour, Prentice-Hall, New Jersey.

Folkes, Valerie S., Susan Koletsky, and John L. Graham (1987). "A Filed Study of Causal Inferences and Consumer Reaction: The View from the Airport", Journal of Consumer Research, Vol. $13(4), 534-40$.

Folkes, Valerie S. and Barbara Kotsos (1986), "Buyers' and Sellers" Explanations for Product Failure: Who Done It?" Journal of Marketing, Vol. 50 (2), 74-80.

Folkes, Valerie S. (1988), "Recent Attribution Research in Consumer Behaviour: A Review and New Directions", Journal of Consumer Research, Vol. 14 (4), 548-65.

Fornell, Claes and David F. Larcker (1981), "Evaluating Structural Equation Models With Unobservable Variables and Measurement Error," Journal of Marketing Research, vol. $18(1), 39-50$,

Fornell, Claes and Fred L. Bookstein (1982), "Two Structural Equation Models: Lisrel and Pls Applied to Consumer Exit-Voice Theory," Joumal of Marketing Research, Vol. $19(4), 440-52$.

$\mathbf{6}$

Gaeth, Gary J., Irwin P. Levin, Shailesh Sood, Chifei Juang, and Jenniffer Castellucci (1997), "Consumers' Attitude Change Across Sequences of Successful and Unsuccessful Product Usage," Marketing Letters, Vol. 8(1), 41-53.

Greatorex, Mike and Vincent W. Mitchell (1994), "Modeling Consumer Risk Reduction Preferences from Perceived Loss Data", Journal of Economic Psychology, Vol. 15, $669-85$. 
Gronhaug, Kjell; Leif Hem, and Rune Lines (2002), "Exploring the impact of product category risik and consumer knowledge in brand extensions ${ }^{a r}$, Brand Management, Vol. $9(6), 463-76$.

Gurhan-Canli; Zeynep and Durairaj Maheswaran (1998), "The Effects of Extensions on Brand Name Dillution and Enhancement", Journal of Marketing Research, Vol. 35 (4), 464-73.

Guseman, D.S. (1981), "Risk Perception and Risk Reduction in Consumer Services" ${ }^{\text {in }}$ in Donnelly, 3.H. and George, W.R. (Eds), Marketing of Services, American Marketing Association, Chicago, IL.

H

Hankinson, Graham and Phillippa Cowking (1993), Branding in Action: Cases and Strategies for Profitable Brand Management. London: McGraw-Hill.

Hardle, Bruce G. S. and Leonard M. Lodish (1994), "Logic of Product-Line Extensions", Harvard Business Review, Vol, $72(6), 54-54$.

Hart, Christopher W. L. (1988), "The Power of Unconditional Service Guarantees", Harvard Business Review, Vol. 66 (4), 54-62.

Harvey, John H. and Gifford Weary (1984), "Current Issues in Attribution Theory and Research", Annual Review of Psychology, Vol. 35, 427-60.

Herr, Paul M., Frank R. Kardes, John Kim (1991), "Effects of Word-of-Mouth and Product-

Attribute Information on Persuasion: An Accessibility-Diagnosticity Perspective", Journal of Consumer Research, Vo. 17 (4), 454-62.

Herr, Paul M., Peter H. Farquhar, and Russell H. Fazio (1996), "Impact of Dominance and Relatedness on Brand Extensions," Journal of Consumer Psychology, Vol. 5 (2), 135-159.

Holden, Stephen 1. S. and Richard 1. Lutz (1992), "Ask Not What the Brand Can Evoke; Ask What Can Evoke the Brand?" Advances in Consumer Research, Vol. 19 (1), 101-07.

Horton, Raymond L. (1976), "The Structure of Perceived Risk", Journal of the Academy of Marketing Sicience, Vol.4 (4), 694-706.

Houwer, Jan, Dirk Hermans, Klaus Rothermund, and Wentura Klaus (2002), "Affective Priming of Semantic Categorisation Responses," Cognition \& Emotion, Vol. 16 (5), 643-67.

Hulland, John (1999), "Use Of Partial Least Squares (PIs) In Strategic Management Research: A Review of Four Recent Studies," Strategic Management Journal, Vol.20 (2), 195-204. 
Iacobucci, Dawn (1998), "Services: What Do We Know and Where Shall We Go? A View from Marketing, "Advances in Services Marketing and Management, Vol.7, 1-96. lacobucci, Dawn(1992), "An Empirical Examination of Some Basic Tenets in Services: Goods-Services Continua," Advances in Services Marketing and Management, Voll, 1, 23-52.

Iacobucci, Dawn and Amy Ostrom (1996), "Perceptions of Services," Journal of Retailing and Consumer Services, Vol 3, 195-212.

Innis, Daniel E. and H. Rao Unnava (1991), "The Usefulness of Product Warranties for Reputable and New Brands", Advances in Consumer Research, Vol, 18 (1), 317-22. Ito, Tiffany A, Jeff T. Larsen, N. Kyle Smith, and John T. Cacioppo (1998), "Negative Information weighs More Heavily on the Brain: The Negativity Bias in Evaluative Categorizations," Journal of Personality and Social Psychology, Vol. 75 (4), 887900.

了

Johnson, Eric J. and Russo J. Edward (1978), "The Organization of Product Information in Memory Identified by Recall Times," in Advances in Consumer Research, Vol. 5 (1), 79-88.

Jorgensen, Brian K. (1994), "Consumer Reaction to Company-Related Disasters: The Effect of Multiple versus Single Explanations", Advances in Consumer Research, Vol. 21 (1), 348-53.

Jun, Sung Y., Tridib Mazumdar, and S. P. Raj (1999), "Effects of Technological Hierarchy on Brand Extension Evaluations," Journal of Business Research, Vol. 46 (1), 31-43.

$\mathbf{K}$

Kapferer, Jean-Noel (1997), Strategic Brand Management: Creating and Sustaining Brand Equity Long Term. London: Kogan Page.

Kaplan, Leon B., George J. Szybillo, and Jacob Jacoby (1974), "Components of Percelved Risk in Product Purchase: A Cross-Vallidation", Journal of Applied Psychology, Voll. $59(3), 287-91$.

Kasper, Hans, Piet van Helsdingen, andWouter de Vries Jr. (1999), Serwices Marketing Management: An International Perspective. Chicester, UK: Wiley.

Keller, Kevin Lane (2003), Strategic Brand Management: Building, Measuring, and Managing Brand Equity. Upper Saddle River, NJ: Prentice Hall.

Keller, Kevin Lane (1993), "Conceptualizing, Measuring, Managing Customer-Based Brand Equity," Journal of Marketing, Vol.57 (1), 1-22. 
Keller, Kevin Lane (1987), "Memory Factors in Adwertising: The Effect of Advertising Retrieval Cues on Brand Evaluations, Jowrnal of Consumer Research, Vol. 14 (3), 316-33.

Keller, Kevin Lane and David Aaker (1992), "The Effects of Sequential Introduction of Brand Extensions", Journal of Marketing Research, Vol.29 (1), 35-50.

Keller, Kevin Lane and Sanjay Sood (2003), "Brand Equity Dilution", MIT Sloan Management Review, Vol.45 (1), 11-15.

Kelley, Harold (1973), "The Processes of Causal Attribution" "American Psychologist, Vol.28, $107-28$

Kim, Byung-Do and Mary Sulliwan (1998), "The Effect of Parent Brand Experience on Line Extension Trial and Repeat Purchase", Marketing Letters, Voll. 9 (2), 181-93.

Kim, Chung $K_{x}$, Anne M. Lavack, and Margo Smith (2001), "Consumer Evaluation of Vertical Brand Extensions and Core Brands," Journal of Business Research, Vol. 52 (3), $211-22$.

Kirmani, Amna and Akshay R. Rao (2000), "No pain, No Gain: a Critical Review of the Literature on Signaling Unobservable Product Quality", Journal of Marketing, Vol. $64(2), 66-79$.

Kirmani, Amna, Sanjay Sood, and Sheri Bridges (1999), "The Ownership Effect in Consumer Responses to Brand Line Stretches", Journal of Marketing, Vol.63 (1), 88-101.

Klein, Jill G. and Baba Shiv (1996), "Under siege: How consumers respond and marketers react to negative information", Advances in Consumer Research, Vol. 23 (1), 45657.

Klein, Jill G. and Niraj Dawar (2004), "Corporate Social Responsibility and Consumers' Attributions and Brand Evaluations in a Product-Harm Crisis," International Journal of Research in Marketing, Vol. 21 (3), 203-18.

Krishnan, H. Shanker (1996), "Characteristics of Memory Associations: A ConsumerBased Brand Equity Perspective," International Journal of Research in Marketing, Vol. $13(4), 389-405$.

Kumar, Piyush (2005), "Customer Evaluation of Brand Counterextensions", Journal of Marketing, Vol. 69 (3), 18-25.

Kurzbard, Gary and George J. Slomkos (1992), "Crafting a Damage Control Plan: Lessons from Perrier", Journal of Business Strategy, Vol.13 (2), 39-43.

$\underline{\mathbf{L}}$

Laforet, Sylvie and John Saunders (1999), "Managing Brand Portfolios: Why Leaders Do What They Do?" Journal of Advertising Research, Vol. 39 (1), 51-66. 
Lane, Vicki R. (1998), "Brand leverage power: The critical role of brand balance",

Business Horizons, Vol. 41 (1), 75-85

Laroche, Michel, Chankou Kim, and Lianxi Zhou (1996), "Brand Familiarity and Confidence as Determinants of Purchase Intention: An Empirica Test in a Multiple Brand Context", Journal of Business Research, Vol. 37 (2), 115-20

Larsson, Rikard and David $E_{.}$Bowen (1989), "Organization and Customer: Managing Design and Coordination," Academy of Management Review, 14 (2), 213-33.

Lawson, Robert (2002), "Consumer Knowledge Structures: Background Issues and Introduction," Psychology \& Marketing, Vol.19 (6), 447-57.

Lee, Moonkyu, Jonathan Lee, and Wagner A. Kamakura (1996). "Consumer Evaluations of Line Extensions: A Conjoint Approach", Advances in Consumer Research, Vol. 26. (1), 289-95.

Loken, Barbara and James Ward (1990), "Alternative Approaches to Understanding the

Determinants of Typicality", Journal of Consumer Research, Vol. 17 (2), 111-26.

Loken, Barbara and John Deborah Roedder (1993), "Diluting Brand Beliefs: When Do Brand Extensions Have a Negative Impact?" Journal of Marketing, Vol, 57 (3), 71 84.

Lord, Robert G. and Jonathan E. Smith (1983), "Theoretical, Information Processing, and

Situational Factors Affecting Attribution Theory Models of Organizational

Behaviour", Acaderny of Management Review, Vol.8 (1), 50-61.

Lovelock, Christopher H. (1991), Services Marketing, 2nd ed. Englewood Cliffs, NJ:

Prentice Hall.

Lovelock, Christopher H. (1984), "Why Marketing Management Needs to Be Different for Services," in Serwice Marketing: Test, Cases and Readings, C.H. Lovelock. Englewood Cliffs, NJ: Prentice-Hall, 479-88.

Lutz. Richard J. (1975), "Changing Brand Attitudes Through Modification of Cognitive Structure," Journal of Consumer Research, Vol.1 (4), 49-59.

M

Mackenzie, Scott B., Richard J. Lutz, and George E. Bellch (1986), "The Role of Attitude Toward the Ad as a Mediator of Advertising Effectiveness: A Test of Competing Explanations," Journal of Marketing Research, Vol. 23 (2), 130-43.

Manrai, Lalita A. and Meryl P. Gardiner (1991), "The Influence of Affect on Attributions for Product Failure", Advances in Consumer Research, Vol. $18(1), 249-55$.

Maoz, Eyal and Alice M. Tybout (2002), "The Moderating Role of Involvement and Differentiation in the Evaluation of Brand Extensions", Journal of Consumer Psychology, Vol. 12 (2), 119-31.

Martin, Ingrid M., David W. Stewart, and Shashi Matta (2005), "Branding Strategies, Marketing Communication, and Perceived Brand Meaning: The Transfer of 
Purposive, Goat-Oriented Brand Meaning to Brand Extensions", Journal of the Academy of Marketing Sclence, vol. $33(3), 275-94$

Martinez, Eva and Jose M. Pina (2005), "Influence of Corporate Image on Brand

Extensions: A Model Applied to the Service Sector" "Journal of Marketing

Conmunications, Vol. $11(4), 263-81$.

McDougall, Gordon H.G., Terrence Levesque, and Peter Vanderplaat (1998), Designing the Service Guarantee: Unconditional or Specific? ? $^{\text {J }}$ loumal of Services Marketing, Vol. $12(6), 278-93$.

Meyvis, Tom and Chris Janiszewski (2004), "When are Broader Brands Stronger Brands?

An Accessibility Perspective on the Formation of Brand Equity", Journal of Consumer Research, Vol. 31 (2), 346-57.

Milberg, Sandra 1., Park C. Whan Park, and Michael S. McCarthy (1997), "Managing Negative Feedback Effects Associated With Brand Extensions: The Impact of Alternative Branding Strategies", Journal of Consumer Psychology, Vol. 6 (2), $119 \times 40$.

Mitchell, V.W. and M. Greatorex (1993), "Risk Perception and Reduction in the Purchase of Consumer Services", The Service Industries Journal, vol.13 (4), 179-200.

Mizerskil, Richard W., Linda L. Golden, and Jerome B. Kernan (1979), "The Attribution Process in Consumer Decision Making", Journal of Consumer Research, Vol. 6 (2), 123-41.

Morrin, Maureen (1999), "The Impact of Brand Extensions on Parent Brand Memory Structures and Retrieval Processes," Journal of Marketing Research, Vol.36 (4), $517-25$

Murray, Keith B. and John L. Schlacter (1990), "The Impact of Services versus Goods on Consumers' Assessment of Perceived Risk and Variability", Journal of the Academy of Marketing, Vol, $18(1), 51-66$.

Muthukrishnan, A.V. and Barton A. Weitz (1991), "Role of Product Knowledge in Evaluation of Brand Extension", Advances in Consumer Research, Vol. 18, 407-13.

$\mathbf{N}$

Nedungadi, Prakash (1990), "Recall and Consumer Consideration Sets: Influencing Choice Without Altering Brand Evaluations," Journal of Consumer Research, Vol.17 (3), $263-76$.

Nedungadi, Prakash, Amitava Chattopadhyay, and A.V. Muthukrishnan (2001), "Category Structure, Brand Recall, and Choice, International Journal of Research in Marketing, Vol. 18 (3), 191-203.

Nedungadi, Prakash and J. Wesley Hutchinson (1985), "The Prototypicality of Brands:

Relationships with Brand Awareness, Preference and Usage," Advances in Consumer Research, Vol.12 (1), 498-503. 
Nijssen, Edwin 1. (1999), "Success Factors of Line Extensions of Fast-Moving Consumer Goods: ${ }^{*}$ European Journal of Marketing, Vol.33 (5/6), 450-69.

Nunnally, Jum C and Ira H. Bernstein (1994), Psychometric theory (Third Edition ed.): McGraw Hill,

0

Olsan, James M. and Mark P. Zanna (1993), "Attitudes and Attitude Change, "Annual Review of Psychology, 117-54.

O'Malley, John R. Ir. (1996), "Consumer Attributions of Product Failures to Channel

Members", Advances in Consumer Research, vol.23 (1), 342-45.

Osselaer, Stijn M. J. Van and Joseph W. Alba (2000), "Consumer Learning and Brand

Equity", Journal of Consumer Research, Vol. $27(1), 1-16$.

Osselaer, Stijn M. J. Van, Chris Janiszewski, David Glen Mick, and Frank R. Kardes

(2001), "Two Ways of Learning Brand Associations", Journal of Consumer

Research, Vol. 28 (2), 202-23.

Ostrom, Amy L. and Down Iacobucci (1998), "The Effect of Service Guarantees on Consumers" Evaluations of Services", Journal of Services Marketing, Vol.12 (5), $362-78$.

Ottewill, Roger, Peter L. Fennings, and Peter Magirr (2000), "Management Competence Development for Professional Service SMEs: The Case of Community Pharmacy," Education and Training, Vol. 42 (4), 246-55.

$\mathbf{P}$

Parasuraman, A. (1997), "Reflections on Gaining Competitive Advantage Through Customer Value", Journal of the Academy of Marketing Science, Vol. 25 (2), 15461.

Parasuraman, A. and Dhruv Grewal (2000), "The Impact of Technology on the QualityValue-Loyalty Chain: A Research Agenda", Journal of the Academy of Marketing Science, Vol. 28 (1), 168-74.

Park, Chan Su and V.A. Srinivasan (1994), "A Survey-Based Method for Measuring and Understanding Brand Equity and Its Extendibility", Joumal of Marketing Research, Vol. $31(2), 271-88$.

Park C. Whan, Sandra Milberg, and Robert Lawson (1991), "Evaluation of Brand Extensions: The Role of Product Feature Similarity and Brand Concept Consistency," Journal of Consumer Research, 18 (2), 185-93.

Park, C. Whan, Sung Y. Jun, and Allan D. Shocker (1996), "Composite Branding Allances: An Investigation of Extensions and Feedback Effects," Joumal of Marketing Research, Vol. 33 (4), 453-66. 
Pedhazur, Elazar 1. and Liora Pedhazur Schmelkin (1991), Measurement, Design, and Analysis. New Jersey: Lawrence Erlbaum Associates.

Peter, Paul J: and Jerry C. Olson (2005), Consumer Behavior and Marketing Strategy, Irwin: McGram-Hill

Peter, Paul J. and Lawrence X. Tarpey Sr. (1975), "A Comparative Analysis of Three Consumer Decision Strategies", Journal of Consumer Research, Vol. 1 (1), 29 -37.

Petrick; James F: (2002), "Development of a Multimimensional Scale for Measuring the Percelved Value of a Service" , Journal of Leisure Research, Vol.34 (2), 119-34.

Petty Richard E. Duane T: Wegener, and Leandre R. Fabrigar (1997), "Attitudes and Attitude Change," Annual Review of Psychology, 609-47.

Petty Richard E. and John T. Cacioppo (1986), "The Elaboration Likelihood Model of Persuasion," Advances of Experimental Social Psychology, Vol.19, 123-205.

Petty, Richard E. and John T. Cacioppo (1984), "Source Factors and the Elaboration Likelihood Model of Persuasion", Advances in Consumer Research, Vol. 11 (1), $668-73$

Petty Richard E., JR. Priester, and DT. Wegener (1994), "Cognitive Processes in Attitude Change," in Handbook of Social Cognition, e.d. RS Wyer, TK Scrull 2: 69-142, Hillsdale, NJ: Erlbaum, $2^{\text {nd }}$ ed.

Pitta, Dennis A. and Lea Prevel Katsanis (1995), "Understanding Brand Equity for Successful Brand Extension", Journal of Consumer Marketing, Vol. 12 (4), 51-64. Posavac, Steven S., David M. Sambonmatsu, Maria Cronley, and Frank R. Kardes (2001), "The Effects of Strengthening Category-Brand Associations on Consideration Set Composition and Purchase Intent in Memory-Based Choice," Advances in Consumer Research, Vol $28(1), 186-90$.

$\mathbf{R}$

Rajagopal, Sanchez R. (2004), "Conceptual Analysis of Brand Architecture and

Relationships within Product Categories," Brand Management, Vol.2 (3), 232-47.

Randall, Taylor, Karl Ulrich, and David Reibstein (1998), "Brand Equity and Vertical Product Line Extent", Marketing Science, Vol. 17 (4), 35.6-79.

Rao, Akshay R. and Kent B. Monroe (1988), "The Moderating Effect of Prior Knowledge on Cue Utilization in Product Evaluations", Journal of Consumer Research, Vol. 15 (2), $253-64$.

Rao, Akshay R. and Robert W. Ruekert (1994), "Brand Alliances as Signals of Product Quality", Sloan Management Review, Vol. 36 (1), 87-97.

Reddy, Srinivas K., Susan L, Holak, and Subodh Bhat (1994), "To Extend or Not to Extend: Success Determinants of Line Extensions." Journal of Marketing Research, Vol. $31(2), 243-62$. 
Roehm, Michelle and Alice M. Tybout (2005), "When Will a Brand Scandal Splllover and How Should Competitors Respond?" Joumal of Marketing Research; forthcoming.

Romeo, Jean B. (1991), "The Effects of Negative Information on the Evaluations of Brand Extensions and the Family Brand", Advances in Consumer Research, Vol. 18 (1). $399-406$.

Roselius, Ted (1971), "Consumer Ranking of Risk Reduction Methods", Jounal of Marketing, Vol.35 (1), 56-61.

Rossiter, John R. and Larry Percy (1980), "Attitude Change Through Visual Imagery in Advertising," Journal of Advertising, Vol. 9(2), 10-16.

\section{$\mathbf{S}$}

Samu, Sridhar. H. Shanker Krishnan, and Robert E. Smith (1999), "Using Advertising

Alliances for New Product Introduction: Interactions Between Product

Complementarity and Promotional Strategies," Journal of Marketing, Vol. 63 (1), $57-74$.

Scott, Carol A. and Alice M. Tybout (1981), "Theoretical Perspectives on the Impact of Negative Information: Does Valence Matter", Advances in Consumer Research, Vol. 8 (1), 408-10.

Settle, Robert B. and Pamela L. Alreck (1989), "Reducing Buyers" Sense of Risk", Marketing Communications, Vol. 14 (1), 34-40.

Sheinin, Daniel A. (2000), "The Effects of Experience with Brand Extensions on Parent Brand Knowledge," Journal of Business Research, 49 (1), 47-55.

Shimp, Terrence A. and William O. Bearden (1982), "Warranty and Other Extrinsic Cue Effects on Consumers' Risk Perceptions", Journal of Consumer Research, Vol. 9(1), $38-46$.

Shocker, Aallan D." Rajendra K. Srivastava, and Rober W. Ruekert (1994), "Challenges and Opportunities Facing Brand Management: An Introduction to the Special Issue", Journal of Marketing Research, Vol. 31 (2), 149-59.

Shostack, G. Lynn (1977), "Breaking Free from Product Marketing," Journal of Marketing, Vol. $41(2), 73-80$.

Shugan, Steven M. (1994), "Explanations for the Growth of Services," in Service Quality: New Directions in Theory and Practice, Richard L. Oliver and Roland T. Rust, eds, Thousand Oaks, CA: Sage, 223-40.

Simonin, Bernard L. and Julie A. Ruth (1998), "Is a Company Known by the Company Itt: Keeps? Assessing the Spillover Effects of Brand Alliances on Consumer Brand Attitudes", Journal of Marketing Research, Vol . 35 (1), 30-42.

Sjoholt, Peter (1999), "Skills in Services. The Dynamics of Competence Requirement in Different Types of Advanced Producer Services. Some Evidence from Norway," The Service Industries Journal, 19 (1), 61-80. 


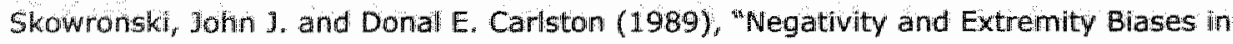
Impression Formation: A Review of Explanations", Psychological Bulletin, Vol. 105 (1), $131-42$.

Skowronsiki, John J" and Donal E. Cariston (1987), "Social Judgment and Social Memory: The Role of Cue Diagnosticity in Negativity, Positivity, and Extremity Biases", Journal of Personality and Social Psychology, Vol. 52, 689-99.

Smith, Daniel C. and C. Whan Park (1992), "The Effiects of Brand Extensions on Market Share and Advertising Efficiency," Journal of Marketing Research, Vol. 29 (3), 296-313.

Smith, Robert E. (1993), "Integrating Information from Advertising and Trial: Processes and Effects on Consumer Response to Product Information, "Journal of Marketing Research, Vol. 30 (2), 204-19.

Smith, Daniel C. and C. Whan Park (1992), "The Effects of Brand Extensions on Market Share and Advertising Efficiency", Journal of Marketing Research, Voll. 29 (3), 296-313.

Smith, Robert E. and William R. Swinyard (1982), "Information Response Models: An Integrated Approach," Journal of Marketing, Vol. 46 (1), 81-93.

Sunde, Lorraine and Roderick 3. Brodie (1993), "International Journal of Research in Marketing", Vol. 10 (1), 47-53.

Sujan, Mita (1985), "Consumer Knowledge: Effects on Evaluation Strategies Mediating Consumer Judgments", Journal of Consumer Research, Vol. 12 (1), 31-46.

Sujan, Mita and James R. Bettman (1989), "The Effects of Brand Positioning Strategies on Consumers' Brand and Category Perceptions: Some Insights from Schema Research," Journal of Marketing Research, Vol.26 (4), 454-67.

Sullivan, Mary (1990), "Measuring Image Spillovers in Umbrella-Branded Products," Journal of Business, Vol.63 (3), 309-29.

Swaminathan, Vanitha and Srinivas K. Reddy (2003), "Spillover Effects of Ingredient Branded Strategies: The Role of Portfolio Quality and Prior Brand Commitment," Working Paper, Katz School of Business, University of Pittsburgh.

Sweeney, Jillian C., Geoffrey N. Soutar, and Lester W. Johnson (1999), "The Role of Perceived Risk in the Quality-Value Relationship: A Study in the Retail Environment", Journal of Retailing, Vol.75 (1), 77-105.

Sweeney, Jillian C. and Geoffrey N. Soutar (2001), "Consumer Perceived Value: the Development of a Multiple Item Scale", Journal of Retailing, Vol. 77 (2), 203-20.

$\mathbf{T}$

Tauber, Edward E. (1988), "Brand Leverage: Strategy for Growth in a Cost Control World" Journal of Advertising Research, Vol. 28 (4), 28-32. 
Taylor S. E and S. T. Fiske (1975), "Point of View and Perceptions of Causality", Journar of Personality and Social Psychology, Vol. $32,439-45$.

Till, Brian D, and Terence A. Shimp (1998), "Endorsers in Advertising: The Case of Negative Celebrity Information," Journal of Advertising, Vol. 27 (1), 67-82.

Tsiros, Michael, Vikas Mittal, and William T. Ross Jr (2004), "The Role of Attributions in Customer Satisfaction: A Reexamination", Journal of Consumer Research, Vol.31 (2), $476-83$.

Tsiros, Michael and Vikas Mittal (2000), "Regret: A Model of Its Antecedents and Consequences in Consumer Decision Making," Journal of Consumer Research, Vol. $26(4), 401-17$.

Tucci, Louis A. and James Talaga (1997), "Service Guarantees and Consumers" Evaluation of Services", Journal of Services Marketing, Vol. 11. (1), 10-18.

Tulving, Endel (1979), "Relation Between Encoding Specificity and Levels of Processing," Psychological Review, Vol. 69, 344-54.

Tulving, Endel and Donald M. Thomson (1971), "Retrieval Processes in Recognition Memory: Effects of Associative Context, "Journal of Experimental Psychology, Vol. 87, 116-24.

Tulving, Endel and Danald M. Thomson (1973), "Encoding Specificity and Retrieval Processes in Episodic Memory," Psychological Review, Vol. 80, 352-73.

W

van Riel, Allard C.R., Jos Lemmink, and Hans Ouwersloot (2001), "Consumer evaluations of service brand extensions," Journal of Service Research, Val. 3 (3), 220-31.

w

Weber, Renee, and Jennifer Crocker (1983), "Cognitive Processes in the Revision of Stereotypic Beliefs," Journal of Personality and Social Psychology, Vol. 45, 961-77. Weiner, Bernard (2000), "Attributional Thoughts about Consumer Behaviour," Journal of Consumer Research, vol.27 (12), 382-87.

Weiner, Bernard (1980), Human motivation, Holt, Rinehart and Winston, New York Weiner, Bernard and Stephen J. Handel (1985), "A Cognition-Emotion-Action Sequence:

Anticipated Emotional Consequences of Causal Attributions and Reported Communication Strategy", Developmental Psychology, Vol. 21 (1), 102-07. Weinberger, Marc G., Chris T. Allen, and William R. Dillon (1981), "Negative Information: Perspectives and Research Directions", Advances in Consumer Research, Vol. 8 (1), 398-405. 
Weinberger, Marc $G$, and Elzbieta Lepkowska-White (2000); "The Influence of Negative Information on Purchase Behaviour", Journal of Marketing Management, vol. 16 (5), $465-82$.

Weinberger, Marc G. and Jean B. Romeo (1991), "Negative Product Safety News:

Coverage, Responses, and Effects," Busimess Horizons, Vol. 34 (3), $23-32$.

Wernerfelt, Birger (1988), "Umbrella branding as a Signal of New Product Quality: an Approach for Premium Pricing and Partner Selection", Marketing Science, Vol.16 (2), 146-65.

White, Chris 3., Rajan Varadarajan, and Peter A. Dacin (2003), "Market Situation Interpretation and Response: The Role of Cognitive Style, Organizational Culture, and Information Use," Journal of Marketing, Vol. 67 (3), 63-79.

Wirtz, Jochen (1998), "Development of a Service Guarantee Model", Asia Pacific Journal of Management, Vol. 15 (1), 51-75.

Wirtz, Jochen, Doreen Kum, and Lee Khal Sheang (2000), "Should a Firm with a Reputation for Outstanding Service Quality Offer a Service Guarantee?" Journal of Services Marketing, Vol. $14(6 / 7)$, 502-12.

Woodruff, Robert B. (1997), "Customer Value: The Next Source for Competitive Advantage", Journal of the Academy of Marketing Science, Vol. 25 (2), 139-53.

$\underline{Y}$

Yeung, Catherine W. M. and Robert S. Wyer Jr. (2005), "Does Loving a Brand Mean Loving Its Products? The Role of Brand-Elicited Affect in Brand Extension Evaluations", Journal of Marketing Research, Vol. 42 (4), 495-506.

$\mathbf{z}$

Zeithaml, Valarie A. (1988), "Consumer Perceptions of Price, Quality, and Value: A Means-End Model and Synthesis of Evidence", Journal of Marketing, Vol. 52 (3), 221.

Zeithaml, Valarie A. (1984), "How Consumer Evaluation Processes Differ between Goods and Services," in Service Marketing: Text Cases and Readings, Chris $H$. Lovelack. Englewood Cliffs, N]: Prentice Hall.

Zeithaml, Vallarie A. and Mary J. Bitner (1996), Serwices Marketing. New York: McGrawHill.

Zeithaml Valarie A. A. Parasuraman, Leonard L. Berry (1990), Delivering Quality Service - Balancing Customer Perceptions and Expectations. New York: The Free Press. 


\section{APPENDIX}


Appendix A: Measurement Items and Reliability Chapter 2

\begin{tabular}{|c|c|c|}
\hline Construct & Measurement Item & $\begin{array}{l}\text { Reliabillty } \\
\text { (Cronbach's a) }\end{array}$ \\
\hline $\begin{array}{c}\text { Quality evaluation of } \\
\text { extensions }\end{array}$ & $\begin{array}{l}\text { I expect the Accura [extension] to be of high } \\
\text { quality. } \\
\text { I expect the Accura [extension] to be superior } \\
\text { services or goods. }\end{array}$ & 0.89 \\
\hline $\begin{array}{l}\text { Feedback effect on the parent } \\
\text { product }\end{array}$ & $\begin{array}{l}\text { Now that I know about the introduction of } \\
\text { Accura [extension], my evaluation of } \\
\text { Accura printers and copiers has } \\
\text { become more positive. } \\
\text { My knowledge about the introduction of } \\
\text { Accura [extension] thas a positive } \\
\text { influence on my purchase } \\
\text { cansiderations for Accura printers and } \\
\text { copiers. }\end{array}$ & 0.66 \\
\hline Percelved similarity & $\begin{array}{l}\text { I believe there is a strong overall degree of } \\
\text { similarity between the Accura printers } \\
\text { and copiers and [extension]. } \\
\text { I stiongly associate laser printers and copiers } \\
\text { with [extension] } \\
\text { I believe that the mainufacturing and selling } \\
\text { printers and copiers are consistent } \\
\text { with offering [extension]. }\end{array}$ & 0.89 \\
\hline Service Intensiveness & $\begin{array}{l}\text { I believe that the Accura [extension] is more } \\
\text { service intensive than: Accura printers } \\
\text { and copiers. } \\
\text { I belleve that, concerning quality evaluation, } \\
\text { the service component is more } \\
\text { important for Accura [extension] than } \\
\text { for printers and coplers. }\end{array}$ & 0.91 \\
\hline $\begin{array}{l}\text { Familiarity with the parent } \\
\text { product }\end{array}$ & I am familiar with printers and copiers. & \\
\hline Familiarity with extensions & I understand what [extensions] are. & \\
\hline
\end{tabular}




\section{Appendix B: Scale Items Chapter" 3}

\section{Items}

Prior Knowledge about hotel services $(C R=0.92)$

(Adapted from Fiynn and Goldsmith 1999)

I feel quite knowledgeable about hotel services

Among my circle of friends, I think I know a lot about hotel servicies

Performance risk $(C R=0.85)$

(Adapted from ostrom and Iacobucci 1998)

Considering the possible problems with the hotel's performance, how much risk would be

involved with choosing to stay at this hotel?

How sure are you about the hotel"s ability to perfarm?

In your opinion, how certain are you that this hotel would perform as well as similar hotels

that you could go to?

How confident are you of the hatel's ability to perform as expected?

0.81

Financial risk $(C R=0.84)$

(Adapted from Ostrom and lacobucd 1998)

Given the expense involved, how much risk would be involved in staying at this hotel?

0.77

How financially risky do you feel it would be to choose the hotel for staying?

How confident are you that the hotel is worth the money you would have to pay for staying

0.75 there?

Extension Evaluation $(C R=0,89)$

(Boshoff 2002,Dawar 2000; Miterg et al. 1997)

I feel that the described hotel is:

Very unfavourable-very favourable

Very negative-Very positive

Very unattractive-Very attractive

0.90

Perceived Value $(C R=0.93)$

(Adapted from Sweeney and Soutar2001 and Petrick 2002)

Overall I believe I will receive a good value for money, compared to similar thotels

I think this hotel will be al good buy, compared to similar hotels

I think I would value the hotel's service a lot, compared to similar hotels

Purchase Intension $(C R=0.92)$

(Bloemer, de Ruyter Wetzels 1999)

Considering the situation, the hotel is an appropriate choice

I would recommend this hotell to other people

I would say positive things about this hotel to others

0.85

I would like to choose this hotel for this trip

0.86

Parent Brand Evaluation ( $C R=0.92)$

I think the hotel is:

Very unfavourable-Very favourable

Very negattive- Very positive

Very unattractive-Very attractive 


\section{Curriculum Vitae}

Jing Lei was born on the $4^{\text {th }}$ of September 1978 in Xianyang, China. She attended Shi Yan High School and Shan Mian High School in Xianyang and graduated in 1995. In September 1995, she started studying International Business at the Faculty of Economics and Management of Nanjing University of Science and Technology, China. She received her Bachelors degree in July 1999. From August 1999 to August 2000, she worked as a market analyst in the Marketing Department of Shanghai DS Telecommunication Equipment Company, China. In September 2000, she started studying her Masters degree in International Business at the Faculty of Management and Organization of Groningen University, the Netherlands, and graduated in September 2001. She joined the Department of Marketing at the Faculty of Economics and Business Administration of Maastricht University as a Ph.D. student in December 2001. She has presented her work at several international conferences and has published the first study of this dissertation in the Journal of Service Research. Currently, she works as an Assistant Professor of Marketing at the Faculty of Business and IT at the University of Ontario Institute of Technology. Her main research interests are in the area of brand management, services marketing, and branding strategies in emerging markets. 